DOE/ID/13548

Reducing Emissions of Volatile Organic Compounds

Final Report - 08/15/1997 - 02/14/2001

H. D. Stensel

S. E. Strand

March 2001

Work Performed Under Contract No. DE-FC07-97ID13548

For

U.S. Department of Energy

Assistant Secretary for

Energy Efficiency and Renewable Energy

Washington, DC

By

University of Washington

Seattle, WA 
DOE/ID/13548

\section{REDUCING EMISSIONS OF VOLATILE ORGANIC COMPOUNDS \\ FINAL REPORT \\ 08/15/1997 - 02/14/2001}

H. D. Stensel

S. E. Strand

March 2001

Work Performed Under Contract No. DE-FC07-97ID13548

Prepared for the

U.S. Department of Energy

Assistant Secretary for

Energy Efficiency and Renewable Energy

Washington, DC

Prepared by

University of Washington

Seattle, WA 


\section{Final Report \\ DOE-OIT Agenda 2000 Project}

(\#DE-FC07-971D13548)

\section{Reducing Emissions of Volatile Organic Compounds}

H. David Stensel, Ph.D., P.E.

Stuart E. Strand, Ph.D.

University of Washington

Seattle, WA 98195

March 14, 2001 
TABLE OF CONTENTS

1.0 INTRODUCTION AND BACKGROUND.......................................................... 1

1.1 BIological TREATMENT OF GAS EMISSIONS ………............................................. 2

1.2 BIOLOGICAL DESCRIPTION OF HAPS At High TEMPERATURE ................................... 6

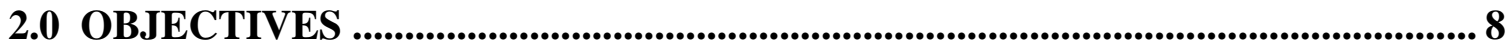

3.0 MATERIALS AND METHOD _.................................................................................... 9

3.1 DESCRIPTION OF LABORATORY SSGR S YSTEM................................................... 9

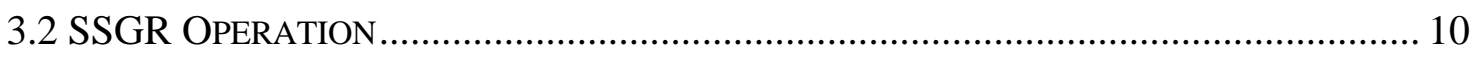

3.3 SEED AND ORGANIC COMPOUNDS USED IN LABORATORY SSGR STUDIES ............... 12

3.4 ENRICHMENT REACTORS FOR TERPENE-DEGRADING CULTURES AT $35^{\circ} \mathrm{C}$ AND $50^{\circ} \mathrm{C}$

3.5 BATCH ACCLIMATION TESTS FOR SULFUR COMPOUNDS ......................................... 16

3.6 GAS-LIQUID MASS TRANSFER CHARACTERIZATION ............................................... 17

3.6.1 Henry's Law Coefficient t.............................................................................. 17

3.6.2 Reactor Oxygen Mass Transfer $\left(K_{L} a\right)$ Coefficient ......................................... 19

3.6.3. Terpenine Gas-Liquid Mass Transfer Coefficient in Sparged Reactor .......... 21

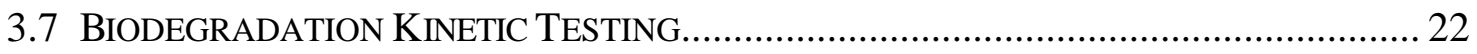

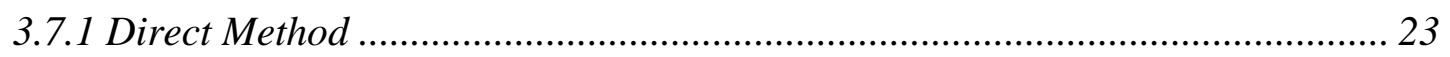

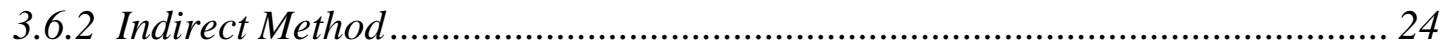

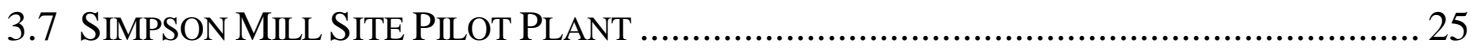

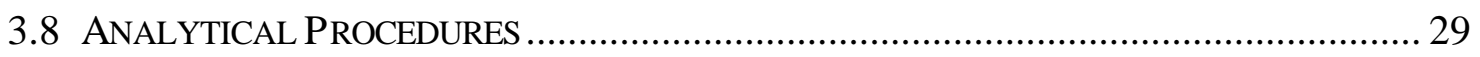

3.8.1 Organic Compounds .......................................................................... 29

3.8.2 Sulfur Compounds.................................................................................... 29

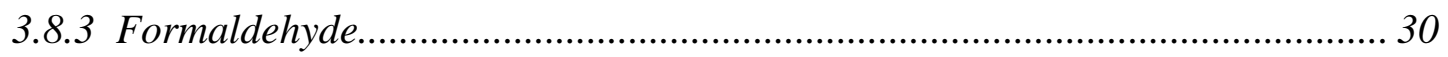

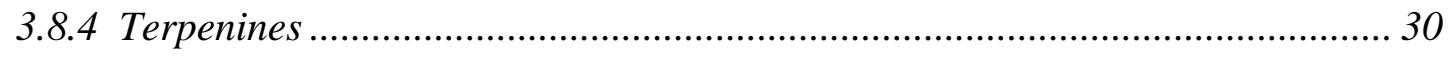

3.8.5 Conventional Reactor Parameters ............................................................... 32

4.0 RESULTS ........................................................................................................................................... 33

4.1 ORGANIC COMPOUND REMOVAL IN THE LABORATORY SSGR ................................ 33 
4.2 APPLICATION OF SSGR MODEL FOR METHANOL REMOVAL .................................. 38

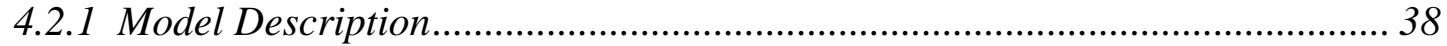

4.2.2 Model Mass Transfer Coefficients ............................................................. 41

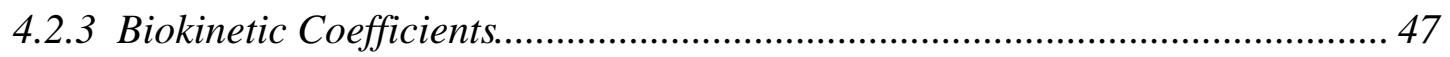

4.2.5 Model Evaluation of BTX removal in SSGR ................................................ 55

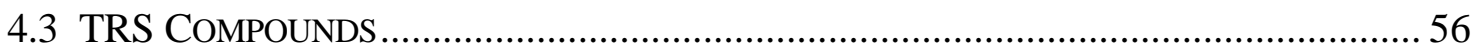

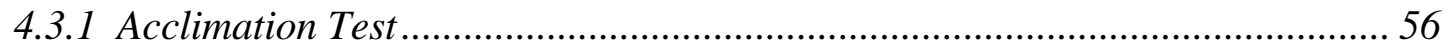

4.3.2 SSGR treatment performance with TRS compounds.................................... 60

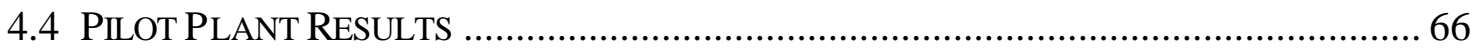

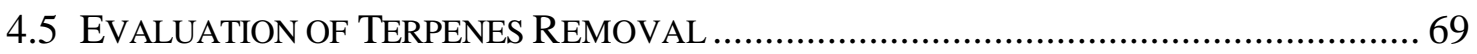

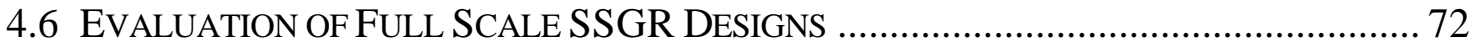

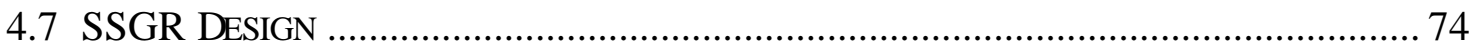

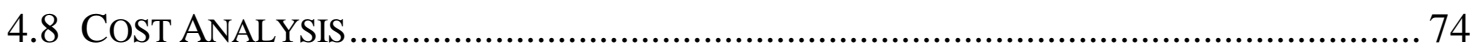

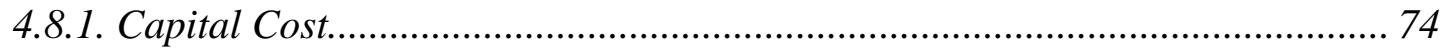

4.8.2. Non Variable operating costs..................................................................... 75

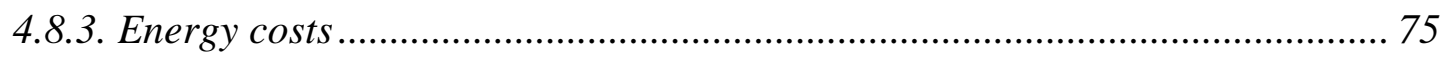

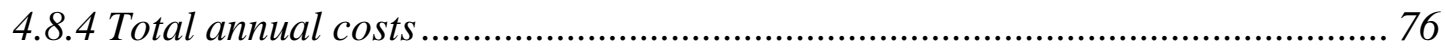

5.0 SUMMARY AND CONCLUSIONS ....................................................................... 77

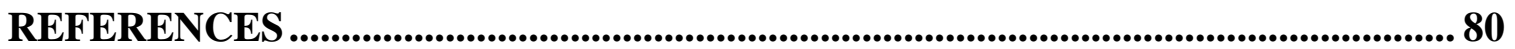




\section{TABLE OF TABLES}

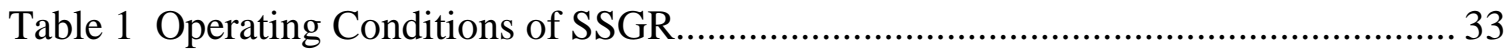

Table 2 The average treatment efficiency for methanol in SSGR in periods I, II and III 36

Table 3 Treatment removal efficiencies of other orga nic compounds in SSGR for periods

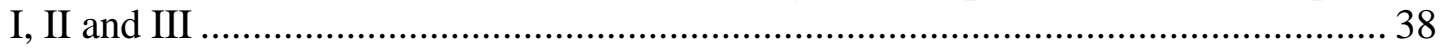

Table 4 Summary of Henry's Law Coefficient values measured by experiment (EPICS

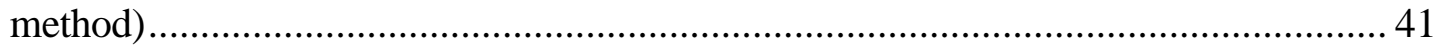

Table 5 Calculated Henry's Law Coefficients for selected compounds ........................... 42

Table $6 \mathrm{~K}_{\mathrm{L}}$ a for oxygen, toluene, $\alpha$-terpinene and $\gamma$-terpinene ...................................... 44

Table 7 Calculated $\mathrm{K}_{\mathrm{L}}$ a for methanol and other more volatile compounds tested in SSGR

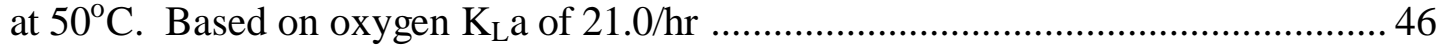

Table 8 Biodegradation kinetic parameters of methanol obtaining from indirect method

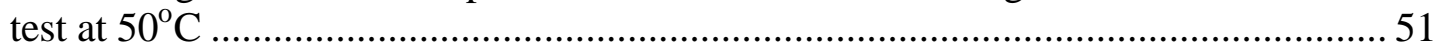

Table 9 Operating conditions and model parameters used to calibrate gas treatment model for methanol removal in the SSGR ...........................................................52

Table 10 Summary of batch acclimation tests for degradation of reduced sulfur compounds

Table 11 SSGR operating conditions and feed concentrations of TRS compounds, formaldehyde and methanol

Table 12 The influent, effluent concentrations and removal efficiency of TRS compounds, formaldehyde, and methanol for different operating periods

Table 13 Summary of pilot plant $\mathrm{K}_{\mathrm{L}}$ a test conditions and results 66

Table 14 The influent, effluent and removal efficiency of TRS and organic compounds of the pilot plant

Table 15 Summary of Henry's Law Coefficient values measured by EPICS method for terpene compounds

Table 16 Summary of $\mathrm{K}_{\mathrm{L}}$ a values for terpene compounds

Table 17 Specific substrate utilization rate $(\mathrm{K})$ values at $35^{\circ} \mathrm{C}$ and $50^{\circ} \mathrm{C}$ for the first-order model. 
Table 18 Summary of $\mathrm{K}_{\mathrm{S}}$ value for alpha- and gamma-terpinene ............................... 71

Table 19 Comparison of energy cost to treat $5000 \mathrm{scfm}$......................................... 75 


\section{TABLE OF FIGURES}

Figure 1 Schematic of laboratory SSGR system....................................................... 10

Figure 2 Laboratory SSGR system ....................................................................... 12

Figure 3 Schematic of terpene enrichment reactor maintained in $35^{\circ} \mathrm{C}$ constant

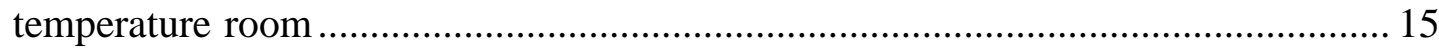

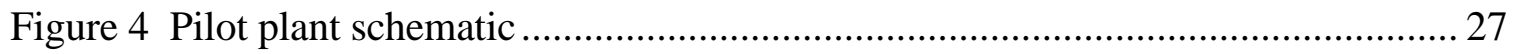

Figure 5 Pilot Plant at Simpson pulp and paper mill .................................................. 28

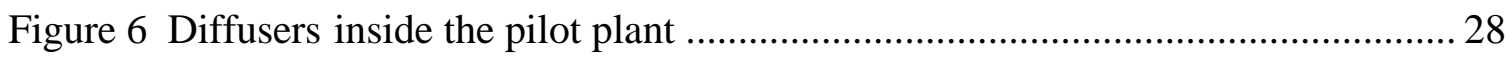

Figure 7 Methanol treatment performance in SSGR in 3 operation periods .................... 35

Figure 8 Treatment removal efficiency of xylene compounds in SSGR ………............ 37

Figure 9 An example of $\mathrm{K}_{\mathrm{L}}$ a test result for oxygen at $50^{\circ} \mathrm{C}$, liquid volume $2.4 \mathrm{~L}$ and

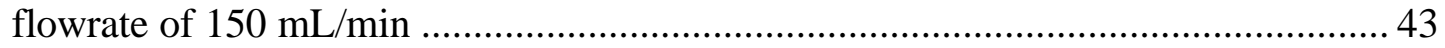

Figure 10 Alpha-terpinene liquid concentration versus time for a $\mathrm{K}_{\mathrm{L}}$ a test and $\mathrm{K}_{\mathrm{L}}$ a data

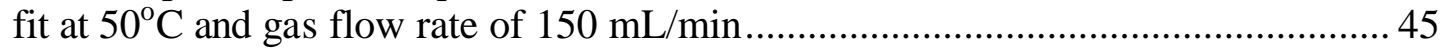

Figure 11 Example plot of DO consumption versus time for indirect test to determine

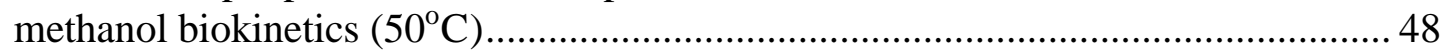

Figure 12 DO consumption curve from Figure 11 after removing endogenous DO consumption rate ........................................................................................... 49

Figure 13 Methanol consumption rate based on DO consumption rate in Figure 12 ...... 50

Figure 14 Laboratory SSGR model evaluation; effect of depth and SRT on................... 53

Figure 15 Model simulation on the effect of gas application rate on effluent gas methanol concentration $(\mathrm{ppm})$ for 10 -day and 20-day SRT operation at $50^{\circ} \mathrm{C}$. $\mathrm{K}_{\mathrm{L}}$ a of only $13.5 / \mathrm{hr}$ assumed. Reactor liquid depth equal 0.40 meter....................................................... 54

Figure 16 Model simulation of the effect of gas application rate on effluent gas methanol concentration for 10-day SRT and $\mathrm{K}_{\mathrm{L}}$ a of $50 / \mathrm{hr}$ at $50^{\circ} \mathrm{C}$ operation. Reactor liquid depth equal 0.40 meter.

Figure 17 Model simulation of the effect of depth on percent removal of benzene, toluene, and p- and o-xylenes, based on mass transfer limitation only....................... 56 
Figure $18 \mathrm{HS}$ degradation in a batch-fed reactor at $50^{\circ} \mathrm{C}$ after 160 days of incubation and repeated feeding of HS 58

Figure 19 MT degradation in a batch-fed reactor at $50^{\circ}$ after 160 days of incubation and repeated feeding of MT. 58

Figure 20 Lack of DMS degradation in a batch reactor at $50^{\circ} \mathrm{C}$ after 75 days of incubation

Figure 21 DMDS degradation in a batch-fed reactor at $50^{\circ} \mathrm{C}$ after 160 days of incubation and repeated feeding of DMDS

Figure 22 Percent removal of DMS and DMDS in the SSGR in period I, SRT $=30$ day, Temperature $=50^{\circ} \mathrm{C}$

Figure 23 Percent removal of DMS and DMDS in the SSGR in period 1I, SRT = 10 day, Temperature $=50^{\circ} \mathrm{C}$ 64

Figure 24 Percent removal of DMS and DMDS in the SSGR in period III, SRT = 30 day, Temperature $=30^{\circ} \mathrm{C}$

Figure 25 Percent removal of DMS and DMDS in the SSGR in period IV, SRT $=30$ day, Temperature $=20^{\circ} \mathrm{C}$ 65

Figure 26 Example of time course of DO for an oxygen $\mathrm{K}_{\mathrm{L}}$ a test and oxygen $\mathrm{K}_{\mathrm{L}}$ a data fit of the pilot plant at flow rate of $157.5 \mathrm{ft}^{3} / \mathrm{m}$.

Figure 27 Schematic of Shallow Suspended Growth Reactor (SSGR) for Gas Treatment. (Dashed boxes indicate powdered activated carbon addition to SSGR with biological regeneration of PAC. Mixed liquor with spent and regenerated PAC represented by lines 1 and 2.) 


\subsection{INTRODUCTION AND BACKGROUND}

The U.S. Environmental Protection Agency (EPA) "Cluster Rules" requires reduction and control of particulate and hazardous air pollutants (HAPs), which include organic and chlorinated organic compounds, and odor causing reduced sulfur compounds from pulp and paper facilities (Vice and Carroll 1998). The air regulations are based on applying maximum achievable control technology (MACT) to achieve 87 to 98 percent removal efficiency of hazardous air pollutants, depending upon the mill types and processes. Each mill can choose to participate in the Voluntary Advanced Technology Implementation Program (VATIP) or comply with MACT I and MACT III by April 15, 2001 (Anon 2000). MACT I air standards are applicable to chemical pulp mills while MACT III are applicable to mechanical, secondary fiber and non-wood pulping and paper making systems at mills.

Air emissions from pulp and paper mills can be categorized into either high volume low concentration gas streams (HVLC) or low volume high concentration gas streams. The low volume high concentration gas streams are generally handled by on-site incineration, and the high volume low concentration gas streams are the ones that will be most impacted by the cluster rules. The content and concentration of the gas streams vary for different processes. The most common organic compounds in HVLC gas streams, are methanol, chloroform, acetaldehyde, acrolein, formaldehyde, methyl-ethyl-ketone, toluene, benzene, xylenes, phenol, dichloromethane, carbon disulfide, hexane and terpenes (Mehta 1995). The major portions of the organic HAPs are methanol (100-500 ppm), formaldehyde (plywood industry) and acetaldehyde. EPA's cluster rules allow methanol to be used as a surrogate for HAPs with 98 percent reduction of methanol or an effluent concentration that does not exceed 20 ppm (Mehta 1995; Vice and Carroll 1998)

Reduced sulfur compounds (TRS) of interest in pulp and paper mill gas streams are hydrogen sulfide (HS), methyl mercaptan (MT), dimethyl sulfide (DMS) and dimethyl disulfide (DMDS). The TRS concentration in pulp and paper gas emission streams was reported to be in the range of 20-50 ppm. However, these compounds have very low 
odor threshold values (0.5-5 ppb for HS, 0.3-3ppb for MT, 1-15ppb for DMS and 1-20 ppb for DMDS (Jarvensivu et al. 1997).

Another important characteristic of pulp and paper mill gas emissions is their high temperature, which can be in the range of $40^{\circ} \mathrm{C}-70^{\circ} \mathrm{C}$.

\subsection{Biological Treatment of Gas Emissions}

While thermal incineration and carbon adsorption are established technologies for treating contaminated gas streams, biological treatment is of interest due to its potential for reduced cost. The most commonly used biological treatment process for gas streams is biofiltration, due to its simplicity and relatively low operating cost. The contaminated gas stream flows up through a media bed, which provides a surface for biomass attachment and growth. Various types of media have been used in biofilters, including compost, peat, perlite and activated carbon, for treating odor containing gases in sewage works, and organic compounds in gases from industrial emissions or hazardous waste remediation (Bielefeldt 1996).

Biofiltration has been evaluated in a limited number of bench scale and pilot plant studies for treating gas emissions from pulp and paper facilities. Mohseni and Allen (1998) studied $\alpha$-pinene and methanol removal efficiency in a $28-\mathrm{cm}$ diameter by $30-\mathrm{cm}$ high biofilter at $40^{\circ} \mathrm{C}$ with the contaminated air fed in a downflow fashion from the top of the biofilter. In this study, two biofilters were tested in parallel with one packed with compost, small wood chips and perlite and the other with compost and small woodchips at influent concentration of 950 and $37 \mathrm{ppm}$ for methanol and $\alpha$-pinene, respectively. The results from both biofilters were very similar, indicating that perlite did not enhance the removal efficiency. The removal efficiency of methanol was $90 \%$ at a methanol loading rate of $280 \mathrm{~g} / \mathrm{m}^{3}-\mathrm{hr}$, based on empty bed volume (EBV). The maximum removal efficiency of $\alpha$-pinene was $95 \%$ with an $\alpha$-pinene loading rate of $45 \mathrm{~g} / \mathrm{m}^{3}-\mathrm{hr}$. The gas detention time based on EBV was 20 to 60 seconds. The methanol removal rate was not 
affected by the presence of $\alpha$-pinene, but the $\alpha$-pinene removal rate decreased as the influent methanol concentration was increased.

In a second study using the same downflow lab biofilters (Mohseni et al. 1998) evaluated the effect of using granular activated carbon (GAC) versus perlite media on biofiltration performance treating air containing $\alpha$-pinene. Both columns contained a mixture of wood chips $(3.2-32 \mathrm{~mm})$ and compost, which was mixed at a ratio of 3:1 with perlite pellets $(4 \mathrm{~mm})$ in one and GAC of similar size in the other. Both contained fertilizer pellets for nutrients and $\mathrm{CaCO}_{3}$ at $10-15 \mathrm{~kg} / \mathrm{m}^{3}$ of bed volume for $\mathrm{pH}$ buffer. The columns were operated at $38-40^{\circ} \mathrm{C}$ and more than $90 \% \alpha$-pinene removal at the loading of 30-35 g/ $/ \mathrm{m}^{3}-\mathrm{hr}$ (correspond to concentration of approximately 70-80 ppm) based on EBV. The gas detention time based on EBV was about 45 seconds. The pressure drop increased from 0.2 to 0.6 in $\mathrm{H}_{2} \mathrm{O}$ in perlite biofilter and $0.4-0.8$ to 1 in $\mathrm{H}_{2} \mathrm{O}$ in $\mathrm{GAC}$ biofilter within 50 days. While the GAC adsorption provided higher $\alpha$-pinene removal at start-up, it did not show any advantage for long-term operation after microbial acclimation.

A pilot-scale biofilter ( $2.13 \mathrm{~m}$ by $1.83 \mathrm{~m}$ and $2.24 \mathrm{~m}$ high) with downflow in an activated carbon media was tested for treating a gas stream from a press vent at an oriented strand board facility in the southeast USA (Pisotti 1997). The gas stream contained $\alpha$-pinene, $\beta$-pinene, limonene, camphene, methanol, ethanol, acetic acid, acetaldehyde, phenol, formaldehyde and diphenyl-methane diisocyanate. The concentration of each VOC was not provided, but the total VOC concentration ranged from 40 to $220 \mathrm{ppm}$ as propane with an average of $100 \mathrm{ppm}$. The inlet gas temperature was $54^{\circ} \mathrm{C}$ and the biofilter temperature was $30-31^{\circ} \mathrm{C}$. The average gas application rate was $2.54 \mathrm{~m}^{3} / \mathrm{m}^{2}-\mathrm{hr}$. The pilot plant was operated for 4 months and the total removal efficiency was $85-96 \%$. The pressure drop across the media was only $19.1 \mathrm{mmH}_{2} \mathrm{O}$. The study with various EBV gas retention times showed that the efficiency was higher at retention time of $30 \mathrm{sec}$ than at $20 \sec (90$ vs. $82 \%)$. 
Several studies showed the removal of TRS compounds from gas streams using biofilters. (Hirai et al. 1990) studied the removal rate of HS, MT and DMS in a $0.75 \mathrm{~m}$ high by 0.15 $m$ diameter peat biofilter. The initial concentrations of HS, MT and DMS were 50, 30 and $30 \mathrm{ppm}$, respectively. The gas application rate ranged from $0.23-0.51 \mathrm{~m}^{3} / \mathrm{m}^{2}-\mathrm{hr}$ with EBV gas residence times of $198 \mathrm{sec}$. The $\mathrm{pH}$ ranged from 4.4 to 6.8 and the temperature was not reported. The removal efficiency of HS and MT was 70-90\%, while that of DMS was only $20-30 \%$.

Zhang et al (1991) inoculated a peat biofilter with Hyphomicrobium sp. I55. The biofilter was fed with a gas mixture of 30 ppm HS, 6 ppm MT and 63 ppm DMS at a constant flow rate of $200 \mathrm{~mL} / \mathrm{min}$. The $\mathrm{pH}$ of the system was 6.8 , but the temperature was not reported. The removal efficiencies of HS, MT and DMS were 70-100\%, 55-90\% and $30-40 \%$, respectively. However, when only DMS was fed to the biofilter at the concentration of $26 \mathrm{ppm}$, the DMS removal efficiency was $90 \%$, suggesting that the DMS degradation was inhibited by the presence of HS and MT. A similar effect was observed in an experiment where a peat biofilter was inoculated with Thibacillus thioparus DW 44 (Cho et al. 1991). The removal efficiency of HS, MT and DMS were 100, 100 and $45 \%$ respectively, when the biofilter was fed with gas mixture (50 ppm HS, 30 ppm MT and 25 ppm DMS ). However, when only DMS was fed at $25 \mathrm{ppm}$, the removal efficiency was $79 \%$. The system was operated at $50 \mathrm{~m}^{3} / \mathrm{m}^{2}-\mathrm{hr}$ and $\mathrm{pH}$ was 6.8 . The temperature was not reported.

A pilot-scale biofilter ( $0.5 \mathrm{~m}$ diameter, $0.85 \mathrm{~m}$ depth) with peat media inoculated with Thiobacillus thioparus DW44 was tested for treating exhaust gas from a night soil treatment plant in Japan (Cho et al. 1992). The gas application rate was $21 \mathrm{~m}^{3} / \mathrm{m}^{2}-\mathrm{hr}$ (EBV retention time $2.4 \mathrm{~min}$ ). The temperature fluctuated from 8 to $20^{\circ} \mathrm{C}$ due to seasonal effects. The biofilter was operated for 185 days and the $\mathrm{pH}$ was 7.1. The initial concentration of HS, MT, DMS and DMDS were 1-45, 0.1-3, 0.3-3, and 0.02 to $0.2 \mathrm{ppm}$, respectively. The average removal efficiencies for HS, MT, DMS and DMDS were $99.8 \%, 99 \%, 89.5 \%$ and $98.1 \%$, respectively. The removal efficiencies of HS and MT were fairly stable through out the experiment, while the removal of DMS and DMDS 
fluctuated from 40 to $100 \%$. The treatment efficiency for DMS and DMDS dropped when the temperature dropped below $8^{\circ} \mathrm{C}$ in the winter and increased when the biofilter inlet gas was heated to $8-10^{\circ} \mathrm{C}$.

In biofilter applications with stringent treatment performance needs, more engineered approaches are needed in media selection and process design, including water recirculation, nutrient addition, and buffer addition to maintain more desirable conditions for biological growth. A major concern for biofiltration is media plugging from excess biomass growth or trapping water in the pore space, which cause the pressure drop to increase. When this happens the gas flow through the bed is not uniform, which can result in a decrease in treatment performance. Periodic media replacement may be necessary to overcome media plugging problems and these difficulties will be more significant for higher concentration gas streams and longer term operation.

An alternative to biofiltration for biological treatment of contaminated gas streams is a shallow suspended growth reactor (SSGR), which eliminates the use of media. In a previous laboratory study using the SSGR to treat gas contaminated with benzene, toluene, ethylbenzene, and o-xylene (BTEX), 99\% of BTEX removal was achieved at $20^{\circ} \mathrm{C}$ using a reactor liquid depth of only $40 \mathrm{~cm}$ at volumetric loadings of 11 to $18 \mathrm{mg}$ BTEX/L-hr (Bielefeldt and Stensel 1998). In the SSGR the contaminated gas is dispersed into a shallow (less than $1 \mathrm{~m}$ depth) liquid suspension of biomass by fine bubble diffusers at the bottom of the reactor. The contaminants are transferred from the gas to the liquid phase, where biodegradation by the suspended biomass maintains a low liquid concentration to maximize gas-liquid transfer rates. The gas contact time is generally less than 1-2 seconds, and a high density diffuser design is used to maximize gas-liquid mass transfer in the relatively shallow liquid depth. The addition of nutrients and alkalinity is easily controlled and uniform, since the SSGR is a completely mixed liquid suspension. The reactor liquid can be removed periodically to control the biomass concentration and cell age. Though the SSGR requires more energy than a biofilter, the shallow depth used minimizes energy requirements. A number of SSGR units can be stacked to minimize land area requirements. 
A mechanistic model to predict SSGR treatment performance, based on fundamental mass transfer processes and biodegradation kinetics, was developed and evaluated by Bielefeldt and Stensel (1999). The contaminant mass transfer rate from the gas to the liquid depends on the Henry's Law coefficient $(\mathrm{H})$ and reactor gas-liquid mass transfer

coefficient, $\left(\mathrm{K}_{\mathrm{L}} \mathrm{a}\right)$. For the compound of interest, the $\mathrm{K}_{\mathrm{L}}$ a value was related to the $\mathrm{K}_{\mathrm{L}} \mathrm{a}$ of oxygen, which can be easily determined for an SSGR system from clean water aeration tests. Lower $\mathrm{H}$ values and higher $\mathrm{K}_{\mathrm{L}}$ a values increase the mass transfer rate of compounds into the liquid, and thus result in a lower required liquid depth. The biokinetic part of the model was based on Michaelis-Menten substrate utilization kinetics, but can be modified to accommodate other biokinetic relationships.

\subsection{Biological Description of HAPs at High Temperature}

Reactor temperature is a significant issue for biotreatment of pulp and paper mill gas emissions. The organic compounds found in gas emissions from pulp and paper mills are reported to be easily biodegraded at mesophilic temperatures (Lund 1971). However, the temperature of the gas streams can be as high as $70^{\circ} \mathrm{C}$ (Mohseni and Allen 1998) requiring biodegradation by the microbial communities acclimated to thermophilic temperature $\left(45-70^{\circ} \mathrm{C}\right)$, unless gas cooling is used.

Biodegradation experience at thermophilic temperature is limited. Biodegradation at $50^{\circ} \mathrm{C}$ to $70^{\circ} \mathrm{C}$ by several Bacillus strains in batch studies has been reported for methanol (AlAwadhi et al. 1989; Dijkhuizen and Artman 1990; Arfman et al. 1992; Arfman et al. 1992). Biodegradation of BTEX compounds at $45^{\circ} \mathrm{C}$ to $77^{\circ} \mathrm{C}$ by a Thermus species in a batch reactor has been demonstrated (Chen and Taylor 1995; Chen and Taylor 1997). The aerobic degradation of selected monoterpenes; $d$-limonene, $\alpha$-pinene, $\gamma$-terpinene, terpinolene and $\alpha$-terpineol has been shown only at $23^{\circ} \mathrm{C}$ (Misra and Pavlostathis 1996; Misra and Pavlostathis 1997) and at $40^{\circ} \mathrm{C}$ for $\alpha$-pinene and methanol(Mohseni and Allen 1997). The ability to biologically treat the range of organic compounds found in pulp and paper emissions at thermophilic temperatures needs investigation. 
Degradation of TRS compounds has been widely reported, by both pure strain and mixed culture, but results at thermophilic temperature are limited. Methylophaga sulfidovorans (deZwart et al. 1996; deZwart and Kuenen 1997) was reported to oxidize HS and DMS in microbial mat at $17-35^{\circ} \mathrm{C}$, with the optimum growth temperature at $22^{\circ} \mathrm{C}\left(\mu_{\max }=0.05 \mathrm{~h}^{-1}\right.$, $\left.\mathrm{K}_{\mathrm{s}}=1 \mu \mathrm{mol}\right)$. HS and DMS were completely consumed in the batch study with the initial HS concentration of $25 \mathrm{mM}$ in gas phase and DMS concentration of $1.5 \mathrm{mM}$ in liquid. Thiobacillus thioparus DW44 (Cho, Hirai et al. 1991), Thibacillus thioparus TK-m (Kanagawa and Mikami 1989) and Hyphomicrobium sp. I55 (Zhang, Hirai et al. 1991) were able to degrade HS, MT, DMS and DMDS at $25^{\circ} \mathrm{C}$ and $\mathrm{pH}$ 6.8. The removal efficiency of 93-99\% was observed with the initial concentration of 30 to $250 \mathrm{ppm}$. Hyphomicrobium EG was reported to degrade DMS and MT at $30^{\circ} \mathrm{C}$ (deBont et al. 1981; Suylen et al. 1987). The removal efficiency for DMS and MT was approximately 93\%, when the liquid concentration of DMS and MT were $0.05 \mathrm{mmol} / \mathrm{L}$ and $0.3 \mathrm{mmol} / \mathrm{L}$, respectively. Pseudonocardia asaccharolytica sp. nov. and Pseudonocardia sulfidoxydans sp. nov. were capable of degrading DMS and DMDS at $25^{\circ} \mathrm{C}$, but the removal efficiency was not reported (Reichert et al. 1998).

Only HS degradation was studied at thermophilic temperature, and this was observed with two strains of pure cultures. Thermothrix azorensis, an obligate autotrophic aerobic microorganism was able to degrade $\mathrm{HS}$ at $63-86^{\circ} \mathrm{C}$ (Odintsova et al. 1996). Thermothrix thiopara is a facultatively autotrophic, microorganism that could oxidize HS and grow at a temperature range of $45-80^{\circ} \mathrm{C}$ and neutral $\mathrm{pH}$ (Brannan and Caldwell 1980; Brannan and Caldwell 1983; Brannan and Caldwell 1986; Odintsova, W.Jannaach et al. 1996). 


\subsection{OBJECTIVES}

The overall objective of this research was to determine if the SSGR could provide sufficient treatment performance of organic and TRS compound at $50^{\circ} \mathrm{C}$ to meet the EPA cluster rule regulatory limits. The biodegradation of a mixture of organic compounds that

could be present in pulp and paper HVLC gas stream was evaluated at $50^{\circ} \mathrm{C}$ in a benchscale SSGR. The removal of methanol was followed in particular, and was mathematically modeled to evaluate the effect of process design and operating parameters on methanol removal. Additional tests were performed to obtained mass transfer and biodegradation kinetic parameters for the model. The acclimation of microbial populations capable of degrading TRS compounds from various seed sources was studied in batch reactors at 30 and $50^{\circ} \mathrm{C}$. The degradation of TRS compounds in bench-scale SSGR was studied at $20-50^{\circ} \mathrm{C}$. Also, the biodegradation kinetic and mass transfer coefficients for $\alpha$-terpinene and $\gamma$-terpinene were studied. Finally, a pilot plant was constructed and operated at Simpson pulp and paper mill in Tacoma, WA. 


\subsection{MATERIALS AND METHOD}

This research focused on the treatment of gas emissions from pulp and paper mills using a sparge suspended gas reactor (SSGR). The following studies were performed.

1. Bench scale SSGR study for removal of organic compounds from a gas stream

2. Bench scale SSGR study for removal of TRS compounds from a gas stream

3. Biological acclimation study using various seed sources for TRS degradation

4. Bench scale tests to obtain mass transfer and biokinetic parameters for methanol

5. Pilot plant construction and operation of the Simpson Mill in Tacoma, WA

6. Bench-scale acclimation, mass transfer, and biokinetic studies for terpene compounds

\subsection{Description of Laboratory SSGR System}

Figure 1 shows a schematic of the laboratory SSGR treatment system used for testing. The bioreactor and stabilizer units were 2-L glass graduate cylinders modified with ports for sampling and taps for attaching connecting tubing. The stabilizer contained deionized water, and the liquid depths for it and the bioreactor were maintained at $0.36 \mathrm{~m}$. The reactor total height was $0.5 \mathrm{~m}$, and its I.D. was $8 \mathrm{~cm}$. Gas flow to the bioreactor and stabilizer was dispersed by air sparging stones located near the bottom of the reactors. The purpose of the stabilizer was to equilibrate the concentrations of the compounds fed to obtain more consistent bioreactor influent sample concentrations. The bioreactor and stabilizer were stirred by a Teflon ${ }^{\mathrm{TM}}$-coated magnetic stir bar and Thermolyne ${ }^{\mathrm{TM}}$ stir plate. The bioreactor and stabilizer were wrapped with heating tapes, which were controlled by a temperature probe and input controller (Omega CN76000) to maintain constant operating temperature at $50^{\circ} \mathrm{C}$.

Stainless steel tubes ( $6.35 \mathrm{~mm}$ diameter) were used between the stabilizer and the bioreactor, for the reactor effluent line, for the influent line to the stabilizer, and for GC sample lines from the reactor influent and effluent. All the tubes were heated by heat tape (Thermolyene silicone rubber) to prevent compound condensation in the lines. 


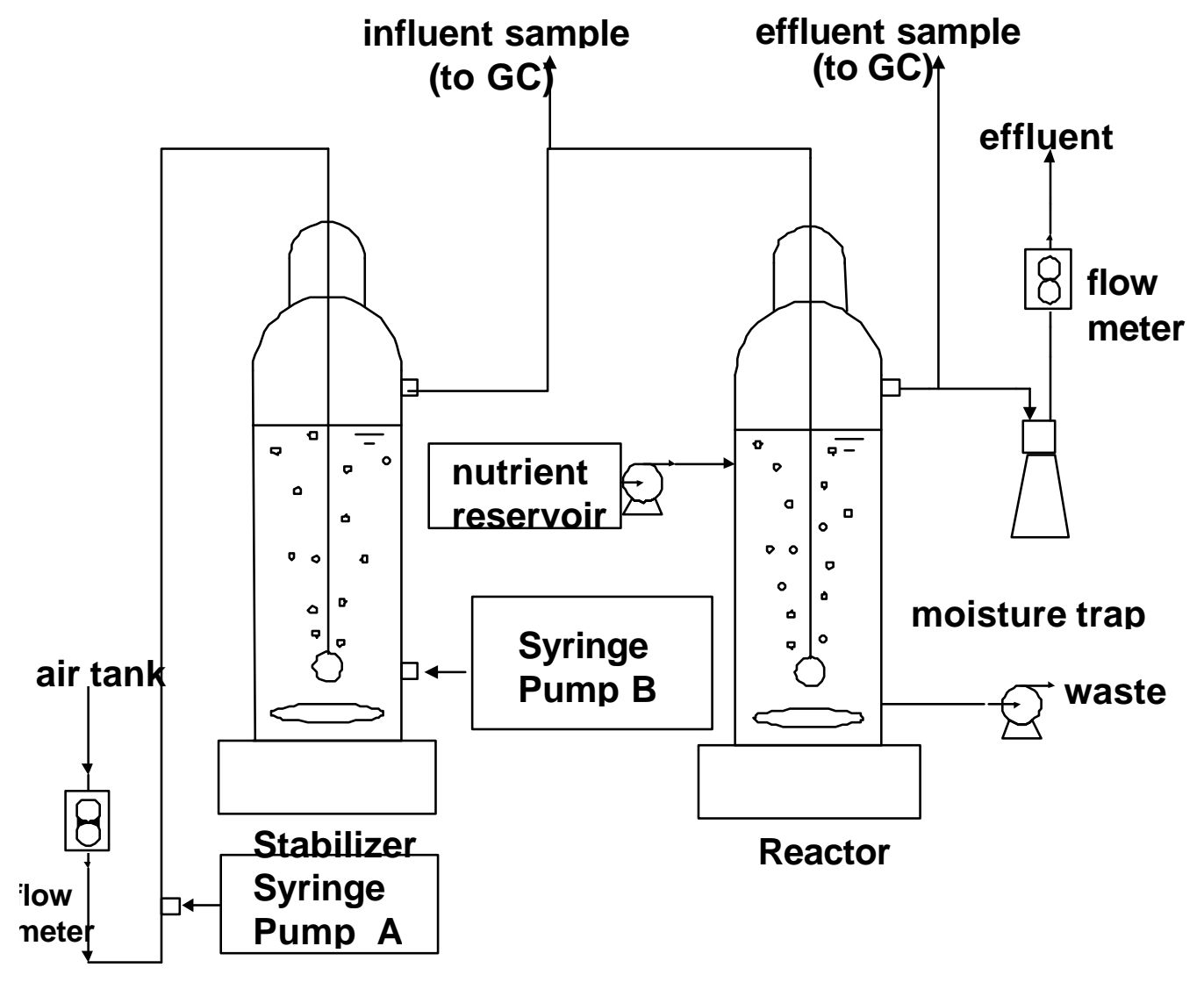

\section{Figure 1 Schematic of laboratory SSGR system}

A compressed air tank supplied a constant air stream flow rate, which was measured by a flowmeter before the stabilizer and in the effluent line after the reactor. Two syringe pumps (Cole-Parmer, 74900 series) were used for feeding chemicals into the reactor. Syringe pump A was used for feeding chemicals directly into the stabilizer feed line and syringe pump B was used for feeding chemicals into the stabilizer. The more volatile compounds were fed with syringe pump A.

\subsection{SSGR Operation}

The SSGR was operated at a gas feed rate of $150 \mathrm{~mL} / \mathrm{min}$ during organic compound feeding and $220 \mathrm{~mL} / \mathrm{min}$ during TRS compound feeding, which correlated to gas application rates of 1.8 and $2.6 \mathrm{~m}^{3} / \mathrm{m}^{2}$-hr, respectively. Equal volumes of nutrient 


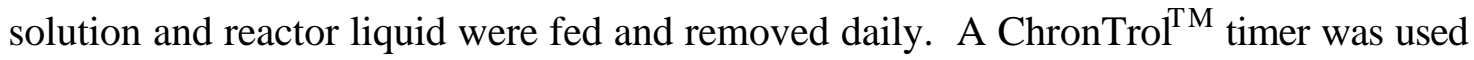
to activate the peristaltic pumps used for nutrient feeding and reactor liquid withdrawal every 3 hours. The reactor solids retention time (SRT) was maintained by feeding and withdrawing a fraction of the reactor volume daily. For a $10-d$ SRT operation, $1 / 10^{\text {th }}$ of the reactor volume was removed daily. Reactor wall growth was minimized by manually scraping the wall with a wire brush every other day. The nutrient media solution contained 1.9g/L KNO $3,1.4 \mathrm{~g} / \mathrm{L} \mathrm{KH}_{2} \mathrm{PO}_{4}, 2 \mathrm{~g} / \mathrm{L} \mathrm{K}_{2} \mathrm{HPO}_{4}, 0.8 \mathrm{~g} / \mathrm{L} \mathrm{NH} 4 \mathrm{Cl}, 1.2 \mathrm{~g} / \mathrm{L}$ $\mathrm{NaHCO}_{3}, 0.1 \mathrm{~g} / \mathrm{L} \mathrm{CaCh}, 0.06 \mathrm{~g} / \mathrm{L} \mathrm{MgSO} 4,0.2 \mathrm{~g} / \mathrm{L} \mathrm{NaCl}, 0.11 \mathrm{mg} / \mathrm{L} \mathrm{CuCb} \cdot \mathrm{H}_{2} \mathrm{O}, 0.3 \mathrm{mg} / \mathrm{L}$ $\mathrm{ZnCh}, 0.044 \mathrm{mg} / \mathrm{L} \mathrm{NiCh} \cdot 6 \mathrm{H}_{2} \mathrm{O}, 1.76 \mathrm{mg} / \mathrm{L} \mathrm{FeSO}_{4} \cdot 7 \mathrm{H}_{2} \mathrm{O}, 0.27 \mathrm{mg} / \mathrm{L} \mathrm{Ah}\left(\mathrm{SO}_{4}\right)_{3} \cdot 18 \mathrm{H}_{2} \mathrm{O}$, $0.564 \mathrm{mg} / \mathrm{L} \mathrm{MnCh} \cdot 4 \mathrm{H}_{2} \mathrm{O}, 0.112 \mathrm{mg} / \mathrm{L} \mathrm{CoCl}_{2} \cdot 6 \mathrm{H}_{2} \mathrm{O}, 0.064 \mathrm{mg} / \mathrm{L} \mathrm{Na}_{2} \mathrm{MoO}_{4} \cdot 2 \mathrm{H}_{2} \mathrm{O}$, and $0.098 \mathrm{mg} / \mathrm{L} \mathrm{H}_{3} \mathrm{BO}_{3}$.

Reactor influent and effluent gas flows were sampled daily. Organic and TRS compounds were analyzed by gas chromatograph (GC) using a flame ionization detector (FID) and a flame photometric detector (FPD), respectively. For organic compounds analyses, samples were taken through an electrically operated 3-way solenoid valve $\left(\right.$ Dayton $^{\circledR}$ ) that was manually connected to either the reactor influent or effluent flowlines. A peristaltic pump was used to pull the samples through the gas chromatograph sampling valve and a sample loop continuously. When the valve was rotated, the sample loop was disconnected from the sample line, and the GC carrier gas was directed through the sample loop, which flushed the sample to the GC separation column. A Chrontrol ${ }^{\mathrm{TM}}$ timer controlled the valve rotation times. For TRS-compounds, the samples were taken manually by using $100-\mu \mathrm{L}$ gas tight syringes (Hamilton). The gas samples were injected by syringe directly into the GC injection port, which was connected to the FPD detector.

Volatile suspended solids (VSS), total suspended solid (TSS) and soluble COD (sCOD) concentrations in the reactor liquid were measured 2-3 times per week. Dissolved oxygen (DO) concentration and $\mathrm{pH}$ were measured once per week. Liquid samples were obtained through reactor sampling ports equipped with Mininert valves. 

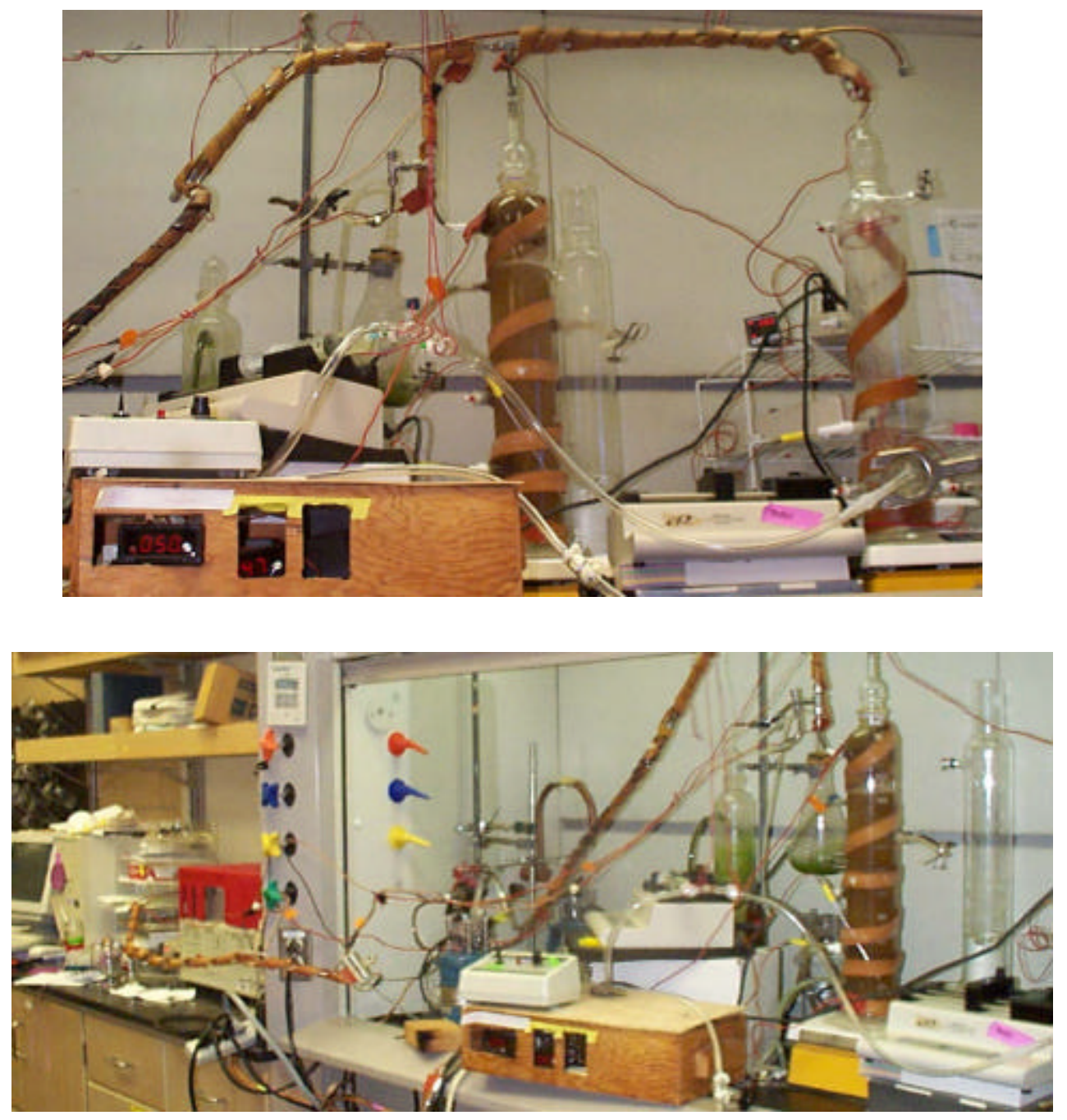

Figure 2 Laboratory SSGR system

\subsection{Seed and Organic Compounds Used in Laboratory SSGR Studies}

The seed for the biotreatment reactor for the tests treating organic compounds was obtained from an activated sludge lagoon at a Weyerhaeuser pulp and paper facility. Later it was also seeded with sludge from a high temperature $\left(60^{\circ} \mathrm{C}\right)$ aerobic sludge digester at the Gig Harbor, WA municipal wastewater treatment plant. For the SSGR tests with TRS compounds, the seed was activated sludge from the wastewater treatment facility at the Simpson pulp and paper mill in Tacoma, WA. Benzene, toluene, p-xylene, 
$\mathrm{m}$-xylene and o-xylene were combined as a pure liquid phase and fed to the air feed line by syringe pump A. Methanol, acrolein, acetaldehyde and methyl-ethyl-ketone were combined as pure liquid phase and fed to the stabilizer by syringe pump B.

Benzene (99.9\%), toluene (99.8\%) and methanol (99\%) were obtained from Fisher scientific. Acrolein (90\%), acetaldehyde (98\%), methyl ethyl ketone (99\%), pxylene(99+\%), m-xylene (99\%) and o-xylene (98\%) were obtained from Aldrich.

For the laboratory SSGR system treatment of TRS compounds, HS and MT were fed as a pure gas phase through pump A to the gas feed line. DMDS, DMS, formaldehyde and methanol were fed in liquid phase through syringe pump B to the stabilizer.

HS (99.5\%), MT (99.5\%), DMS (99+\%) and DMDS (98\%) were obtained from Aldrich. Formaldehyde (37\%) was obtained from Fisher scientific.

\section{$\underline{\text { 3.4 Enrichment Reactors for Terpene-Degrading Cultures at } 35^{\circ} \mathrm{C} \text { and } 50^{\circ} \mathrm{C}}$}

Alpha-terpinene- and gamma-terpinene- degrading enrichments were developed in separate enrichment reactors at $35^{\circ} \mathrm{C}$ and $50{ }^{\circ} \mathrm{C}$. Alpha-terpinene (1-isopropyl-4-methyl1,3-cyclohexadiene) with purity of $89 \%$ and gamma-terpinene (1-isopropyl-4-methyl-1,4cyclohexadiene) with purity of $99 \%$ were obtained from Sigma-Aldrich Co. The enrichment seed source was from the laboratory SSGR when it was treating the organic compound mixture.

Terpene-degrading cultures were initially grown in $125-\mathrm{mL}$ serum bottles, and turbidity was used as an indication of biomass growth. After growth was observed the culture was transferred to one of two enrichment reactors (fed alpha or gamma terpinene) for growth with a constant feed supply. Terpene chemicals had been temporarily fed to the SSGR system stabilizer for approximately one month at a rate of $90 \mathrm{mg} / \mathrm{L} /$ day prior to removing SSGR mixed liquor for seed. 
Figure 3 shows a schematic of the enrichment growth reactor design. The enrichment growth reactors were 4-L Erlenmeyer flasks with approximately 2-L of liquid volume and were connected by Teflon tubing in a closed system to a manometer containing oxygen. The enriched reactor operation was maintained at $35^{\circ} \mathrm{C}$ in a constant temperature room. Teflon mininert valves were used for the sampling and feed port on the reactor and the injection port on the manometer to prevent chemical losses due to adsorption. The reactor liquid was continuously mixed with a magnetic stir-bar controlled by a Thermolyne stir-plate. Mixing was sustained at the maximum level to create a vortex in the liquid, which enhanced gas transfer between the liquid and the headspace. An alkaline trap $(60-\mathrm{mL}$ of $10 \mathrm{~N} \mathrm{KOH}$, with a glass fiber filter used as a wick) was attached to the reactor to remove carbon dioxide produced through bacterial respiration. By removing the carbon dioxide the oxygen consumed from the reactor headspace was replaced with oxygen from the attached manometer headspace. The oxygen consumption could then be determined by changes in the manometer liquid level. Pure oxygen was added as needed via syringe to the manometer to maintain an adequate reservoir of oxygen.

Based on a yield of $1.5 \mathrm{mg}$-VSS/mg-terpene (0.45 mg-VSS/mg-COD), the reactors were expected to use approximately $12 \mathrm{~mL}$ of oxygen daily. However, this rate of oxygen consumption was not indicated by the manometer liquid level measurements, which suggested that a small leak was present.

The reactors were maintained at an HRT and SRT of 5 days by manually wasting 400$\mathrm{mL}$ once per day, which included sampling volumes. Nutrient solution was added daily to maintain a liquid volume of $2-\mathrm{L}$. The same nutrient recipe used for the SSGR biotreatment reactor was used here also. 


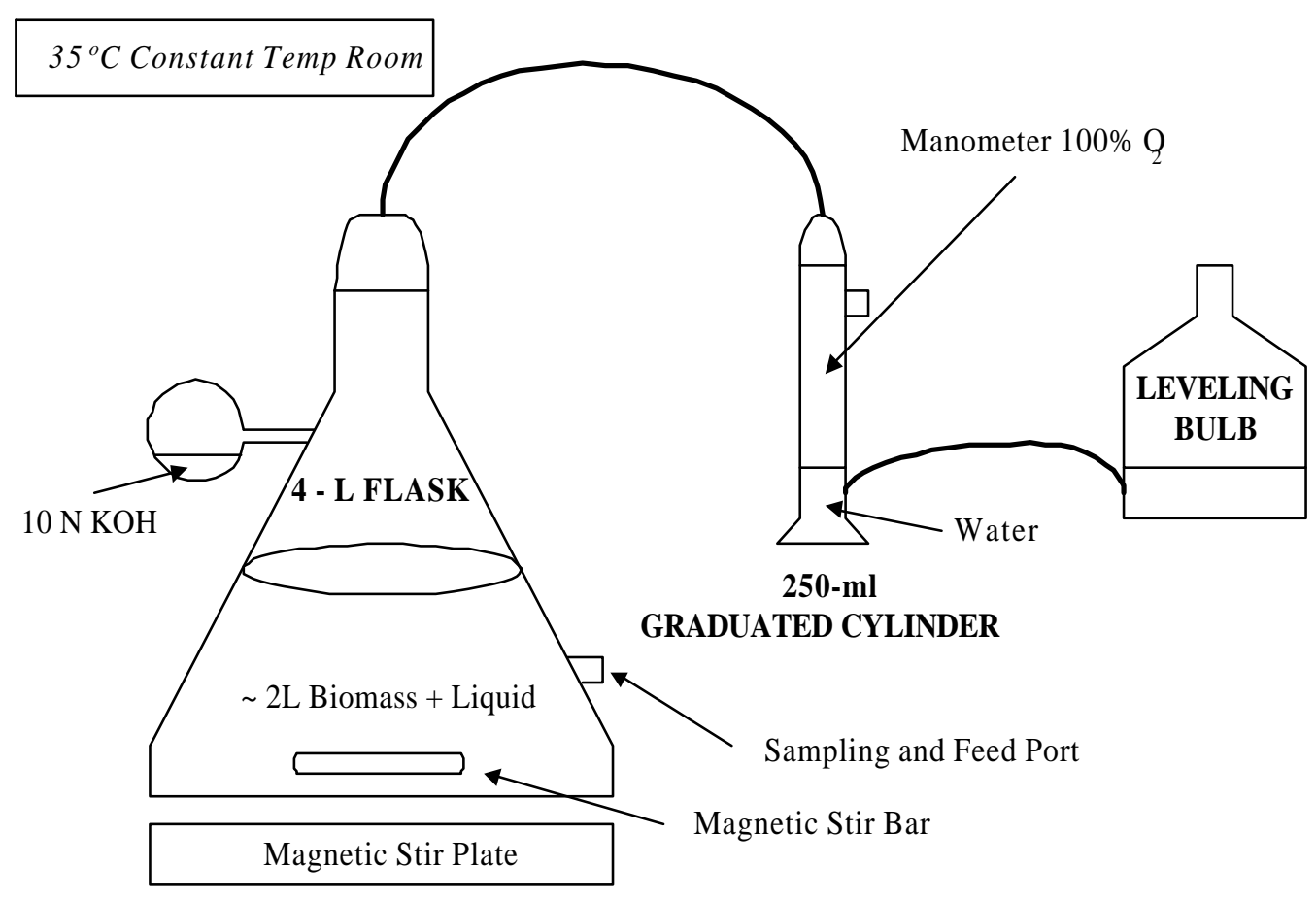

Figure 3 Schematic of terpene enrichment reactor maintained in $35^{\circ} \mathrm{C}$ constant temperature room

Each reactor was fed daily with $10 \mathrm{mg} / \mathrm{L}$ of the appropriate pure phase terpene chemical, which was injected manually with a Hamilton gas-tight $25-\mu \mathrm{L}$ glass syringe. The low solubility of the terpene compounds prevented feeding dissolved terpene in the nutrient solution. Liquid concentration of terpene was measured regularly to verify degradation. The VSS (volatile suspended solids) was measured weekly and used as an indication of acclimation and growth. Both reactors maintained approximately $40 \mathrm{mg} / \mathrm{L} \mathrm{VSS}$ after the acclimation period. The reactor $\mathrm{pH}$ was maintained at about 7.5 , slightly basic because of the alkaline trap and low $\mathrm{CO}_{2}$ content in the gas phase.

For growth at $50{ }^{\circ} \mathrm{C}$ two enrichment reactors fed alpha-terpinene and gamma-terpinene, respectively, were seeded with the $35^{\circ} \mathrm{C}$ enrichment cultures. A 400 - $\mathrm{mL}$ liquid volume from each of the $35^{\circ} \mathrm{C}$ reactors was centrifuged, washed with nutrient solution and centrifuged again. The concentrated biomass was added to 1-L of fresh nutrient media. 
The reactor temperature was increased $1^{\circ} \mathrm{C}$ per day from $35^{\circ} \mathrm{C}$ to $50^{\circ} \mathrm{C}$ while being fed 10 $\mathrm{mg} / \mathrm{L}$ of the terpene daily. The terpene liquid concentration was measured before feeding to verify terpene degradation, and it was always below the detection limit of $0.5 \mathrm{mg} / \mathrm{L}$ terpene.

The $50^{\circ} \mathrm{C}$ enrichment reactors were sealed 2-L Erlenmeyer flasks with approximately 1$\mathrm{L}$ of liquid volume and were maintained at $50^{\circ} \mathrm{C}$ in a rotary shaker $(140 \mathrm{rpm})$ incubator. Glass and Teflon stoppers were used to prevent terpene loss. The reactor headspace was flushed with pure oxygen every other day to provide oxygen and remove accumulated carbon dioxide.

After the initial acclimation of approximately 3 weeks, the reactors were maintained at an HRT and SRT of 5 days by removing 200-mL of reactor liquid each day (including sampling volumes) and replacing it with nutrient solution. Liquid terpene and VSS concentrations were measured regularly to monitor terpene degradation and enrichment acclimation. The enrichments maintained a VSS of approximately $15 \mathrm{mg} / \mathrm{L}$ after the acclimation period.

\subsection{Batch Acclimation Tests for Sulfur Compounds}

Seeds from different sources were tested for the ability to degrade HS, MT, DMS, and DMAS. The seed sources were municipal aerobic thermophilic digester sludge, Simpson Mill activated sludge, Simpson Mill pulp washer water, a high temperature lake sediment and a hot spring culture. Each sulfur compound degrading enrichment was acclimated in batch fed Erlenmeyer flasks at $35^{\circ} \mathrm{C}$ and $50^{\circ} \mathrm{C}$. The flasks had a $400 \mathrm{~mL}$ liquid volume and $225 \mathrm{~mL}$ gas volume. The seeds were diluted in nutrient solution, and the flasks were capped with rubber stoppers. A side port, equipped with Mininert ${ }^{\mathrm{TM}}$ valve was added to the flask to allow the addition of sulfur compounds and sampling.

The $50^{\circ} \mathrm{C}$ flasks were incubated in a rotary shaker incubator, and the $35^{\circ} \mathrm{C}$ flasks were incubated in a walk-in environmental chamber. The $35^{\circ} \mathrm{C}$ flasks were stirred by a 
Teflon $^{\text {TM }}$ coated magnetic stir bar and Thermolyne ${ }^{\text {TM }}$ stir plate. HS and MT were added as pure gases, and DMS and DMDS were added as pure liquid phase by syringe. Target initial concentration were $100 \mathrm{ppm}$ based on headspace concentration. Care was taken in the feeding and flask maintenance to prevent pressurization due to feed volumes. After the reduced sulfur compounds were added, each reactor was mixed and incubated at the desired temperature for 15 to 30 min to allow the system to reach equilibrium between liquid and gas concentration. Then, the initial headspace gas concentration was determined. The reduced sulfur concentrations were measured daily in the headspace until they were completely consumed. Each day, pure oxygen was replenis hed in each flask by inserting a needle connected to a lubricated glass syringe filled with pure oxygen. The vacuum created by oxygen consumption in the flasks automatically pulled in the oxygen. After the sulfur compound was completely consumed, the top of the reactor was removed and the liquid content of the reactor was sparged with clean air for 5 min to remove accumulated $\mathrm{CO}_{2}$ or in the case of $\mathrm{HS}$ to replenish $\mathrm{CO}_{2}$ used by the autotrophic bacteria. After every feeding 3-4 cycles, $50 \mathrm{ml}$ of liquid sample was removed from the reactor to remove possible metabolite accumulation. The liquid was centrifuged. The biomass was separated and made up to the same volume by addition of nutrient solution. Then, the diluted biomass was returned to the bioreactor.

\subsection{Gas-liquid Mass Transfer Characterization}

\subsubsection{Henry's Law Coefficient}

Henry's Law coefficients of most compounds were available from the literatures.

Otherwise the Henry's law coefficient was determined experimentally. The experimental procedure was done for methanol, toluene, terpenes, HS, MT, DMS and DMDS.

The most direct method for measuring the Henry's Law coefficient of a compound is to measure both the air and liquid concentrations of the compound in a closed system at equilibrium $(\mathrm{H}=\mathrm{Cg} / \mathrm{Cl})$. However, this method is highly sensitive to the accuracy of the concentration measurements. It also requires the ability to accurately sample and measure both phases. Alternatively, the EPICS (Equilibrium Partitioning in Closed 
Systems) method (Yuteri et al. 1987) is used to determine the Henry's Law coefficient.

In this test, bottles with different liquid and gas volumes are prepared with the same mass of test compound added. The equation used in the EPICS method when only the gas phase concentration is measured is as follows:

$$
H=\frac{C_{G 1}}{C_{L 1}}=\frac{C_{G 2} V_{L 2}-C_{G 1} V_{L 1}}{C_{G 1} V_{G 1}-C_{G 2} V_{G 2}}
$$

where:

$$
\begin{aligned}
& \mathrm{C}_{\mathrm{L}}=\text { concentration in the liquid phase, } \mathrm{mg} / \mathrm{L} \\
& \mathrm{C}_{\mathrm{G}}=\text { concentration in the gas phase, } \mathrm{mg} / \mathrm{L} \\
& \mathrm{V}_{\mathrm{L}}=\text { liquid volume in the bottle, } \mathrm{L} \\
& \mathrm{V}_{\mathrm{G}}=\text { gas volume in the bottle, } \mathrm{L} \\
& \mathrm{H}=\text { Henry's coefficient, } \mathrm{L} / \mathrm{L}
\end{aligned}
$$

and 1 and 2 denote the two different batch bottles

Similarly, if the liquid phase concentration is measure, the equation used is:

$$
H=\frac{C_{G 1}}{C_{L 1}}=\frac{C_{L 2} V_{L 2}-C_{L 1} V_{L 1}}{C_{L 1} V_{G 1}-C_{L 2} V_{L 2}}
$$

Using the EPICS method, Henry's Law coefficients were determined at $50^{\circ} \mathrm{C}$ for methanol and toluene, and at $20^{\circ} \mathrm{C}, 35^{\circ} \mathrm{C}$ and $50^{\circ} \mathrm{C}$ for alpha and gamma terpinenes. Two bottles with different gas-liquid volumes, but the same chemical mass, were compared at equilibrium using the EPICS method equation to calculate Henry's Law coefficient.

The Henry's Law coefficient experiments were performed in $125-\mathrm{mL}$ serum bottles capped with Teflon-lined crimp-top seals. Initially, each bottle was weighed to $0.1-\mathrm{mg}$ precision. DI water was added to each bottle of liquid volumes between 25 and 100- $\mathrm{mL}$, and the bottles with the water addition were weighed again. Each batch was allowed to reach equilibrium with the assigned temperature before any chemical was added. To relieve the pressure in the $50^{\circ} \mathrm{C}$ bottles, a needle was inserted through the septa in order to equilibrate the bottle pressure with atmospheric pressure. A Hamilton 5- $\mu \mathrm{L}$ gas-tight 
syringe was used to inject an equal volume of pure phase compound into each bottle. The batch bottles were incubated at their respective temperatures on a rotary shaker (>100 rpm) for at least 48 hours to allow equilibrium of the compounds between the gas and liquid phases in the bottles prior to sampling. Two liquid volumes were used and three identical bottles set up for each volume to ensure reproducibility. Duplicate samples from each batch bottle were taken and measured. Concentrations of methanol, toluene and sulfur compounds were measured by gas samples, and the terpinenes by liquid samples.

\subsubsection{Reactor Oxygen Mass Transfer $\left(K_{L} a\right)$ Coefficient}

The volumetric mass transfer rate of oxygen $\left(\mathrm{K}_{\mathrm{L}}\right.$ a) was determined at $35^{\circ} \mathrm{C}$ and $50^{\circ} \mathrm{C}$ in a 2-L sparged test reactor identical to the SSGR reactor. Deoxygenated DI water was sparged with air and the increase in dissolved oxygen (DO) was measured and recorded with time (Metcalf \& Eddy, 1991). Multiple tests were conducted at different liquid volumes and airflow rates.

For the test reactor, a 2-L glass graduated test cylinder was modified by adding two ports for mininert sampling valves and a fitting for the sparge stone to be inserted from the side near the reactor bottom. Lab air was sparged through a $2.5-\mathrm{cm}$ diameter spherical fritted sparge stone, and the gas flow rate was measured by a Gilmont GF-1160 flowmeter (range 0 to $289 \mathrm{~mL} / \mathrm{min}$ ). This is the same sparge stone design used in the SSGR test reactor. The target air flow rates were 50,100 and $150 \mathrm{~mL} / \mathrm{min}$, and the flow varied \pm 2 $\mathrm{mL} / \mathrm{min}$. Gas escaped through the top of the reactor that was open to atmospheric conditions. The reactor was heated to the appropriate temperature using a four foot Thermolyne heat tape attached to an Omega CN76000 digital temperature controller. A thermometer, as well as the temperature sensor on the DO probe, was used to verify accuracy and consistency of the temperature. The temperature varied $\pm 0.2^{\circ} \mathrm{C}$. Total liquid volume in the reactor for each test was $1815 \mathrm{~mL}$, and the liquid depth was $0.36 \mathrm{~m}$. 
A calibrated YSI DO probe and meter were used to measure DO concentration as a function of time. The probe was calibrated as described in the Indirect Method section. The probe was suspended in the liquid at about $5 \mathrm{~cm}$ below the water surface to measure DO concentration $(0.01 \mathrm{mg} / \mathrm{L}$ precision $)$. The probe was suspended with the membrane side up to prevent discrepancies in readings due to the air bubbles contacting the probe membrane.

After the DI water was heated to the designated temperature, deoxygenating chemicals were added to the liquid to remove the dissolved oxygen. The deoxygenating chemicals consisted of approximately $0.005 \mathrm{~g} / \mathrm{L} \mathrm{CoCl} \cdot 6 \mathrm{H}_{2} \mathrm{O}$ and $0.10 \mathrm{~g} / \mathrm{L} \mathrm{Na}_{2} \mathrm{SO}_{3}$ as demonstrated by Bielefeldt (1996). While dissolving the chemicals, and throughout the test, a magnetic stir-bar on a Thermolyne stir-plate set on speed 5 provided the necessary mixing. The aeration was continued through out the study, but the dissolved oxygen will drop due to the reaction rate of $\mathrm{Na}_{2} \mathrm{SO}_{3}$ and $\mathrm{CoCh}_{2} \cdot 6 \mathrm{H}_{2} \mathrm{O}$. When deoxygenation achieved a stable DO concentrate near zero, about $0.03 \mathrm{mg} / \mathrm{L}$, the airflow was started. The increase in DO concentration was manually recorded with time in 10 to 30 second intervals. Gas flow rate and temperature were also recorded for each test.

The DO concentration change with time can be related to the $\mathrm{K}_{\mathrm{L}}$ a as follows:

$$
\ln \left[\frac{\mathrm{C}_{\text {tat }}-\mathrm{C}_{\mathrm{t}}}{\mathrm{C}_{\mathrm{sat}}-\mathrm{C}_{\mathrm{o}}}\right]=-\mathrm{K}_{\mathrm{L}} \mathrm{a} \cdot \mathrm{t}
$$

where:

$$
\begin{aligned}
& \mathrm{C}_{\mathrm{t}}=\text { DO concentration at time } \mathrm{t}, \mathrm{mg} / \mathrm{L} \\
& \mathrm{C}_{\mathrm{sat}}=\text { DO saturation concentration, } \mathrm{mg} / \mathrm{L} \\
& \mathrm{C}_{\mathrm{o}}=\text { initial DO concentration in the system at } \mathrm{t}=0, \mathrm{mg} / \mathrm{L} \\
& \mathrm{K}_{\mathrm{L}} \mathrm{a}=\text { oxygen mass transfer coefficient, } \mathrm{min}^{-1} \\
& \mathrm{t}=\text { time, min }
\end{aligned}
$$


The value for $\mathrm{K}_{\mathrm{L}}$ a was determined from test data by a linear regression of $\ln \left(\mathrm{C}_{\mathrm{sat}}-\mathrm{C}_{\mathrm{t}}\right)$ versus t.

The DO saturation concentration $\left(\mathrm{C}_{\mathrm{sat}}\right)$ was selected for the reactor temperature from the YSI meter saturated DO versus temperature calibration table at zero salinity. Salinity has minimal effects below $300 \mathrm{mg} / \mathrm{L}$ and the effect of depth on DO saturation is minimal in this case because of the shallow liquid depth. At $35^{\circ} \mathrm{C}$, the saturated DO is $6.95 \mathrm{mg} / \mathrm{L}$ and at $50^{\circ} \mathrm{C}$ it is $5.47 \mathrm{mg} / \mathrm{L}$. As recommended by the ASCE Standard Method (1984), the initial low DO values (less than $10 \%$ of $\mathrm{C}_{\mathrm{sat}}$ ) and the $\mathrm{DO}$ values near the $\mathrm{C}_{\mathrm{sat}}$ (greater than $90 \%$ of $\mathrm{C}_{\text {sat }}$ ) were not included in the slope calculation. The gas/liquid mass transfer coefficient for the other compounds can be related to the oxygen $\mathrm{K}_{\mathrm{L}}$ a by a factor equal to the ratio of the compound/oxygen diffusion coefficients (Bielefeldt and Stensel, 1999). Thirteen $\mathrm{K}_{\mathrm{L}}$ a tests were done with test reactor. One test was done with the lab SSGR reactor by temporarily replacing biomass liquid with clean water to determine if lab SSGR $\mathrm{K}_{\mathrm{L}} \mathrm{a}$ was in the same range as the test reactor.

\subsubsection{Terpenine Gas-Liquid Mass Transfer Coefficient in Sparged Reactor}

Since diffusion coefficients for the terpene compounds were not available, their $\mathrm{K}_{\mathrm{L}} \mathrm{a}$ values had to be determined experimentally. The mass transfer coefficient rate for each terpenine in water was determined by a stripping test which was conducted as described by Bielefeldt (1996). A DO K $\mathrm{L}_{\mathrm{L}}$ a test was performed immediately prior to the stripping $\mathrm{K}_{\mathrm{L}} \mathrm{a}$ test at the same air flow rate in order to compare oxygen and terpene $\mathrm{K}_{\mathrm{L}}$ a values. Terpenine $\mathrm{K}_{\mathrm{L}}$ a experiments were done in the mass transfer test reactor and were conducted at $35^{\circ} \mathrm{C}$ and $50^{\circ} \mathrm{C}$ for both terpenine compounds.

A single pure terpenine compound was injected directly into DI water through a mininert valve using a Hamilton glass gas-tight syringe. Mixing was provided by a magnetic stir bar controlled by a Thermolyne stir plate on setting number five. The pure terpene chemical was allowed to dissolve for at least 30 minutes. Airflow was started after an initial liquid terpene concentration sample was taken, and decreasing terpene 
concentrations were measured with time. Experimental conditions such as air flow, temperature and liquid volume were recorded for each test. Test target conditions were on air flow of $150 \mathrm{~mL} / \mathrm{min}$, temperature of $35^{\circ} \mathrm{C}$ or $50^{\circ} \mathrm{C}$, and liquid volume of $1815 \mathrm{~mL}$. A plot of $-\ln \left(C / C_{0}\right)$ versus time was plotted $\left(C_{o}=\right.$ initial concentration, $C=$ concentration at time $\mathrm{t}$ ). The slope of this plot was used in the following equation:

$$
\mathrm{K}_{\mathrm{L}} \mathrm{a}=\frac{-\mathrm{Q}_{\mathrm{g}} \cdot \mathrm{H}}{\mathrm{Vl}} \cdot \ln \left[1-\text { slope } \cdot\left(\frac{\mathrm{Vl}}{\mathrm{Q}_{\mathrm{g}} \cdot \mathrm{H}}\right)\right]
$$

where: $\mathrm{K}_{\mathrm{L}} \mathrm{a}=$ mss transfer coefficient, $\min ^{-1}$

$\mathrm{Q}_{\mathrm{g}}=$ air flow rate, $\mathrm{mL} / \mathrm{min}$

$\mathrm{H}=$ Henry's coefficient, $\mathrm{L} / \mathrm{L}$

$\mathrm{Vl}=$ volume of liquid in reactor, $\mathrm{mL}$

Slope $=$ slope of $-\ln \left(C_{t} / C_{o}\right)$ versus time plot, $\min ^{-1}$

\subsection{Biodegradation Kinetic Testing}

The Michaelis-Menten model was used to describe biodegradation kinetics:

$$
\mathrm{r}_{\mathrm{S}}=\frac{\mathrm{kSX}}{\mathrm{K}_{\mathrm{S}}+\mathrm{S}}
$$

Where: $r_{\mathrm{s}}=$ substrate utilization rate, $\mathrm{mg} / \mathrm{L}-\mathrm{d}$

$\mathrm{S}=$ substrate concentration, $\mathrm{mg} / \mathrm{L}$

$\mathrm{X}=$ biomass concentration, $\mathrm{mg} / \mathrm{L}$

$\mathrm{K}_{\mathrm{S}}=$ half- velocity coefficient, $\mathrm{mg} / \mathrm{L}$

$\mathrm{k}=$ methanol specific substrate utilization rate, $\mathrm{g} / \mathrm{g}-\mathrm{d}$

Biodegradation kinetic tests were conducted using two different methods to determine model coefficients, a direct method and an indirect method. For the direct method, batch serum bottle tests were inoculated with the enrichment culture and the concentration of the compound of interest was measured directly as a function of time. The indirect 
method tests were also performed in batch serum bottles, with dissolved oxygen (DO) concentration measured with time instead of the actual compound concentrations. The concentration of the compound was assumed to decline in proportion to the amount of DO used, since a portion of the substrate was oxidized during substrate consumption to provide energy for growth. The advantages for the indirect method are that numerous data points can be obtained with time, and that reaction rates at very low substrate concentrations can be observed compared to the direct method.

\subsubsection{Direct Method}

Degradation rates were determined in batch tests conducted in $125-\mathrm{mL}$ glass serum bottles capped with Teflon-lined crimp-top seals. The compound was pre-dissolved in $100-\mathrm{mL}$ of nutrient solution that was added to the bottle, leaving a $25-\mathrm{mL}$ headspace.

The nutrient solution composition was the same as that used for the growth reactors. The test bottles were inoculated with biomass from the SSGR or enrichment reactors. The biomass sample was centrifuged and washed twice with nutrient solution to remove any residual chemical and to concentrate the biomass. The concentrated biomass was then added to the serum bottle using a syringe with volumes from $1 \mathrm{~mL}$ to $5 \mathrm{~mL}$. Test bottle VSS concentrations were generally in the range of $40-100 \mathrm{mg} / \mathrm{L}$. Bottles were incubated and shaken at the appropriate temperature. The $35^{\circ} \mathrm{C}$ experiments were performed on a shaker table in a $35^{\circ} \mathrm{C}$ constant temperature room. The $50^{\circ} \mathrm{C}$ biodegradation studies were performed in a rotary shaker incubator.

For tests with terpenine the terpenine concentration changes with time were determined from liquid samples taken about every 10 minutes. The first sample (time equal zero) was taken immediately after the concentrated biomass was injected into the bottle. The liquid samples were extracted into hexane immediately and later analyzed by gas chromatography (GC).

A linear plot of terpene concentration versus time was used to determine the specific substrate utilization rates (K') for different initial terpene concentrations. $\mathrm{K}^{\prime}$ was 
determined from the slope of the liquid terpene concentration versus time data divided by the biomass concentration in the bottle. The biomass concentration was measured at the end of each biodegradation test by VSS analysis. This rate was then corrected to determine the maximum specific substrate utilization rate $(\mathrm{k})$ by accounting for the terpene partitioned into the headspace gas using Henry's Law coefficient and gas and liquid volumes in the serum bottle:

$$
\mathrm{k}=\mathrm{K}^{\prime} *\left(1+\mathrm{H} * \mathrm{~V}_{\mathrm{g}} / \mathrm{V}_{\mathrm{L}}\right)
$$

where:

$$
\begin{aligned}
\mathrm{k}= & \text { maximum specific degradation rate, } \mathrm{g} \text { Terp/g VSS-day } \\
\mathrm{K}^{\prime}= & \text { maximum specific degradation rate from liquid concentrations, } \\
& \mathrm{g} \text { Terp/g VSS-day } \\
\mathrm{V}_{\mathrm{g}}= & \text { gas volume in bottle, } \mathrm{mL} \\
\mathrm{V}_{\mathrm{L}}= & \text { liquid volume in bottle, } \mathrm{mL}
\end{aligned}
$$

A limited number of control bottle tests were performed in order to conserve biomass. Bottles were set up as described above, then $5 \mathrm{~mL}$ of $37 \%$ formaldehyde was added to the control bottle to kill the biomass. Control bottles were run to confirm no leaks or abiotic losses of the chemical from the serum bottles.

\subsubsection{Indirect Method}

The indirect method of determining biokinetics involves a respirometric method modeled after that used by Ellis et al. (1994). The method assumes that the decline of dissolved oxygen in a closed batch system is directly proportional to the bacterial consumption of a single organic compound spiked into the system. This technique has been used to determine both $\mathrm{k}$ and $\mathrm{K}_{\mathrm{S}}$ in the Michaelis-Menten model and was used here to determine methanol and terpinene degradation kinetics.

The test apparatus consisted of a modified 250- $\mathrm{mL}$ Erlenme yer flask. The top of the flask was modified to a BOD bottle opening to accommodate a dissolved oxygen (DO) 
probe. Two mininert ports were created for liquid sampling purposes. The liquid in the bottle was mixed by a Teflon ${ }^{\mathrm{TM}}$ coated magnetic stir bar and Thermolyne ${ }^{\mathrm{TM}}$ stir plate.

The seed culture for the biodegradation test was extracted from the selected reactor, washed with nutrient solution and centrifuged to concentrate the biomass. Then, the biomass was added to nutrient solution in the test apparatus that was pre-aerated with pure oxygen at the desired temperature. A calibrated YSI DO probe, connected to a YSI digital DO meter, was submerged into the flask and the data collection was started. Before the chemical was added, the dissolved oxygen concentration started dropping slowly due to the endogenous oxygen consumption. After approximately $15 \mathrm{~min}$, a known amount of pure liquid methanol was injected into the test system.

The data collection procedure was automated to produce more consistent DO readings and reduce the labor time required. The data from the DO meter was logged into a computer continuously at 1 -second increments with a program called Black Knight. It was then transferred to a spreadsheet in Microsoft ${ }^{\circledR}$ Excel. The large data set was compressed by taking a point every minute for graphing and interpretation purposes.

The test method requires subtracting the DO consumption due to endogenous respiration from the total DO consumption to determine the DO consumption related to substrate removal.

\section{$\underline{\text { 3.7 Simpson Mill Site Pilot Plant }}$}

A pilot plant was constructed and installed at the Simpson Pulp and Paper Mill in Tacoma, WA. Figure 4 shows the schematic of the pilot plant. The SSGR system reactor was an 8-ft diameter by 5-ft deep steel tank (Figure 5). The system was operated at a 4ft. liquid depth. A fine bubble diffuser grid containing 37, 1- $\mathrm{ft}$ diameter Sanitaire ${ }^{\circledR}$ flexible membrane diffusers covered the tank floor (Figure 6). Contaminated air from the pulp washer operation was directed to the inlet of a positive displacement blower, which forced the air through the diffusers. The blower was supplied by Hoffman and was rated 
at 7.5 HP, maximum pressure of 7 PSI, and maximum speed of 3600 RPM. The top of the tank was covered with plywood with an opening for exit gas.

The air flow rate to the bioreactor was controlled by a bleed valve down stream from the blower. High temperature 2 inch O.D. CPVC plastic piping was used for gas flow before and after the blower. A demister with 6-inch diameter by 6-inch high packing provided by Koch Engineer and a paper filter was installed upstream from the blower to trap foam, moistures and particles.

The SRT of the bioreactor would be controlled by feeding and draining liquid from the tank. The feed and drain pipes were controlled by solenoid valves and timers. Because of the excessively high temperature of the influent gas, it was necessary to cool the pilot plant reactor liquid to operate at $50^{\circ} \mathrm{c}$ or lower. Once the cooling system was installed, a $30^{\circ} \mathrm{C}$ temp was selected in an attempt to maximize DMS degradation. The temperature of the system was controlled by three loops of a 1" O.D. stainless steel cooling coil submerged along the tank well. The coil was connected to a tap water supply through a $3 / 4$ " solenoid valve, which opened in the normal position. The solenoid valve was controlled by a temperature controller connected to a type $\mathrm{K}$ temperature probe (Cole Parmer) submerged in the reactor liquid. When the temperature was over the set point, the water valve was opened and water flowed through the cooling coil until the temperature dropped below the set point. 


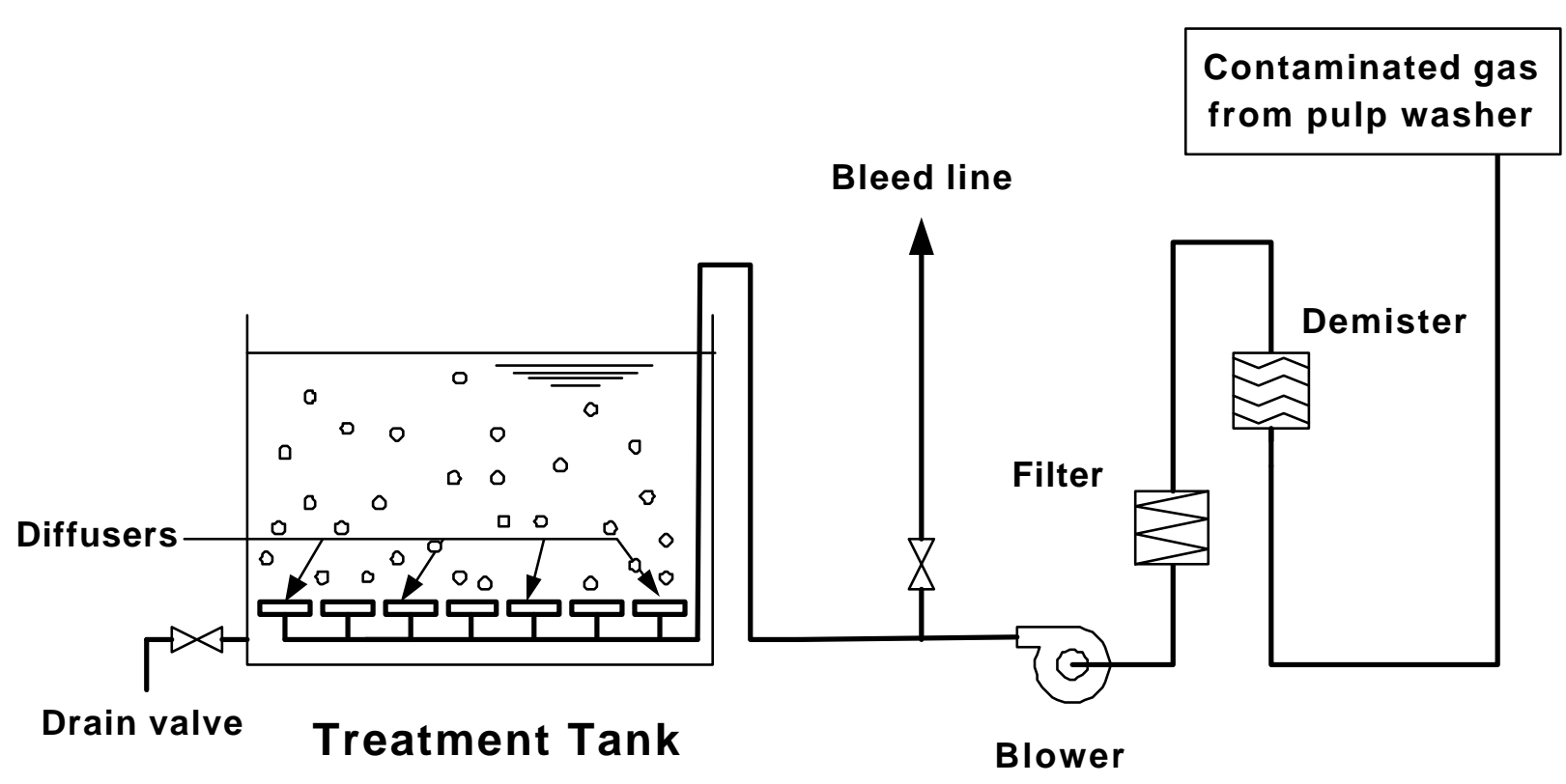

\section{Figure 4 Pilot plant schematic}

A gas influent sampling port was installed in the CPVC pipe section after the bleed line and before entering the tank. The influent sample was taken by connecting the Tedlar gas sampling bag (SKC) to the sampling port with a Teflon tube. The bag was filled by the gas pressure in the line. The effluent gas sample was collected in a Tedler gas sampling bag located in a closed and sealed container. An air pump evacuated air from the container, which created a negative pressure allowing gas to flow from the headspace in the treatment reactor to the sample bag. This method eliminates problems of sample contamination from a sample pump. The samples were stored in an insulated and closed box to prevent light exposure and to minimize cooling. When the sample was brought back to the lab, it was heated in a water bath to the same temperature as the reactor gas. The sample was then analyzed for sulfur and organic compounds by injection into the GC-FPD and GC-FID respectively.

The feed gas flow rate to the reactor was measured using a hot wire anemometer inserted through a port on a pipe section prior entering the tank. 


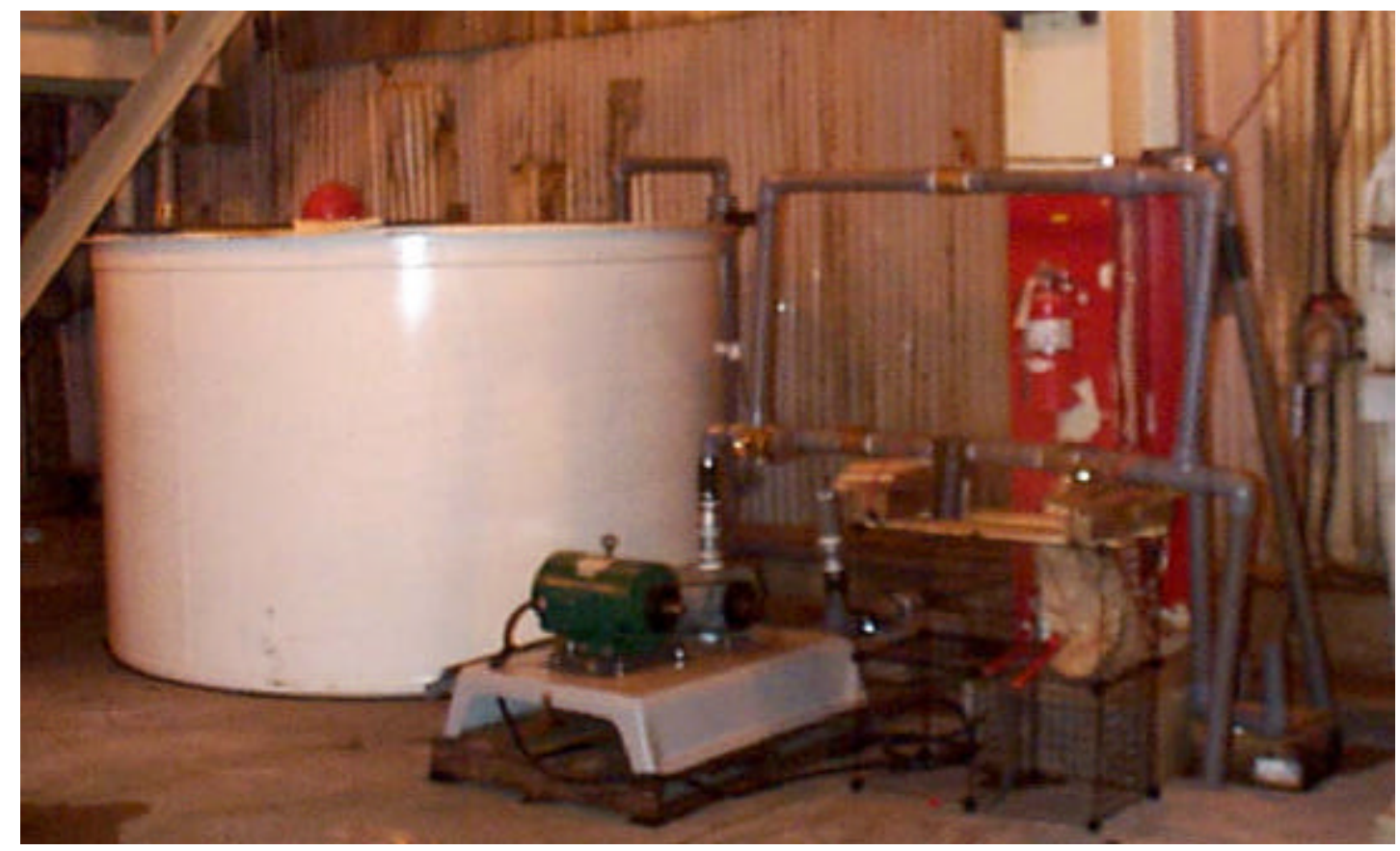

Figure 5 Pilot Plant at Simpson pulp and paper mill

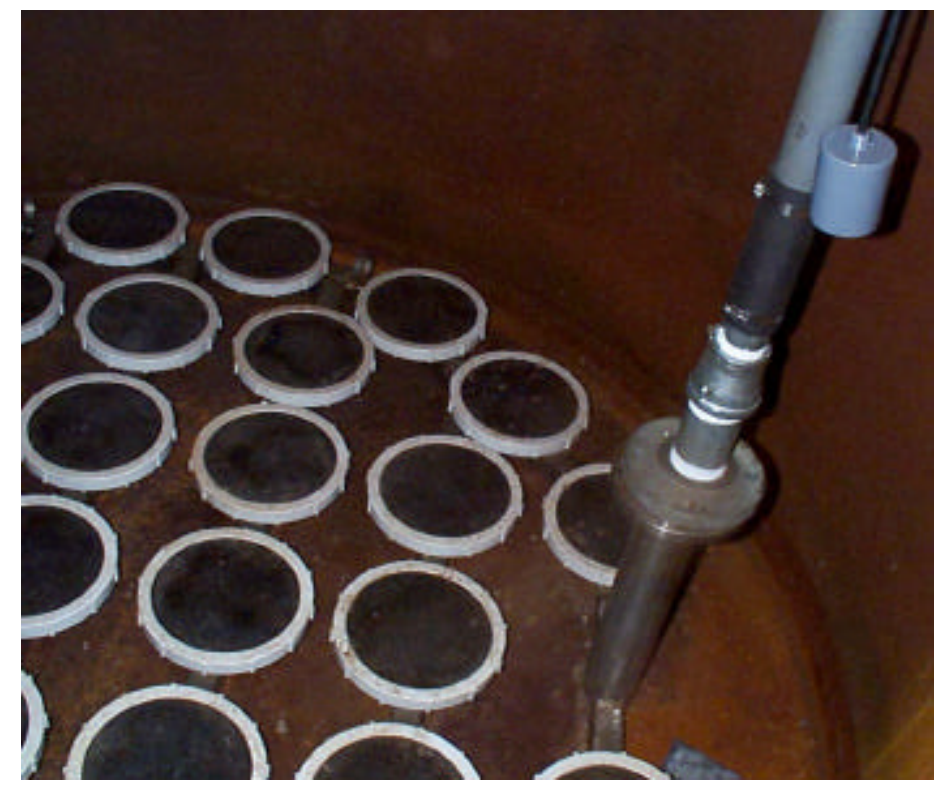

Figure 6 Diffusers inside the pilot plant 
Prior to system start up, oxygen transfer $\mathrm{K}_{\mathrm{L}}$ a tests were performed with different air flowrates. The $\mathrm{K}_{\mathrm{L}}$ a tests were done with the same procedure as that for the laboratory reactor.

The tank was seeded with activated sludge from the Simpson pulp and paper mill. Industrial grade sodium bicarbonate (Van Water and Roger) was added to the system to assure a minimum alkalinity of $100 \mathrm{mg} / \mathrm{L}$ as $\mathrm{CaCO}_{3}$. Nutrients were added as $\mathrm{NaNO}_{3}$ and $\mathrm{KH}_{2} \mathrm{PO}_{4}$ to provide sufficient nitrogen and phosphorus for biogrowth.

\subsection{Analytical Procedures}

\subsubsection{Organic Compounds}

Organic compounds in the influent and effluent gases were analyzed on an SRI 8610C $\mathrm{GC}$ with a flame ionization detector (FID). The GC was equipped with a SUPELCOWAX ${ }^{\mathrm{TM}}-10$ fused silica capillary column $(60 \mathrm{~m} \times 0.53 \mathrm{mmID}, 1.00 \mu \mathrm{m}$ film thickness). The oven temperature was set at $50^{\circ} \mathrm{C}$ for 2.5 minutes, then ramped $15^{\circ} \mathrm{C} / \mathrm{min}$ for 7.5 min. Peaksimple ${ }^{\mathrm{TM}}$ software was used to integrate the peak areas from the GCFID. The gas concentration of the VOC was then determined from linear standard curves. The linear standard curves for each compound were developed from sampling and analysis of prepared gas standards. The standards were prepared by adding a known amount of pure compound into a gas bag, which was filled with a known volume of air. Five to seven standard values were prepared to obtain each standard curve for each compound ranging from $1 \mathrm{ppm}$ to $500 \mathrm{ppm}$. Sample detection limits for methanol, methyl-ethyl-ketone, acetaldehyde, acrolein, benzene, toluene, and xylenes were 1, 1, 3, $2,1,1$, and $1 \mathrm{ppm}$, respectively.

\subsubsection{Sulfur Compounds}

Sulfur compounds were analyzed on an SRI 8610C GC with flame photometric detector (FPD). The column used was SUPELPAK-S teflon column (30" $\times 1 / 8$ " OD). The oven temperature was set at $60^{\circ} \mathrm{C}$ for $1 \mathrm{~min}$, then ramped $40^{\circ} \mathrm{C} / \mathrm{min}$ for $3.25 \mathrm{~min}$ until the 
temperature reached $190^{\circ} \mathrm{C}$ and held for $0.5 \mathrm{~min}$. The standard curve was prepared similarly as with organic compounds. Seven to nine standard samples were prepared for each compounds ranging from $1 \mathrm{ppm}$ to $500 \mathrm{ppm}$. The detection limits for HS, MT, DMS, and DMDS were 1, 2, 2, and 2 ppm, respectively.

\subsubsection{Formaldehyde}

The formaldehyde analysis method was adapted from NIOSH method 2541 (NIOSH, 1994). Influent and effluent gas stream was pumped through glass tube containing $10 \%$ (2-hydroxymethyl)piperdine on XAD-2 as a sorbent (SKC 226-118). The flow rate was $98 \mathrm{ml} / \mathrm{min}$. The total volume of sample was $1728 \mathrm{~mL}$. The sorbent were then desorbed by adding $1.0 \mathrm{ml}$ toluene and placed in an ultrasonic water bath for $60 \mathrm{~min}$. Then, $3 \mu 1$ of aliquot was injected into a Hewlett Packard GC equipped with DB-WAX capillary column (30 $\mathrm{m} \times 0.32 \mathrm{~mm} \mathrm{ID,} 0.5 \mu \mathrm{m}$ film thickness). The injector temperature was $250^{\circ} \mathrm{C}$, and the detector temperature was $300^{\circ} \mathrm{C}$. The initial column temperature was held at $70^{\circ} \mathrm{C}$ for $1 \mathrm{~min}$., was ramped at a rate of $15^{\circ} \mathrm{C} / \mathrm{min}$ until the temperature reached $240^{\circ} \mathrm{C}$, and held for another $10 \mathrm{~min}$. The linear standard curve was prepared by injecting various concentrations of formaldehyde standard solution into vials containing sorbent. After $24 \mathrm{hr}$, the sorbent was desorbed and analyzed using the same procedure as the samples. Linear standard curves were developed. The percent recovery was determined by preparing gas standard in gas bag (as described in section 3.8.1) and sampled by pumping through sorbent tube, desorbed and analyzed. The recovery rate was $80 \%$. The minimum detection limit was $5 \mathrm{ppm}$.

\subsubsection{Terpenines}

Liquid/liquid extraction and gas chromatography analysis was used to measure alphaterpinene and gamma-terpinene concentrations. The method used was similar to that described by Misra et al. (1996) for measuring various monoterpene hydrocarbons with the modification of using hexane instead of isooctane for the extraction. 
A 1-mL liquid sample was obtained with a 1-mL Hamilton glass gas-tight syringe. Samples were transferred to a 4- $\mathrm{mL}$ glass serum tube containing $1 \mathrm{~mL}$ of hexane spiked with approximately $10 \mathrm{mg} / \mathrm{L}$ bornyl acetate, which served as the internal standard. The glass serum tubes were sealed with screw-top, Teflon-lined rubber septa. Hexane extraction was facilitated by agitating with a vortex mixer for 6 minutes, then centrifuging for 5 minutes if needed to allow phase separation. A disposable pipette was employed to transfer $700-\mu \mathrm{L}$ of the solvent extract into a 2 -mL crimp-top auto-sampler vial, and vials were immediately sealed with Teflon-lined crimp cap. Samples were analyzed the same day.

Hexane-extracted samples were analyzed using a Perkin-Elmer Auto System Gas Chromatograph (GC) equipped with a flame ionization detector (FID) and a DB-5 capillary column (30- $\mathrm{m}$ long, 0.548-mm inner diameter: J\& W Scientific). The oven was operated under the following temperature program: $70^{\circ} \mathrm{C}$ for $3 \mathrm{~min} ; 10^{\circ} \mathrm{C} / \mathrm{min}$ to $180^{\circ} \mathrm{C}$ where it was held for $2 \mathrm{~min}$ (Misra et al. 1996). The injector and detector temperatures were maintained at $250^{\circ} \mathrm{C}$ and $380^{\circ} \mathrm{C}$ respectively. Omega integrating software on a Genesis computer was used to analyze the GC output.

Standards were prepared with pure terpene chemical dissolved in $1 \mathrm{~L}$ of DI water. Pure liquid phase terpene was injected with a glass, gas-tight Hamilton syringe into $1 \mathrm{~L}$ of DI water in a $1 \mathrm{~L}$ graduated flask. The air headspace was insignificant compared to the flask volume, and it was capped so that volatilization of terpene did not occur. The liquid was mixed for at least 30 minutes after the terpene was added with a magnetic stir-rod on a Thermolyne stir-plate. Standards were made for concentrations between $0.5 \mathrm{mg} / \mathrm{L}$ and 6 $\mathrm{mg} / \mathrm{L}$ and at least 5 concentrations per standard curve. Concentrations higher than 6 $\mathrm{mg} / \mathrm{L}$ would have approached the solubility limit of approximately $8 \mathrm{mg} / \mathrm{L}$ and resulted in inconsistent concentrations. Duplicate samples were taken at each concentration and averaged.

Standard curves were corrected for the internal standard response. The average response from the standards divided by the internal standard response was plotted versus terpene 
concentration in a Microsoft $^{\circledR}$ Excel spreadsheet. An equation of the best-fit curve was determined for the linear relationship. The equation was used to convert area responses of samples to concentration.

\subsubsection{Conventional Reactor Parameters}

Volatile suspended solids (VSS) and total suspended solid (TSS) were used as an indication of biomass concentration. The procedure for VSS and TSS analysis was taken from Standard Method (1995).

Soluble COD was used as an indicator of non-degraded compounds and the formation of intermediate compounds. Liquid samples from the growth reactors were periodically analyzed for soluble COD using Hach Low Range (0-150 mg/L COD) reagent vials and Hach DR/40000U spectrophotometer at $420 \mathrm{~nm}$. Millipore $0.45-\mu \mathrm{m}$ glass fiber syringe filters $(47 \mathrm{~mm})$ were used to eliminate biomass and suspended matter from liquid samples.

The $\mathrm{pH}$ of the growth reactors was periodically measured using Hydrion brand $\mathrm{pH}$ paper (range 6.0 to 8.0 ). Color change of the $\mathrm{pH}$ paper was compared to the color chart provided on the container. Visual judgement was estimated to be accurate to $0.2 \mathrm{pH}$ units. 


\subsection{RESULTS}

This section presents results on the laboratory SSGR experiments treating organic and reduced sulfur compounds, modeling of methanol removal in the SSGR, seed source acclimation studies for reduced sulfur compounds, mass transfer and biodegradation tests with terpenine, and pilot plant test observations.

\subsection{Organic Compound Removal in the Laboratory SSGR}

Table 1 Operating Conditions of SSGR

\begin{tabular}{|l|c|c|c|}
\hline \multicolumn{1}{|c|}{ Period } & I & II & III \\
\hline \# Days & 21 & 26 & 7 \\
\hline SRT, Days & 10 & 10 & 10 \\
\hline VSS, mg/L & $692 \pm 21$ & $647 \pm 12$ & $642 \pm 16$ \\
\hline TSS, mg/L & $974 \pm 31$ & $818 \pm 21$ & $822 \pm 37$ \\
\hline SCOD, mg/L & $100 \pm 6$ & $61 \pm 10$ & $58 \pm 2$ \\
\hline pH & 6.4 & 6.4 & 6.9 \\
\hline DO, mg/L & 6 & 6 & 6 \\
\hline Temp, ${ }^{\circ} \mathrm{C}$ & 50 & 50 & 50 \\
\hline Gas Application $\left(\mathrm{m}^{3} / \mathrm{m}^{2}-\mathrm{hr}\right)$ & 1.8 & 1.8 & 1.8 \\
\hline Compounds Fed & & & \\
\hline Methanol & $1274 \pm 46$ & $1077 \pm 46$ & $1089 \pm 6.8$ \\
\hline Acrolein & $162 \pm 27$ & $134 \pm 14$ & $134 \pm 3.2$ \\
Acetaldehyde & $191 \pm 21$ & $170 \pm 14$ & $161 \pm 4.0$ \\
Methyl-ethyl-ketone & $174 \pm 16$ & $134 \pm 9.5$ & $134 \pm 3.7$ \\
Benzene & $152 \pm 23$ & $131 \pm 8.6$ & $135 \pm 3.2$ \\
Toluene & $135 \pm 19$ & $121 \pm 11$ & $128 \pm 3.7$ \\
\hline p-xylene & $14 \pm 1.6$ & $16 \pm 1.7$ & $19 \pm 0.6$ \\
m-xylene & $16 \pm 1.9$ & $16 \pm 0.9$ & $19 \pm 0.6$ \\
o-xylene & $15 \pm 2.1$ & $16 \pm 1.2$ & $18 \pm 1.0$ \\
\hline
\end{tabular}


Table 1 shows the steady-state operating conditions in three consecutive periods after a 106 day start up and operating period. The feed composition and concentrations were selected to simulate a HVLC stream from pulp and paper mills. The gas feed rate was set at $1.8 \mathrm{~m}^{3} / \mathrm{m}^{2}$-min and the reactor was maintained at $50^{\circ} \mathrm{C}$. Methanol, which is the major component in HVLC gas stream from pulp and paper mill was fed at a concentration of 1000 to 1200 ppm. Acrolein, acetaldehyde, methyl-ethyl-ketone, benzene and toluene were present at moderate concentrations (120 to $190 \mathrm{ppm}$ ). Xylenes were fed at around 20 ppm, since they have been observed at low concentration in pulp mill emissions. All three periods were operated at the same SRT (10 days) with similar VSS concentrations (642 to $692 \mathrm{mg} / \mathrm{L}$ ). The reactor soluble COD concentrations were slightly different, which reflected the removal efficiency. The $\mathrm{pH}$ in phase I and II were 6.4. Period II is separated from period I based on the lower methanol feed concentration. In phase III, the $\mathrm{pH}$ was adjusted to 6.9 by adding $\mathrm{NaOH}$ solution to the reactor. The low $\mathrm{pH}$ in Phase I and II was suspected to be from nitrification. Therefore, in period III, the ammonia in nutrient feed was substitute with nitrate.

Since methanol is a cluster rule surrogate for treatment efficiency, its removal is reviewed separately here and shown in Figure 7 and Table 2. In period I and II, the methanol removal efficiencies were 94 and 96\%, respectively. The average effluent concentrations in these periods were 71 and $49 \mathrm{ppm}$, above the $20 \mathrm{ppm}$ treatment goal. However, after $\mathrm{pH}$ adjustment in period III, the removal efficiency increased to $99 \%$ and the average effluent concentration decreased to $10 \mathrm{ppm}$. During phase III the influent methanol concentration remained as high as that in phase II. The reactor VSS concentration was also similar, so that the only parameter that changed and appeared to be related to the improved methanol removal was $\mathrm{pH}$. The surge of methanol feed concentration from 1000 ppm to 1200 ppm in Phase II, was followed by the decrease in the removal efficiency. 


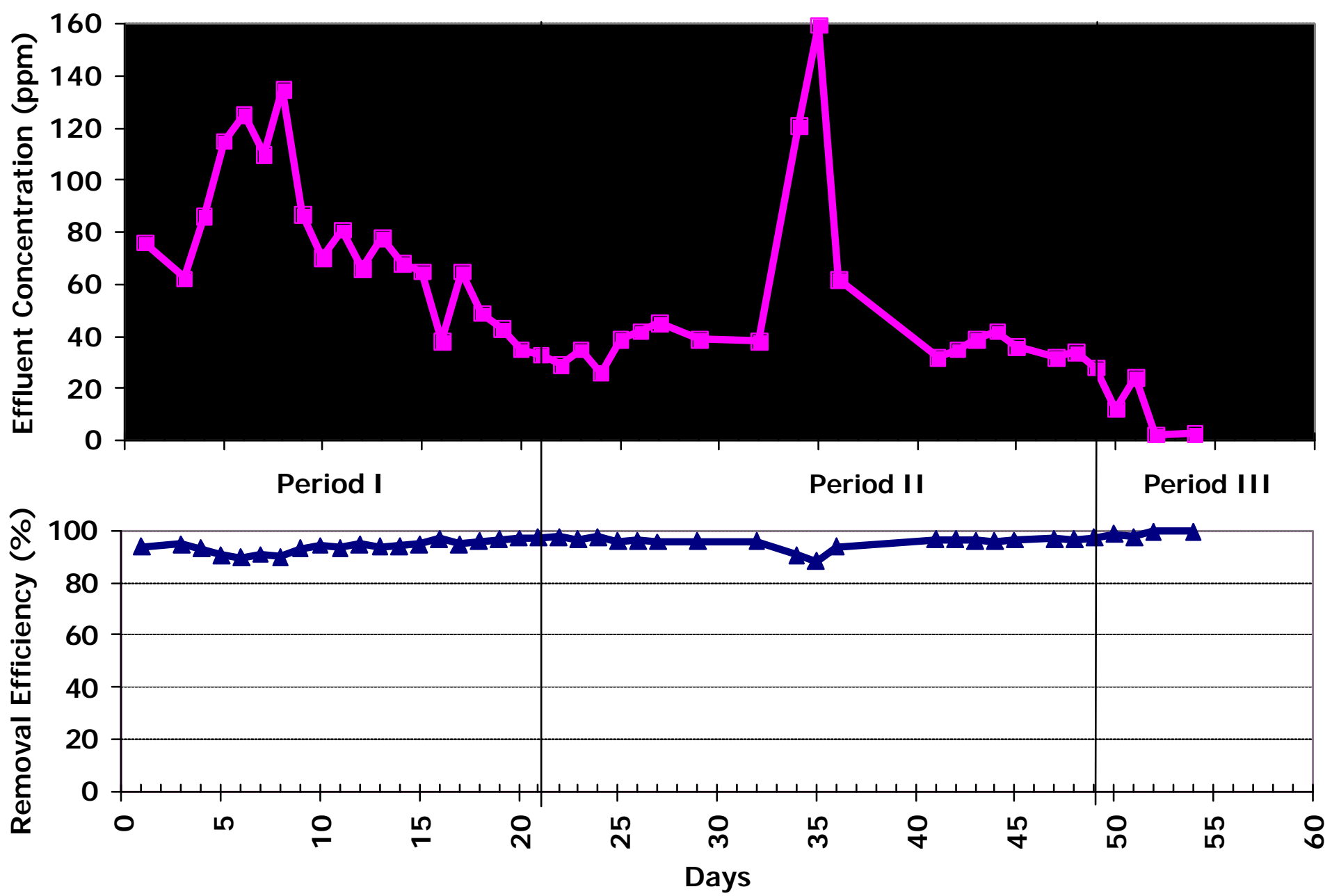

Figure 7 Methanol treatment performance in SSGR in 3 operation periods 
Table 2 The average treatment efficiency for methanol in SSGR in periods I, II and III

\begin{tabular}{|l|c|c|c|}
\hline Period & I & II & III \\
\hline Influent, ppm & $1275 \pm 46$ & $1077 \pm 45$ & $1089 \pm 7$ \\
\hline Effluent, ppm & $71 \pm 31$ & $49 \pm 35$ & $10 \pm 10$ \\
\hline \% Removal & 94 & 96 & 99 \\
\hline Detection Limit, ppm & 2 & 2 & 2 \\
\hline $\mathrm{pH}$ & 6.4 & 6.4 & 6.9 \\
\hline
\end{tabular}

The removal efficiencies for all other organic compounds are shown in Table 3. The removal efficiencies of acrolein, acetaldehyde, MEK, benzene and toluene were $99 \%$ in period I and above $99 \%$ in period II. For $>99 \%$ removal efficiencies, the compound was not detected so the detection limit concentration was used to calculate the removal performance. Since the removal efficiencies of these compounds were very high in periods I and II, the effect of the higher $\mathrm{pH}$ on their removal in period III could not be determined. Because of their lower treatment levels, the removal efficiencies of xylenes are shown in Figure 8 as well as in Table 3. The removal efficiency in period I was only $74-84 \%$, which was substantially lower than other compounds. This may have been due to time needed for acclimation, because in period II, the removal efficiency increased to 86-94\%. After the $\mathrm{pH}$ adjustment, the removal efficiency of xylene increased further, but was still lower than the target treatment. Despite the lower removal efficiencies, the actual effluent concentrations of xylenes were only 1-4 ppm, due to their low influent concentrations. It should be noted that BTX compounds are much more volatile than the other organic compounds, so that for the same liquid concentrations resulting from biodegradation in the SSGR, they will have higher effluent gas concentrations. 


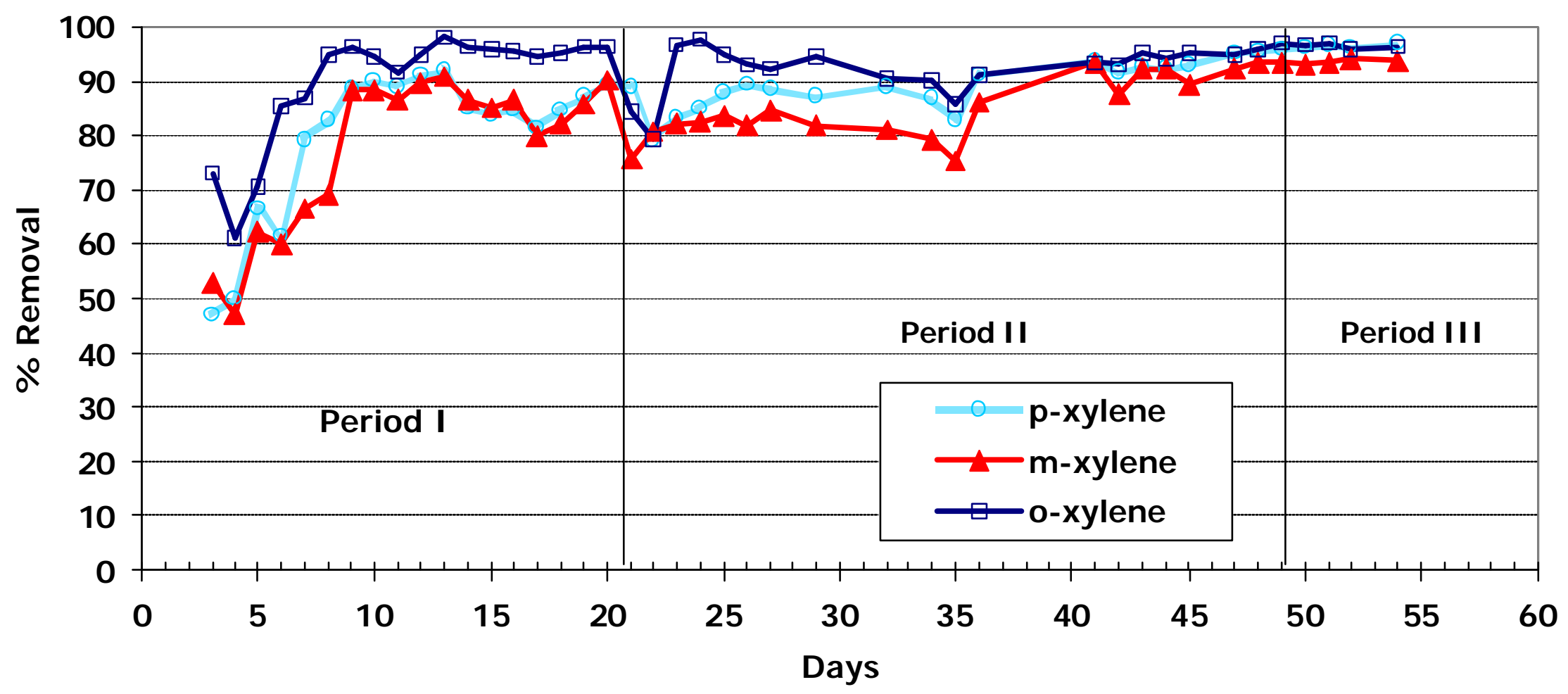

Figure 8 Treatment removal efficiency of xylene compounds in SSGR 
Table 3 Treatment removal efficiencies of other organic compounds in SSGR for periods I, II and III

\begin{tabular}{|l|c|c|c|c|}
\hline Compounds & Detection limits & \multicolumn{3}{|c|}{ \% Removal } \\
\cline { 2 - 5 } & PPM & I & II & III \\
\hline Acrolein & 2 & 99 & $>99$ & $>99$ \\
\hline Acetaldehyde & 3 & 99 & $>99$ & $>99$ \\
\hline MEK & 1 & 99 & $>99$ & $>99$ \\
\hline Benzene & 1 & 99 & $>99$ & $>99$ \\
\hline Toluene & 1 & 99 & 98 & $>99$ \\
\hline p-xylene & 0.1 & 76 & 90 & 97 \\
\hline m-xylene & 0.1 & 74 & 86 & 94 \\
\hline o-xylene & 0.1 & 84 & 94 & 97 \\
\hline
\end{tabular}

\subsection{Application of SSGR Model for Methanol Removal}

Since methanol can serve as a surrogate for gas emission organic compounds under the cluster rules, it was selected for the organic compound to be used in the mechanistic model evaluation. This section describes the gas treatment mechanistic model, provides mass transfer and biokinetic parameters for methanol for the model, and uses the model to analyze methanol removal performance in the SSGR system.

\subsubsection{Model Description}

The model has been developed and described by us previously (Bielefeldt and Stensel, 1999) and is summarized here. The first equation describes the effluent gas compound concentration as a function of the reactor liquid compound concentration, the air reactor application rate $\left(\mathrm{m}^{3}\right.$ gas $/ \mathrm{m}^{2}$ reactor area $-\mathrm{hr}$ ), the mass transfer coefficients, $\mathrm{K}_{\mathrm{L}}$ a and $\mathrm{H}$, the influent gas compound concentration, and liquid depth. This equation is based on a mass balance for gas/liquid transfer for a bubble traveling up through a liquid column. 
An important, and valid assumption in this case, is that the reactor liquid is completely mixed so that $\mathrm{C}_{\mathrm{L}}$ is constant.

$C_{g e}=C_{g o} e^{\frac{- \text { Kla.d }}{H\left(Q_{g} / A\right)}}+C_{L} H\left[1-e^{\frac{- \text { Kla.d }}{H\left(Q_{g} / A\right)}}\right]$

Where:

$\mathrm{C}_{\mathrm{ge}}=$ Effluent gas compound concentration, $\mathrm{mg} / \mathrm{L}$

$\mathrm{C}_{\mathrm{go}}=$ Influent gas compound concentration, $\mathrm{mg} / \mathrm{L}$

$\mathrm{C}_{\mathrm{L}}=$ Liquid compound concentration, $\mathrm{mg} / \mathrm{L}$

$\mathrm{H}=$ Henry's coefficient, $\frac{\text { air }, m g / L}{\mathrm{H}_{2} \mathrm{O}, m g / L}$

$\mathrm{K}_{\mathrm{L}} \mathrm{a}=$ Mass transfer coefficient, $\mathrm{hr}^{-1}$

$\mathrm{Q}_{\mathrm{g}}=$ Air flow rate, $\mathrm{m}^{3} / \mathrm{hr}$

$\mathrm{Q}_{\mathrm{g}} / \mathrm{A}=$ Air rate per unit area of reactor, $\mathrm{m}^{3} / \mathrm{m}^{2}-\mathrm{hr}$

$\mathrm{d}=$ Liquid depth, $\mathrm{m}$

The liquid concentration is controlled by biodegradation, which is a function of the biokinetic and growth coefficients $\left(\mathrm{k}, \mathrm{K}_{\mathrm{S}}, \mathrm{Y}\right.$ and $\left.\mathrm{b}\right)$ and the reactor SRT. The biokinetic and growth parameters, $\mathrm{k}, \mathrm{K}_{\mathrm{S}} \mathrm{Y}$ and $\mathrm{b}$ must be known, estimated or obtained experimentally. At steady state conditions the fundamental and convenient equation that predicts the reactor liquid compound concentration is as follows:

$$
C_{L}=\frac{K_{S}(1+b \cdot S R T)}{S R T(Y \cdot k-b)-1}
$$

For the gas reactor the SRT can be controlled by how much reactor liquid is removed each day and replaced by liquid containing nutrients and alkalinity: 


$$
S R T=\frac{V}{Q_{L}}
$$

Where:

$\mathrm{C}_{\mathrm{L}}=$ Liquid concentration, $\mathrm{mg} / \mathrm{L}$

$\mathrm{K}_{\mathrm{S}}=$ Michaelis-Menten half- velocity constant, mg/L

$\mathrm{k}=$ Max. specific substrate utilization rate, $\mathrm{g} / \mathrm{g}$-day

$\mathrm{b}=$ Cell decay coefficient, $\mathrm{g} / \mathrm{g}-\mathrm{d}$

$\mathrm{Y}=$ Cell synthesis yield, $\mathrm{g}$ cell/g organic compound degraded

$\mathrm{Q}_{\mathrm{L}}=$ Liquid removal rate, $\mathrm{m}^{3} / \mathrm{d}$

$\mathrm{V}=$ Reactor volume, $\mathrm{m}^{3}$

The organic compound removal efficiency is given as follows:

$$
\% R=100 \cdot\left(1-\frac{C_{g e}}{C_{g o}}\right)
$$

Where:

$\% \mathrm{R}=$ Compound removal efficiency, percent

The maximum treatment potential for a given design would be at a long reactor SRT so that biodegradation reduces the liquid concentration to a minimal value, and the performance is then governed mainly by mass transfer. To study this limiting case and the effects of mass transfer, $\mathrm{C}_{\mathrm{L}}$ in equation (7) is assumed to be very low (near zero). Therefore, the second term in equation (7) is less significant and can be eliminated for calculation purpose. Substituting (7) into (10) yields:

$$
\% R=100 \cdot\left(1-e^{\frac{-K_{l} a \cdot d}{H \cdot\left(Q_{g} / A\right)}}\right)
$$

The reactor depth required for a given $\% \mathrm{R}$ is shown as follows: 


$$
d=\frac{H \cdot\left(\frac{Q_{g}}{A}\right) \cdot \ln \left(1-\frac{\% R}{100}\right)}{-K_{L} a}
$$

Given $\mathrm{H}$ and $\mathrm{K}_{\mathrm{L}}$ a values, equation (12) can be used to determine the reactor liquid depth for a specific removal efficiency where only mass transfer controls. The equation shows that for low $\mathrm{H}$ values or high $\mathrm{K}_{\mathrm{L}}$ a values, a lower liquid depth is needed for a given treatment performance.

\subsubsection{Model Mass Transfer Coefficients}

The compound gas/liquid mass transfer coefficient, $\mathrm{K}_{\mathrm{L}} \mathrm{a}$, and Henry's coefficients are critical elements of the model and reactor performance. The Henry's coefficient value depends on the compound's solubility and partial pressure, which are also temperature dependent. Henry's coefficient can be obtained experimentally or from calculation. Table 4 summarizes the Henry's coefficient values measured experimentally in this work for methanol, terpenes and the reduced sulfur compounds. Of these compounds, methanol has a relatively much lower $\mathrm{H}$ value, which means it is more readily transferred from the gas to liquid phase than the terpenes or sulfur compounds.

Table 4 Summary of Henry's Law Coefficient values measured by experiment (EPICS method)

\begin{tabular}{|c|c|c|c|c|}
\hline \multirow{2}{*}{ Compounds } & \multicolumn{4}{|c|}{ Henry's Coefficient (L water/L air) } \\
\cline { 2 - 5 } & $\mathbf{2 0}^{\mathbf{0}} \mathbf{C}$ & $\mathbf{2 5}^{\mathbf{}} \mathbf{C}$ & $\mathbf{3 5}^{\mathbf{C}} \mathbf{C}$ & $\mathbf{5 0}^{\mathbf{0}} \mathbf{C}$ \\
\hline Methanol & & & & $0.012(0.002)$ \\
\hline$\alpha$-terpinene & $1.3(0.2)$ & & $2.4(0.3)$ & $3.5(1.0)$ \\
\hline$\gamma$-terpinene & $1(0.2)$ & & $1.6(0.1)$ & $3.5(0.9)$ \\
\hline HS & & 0.385 & & 0.5 \\
\hline MT & & 0.18 & & 0.48 \\
\hline DMS & & & 0.115 & 0.15 \\
\hline DMDS & & & & 0.19 \\
\hline
\end{tabular}


Henry's coefficient of a compound can also be calculated from the following equation (LaGrega et al. 1994):

$$
\begin{array}{r}
H=\frac{e^{(A-B / T)}}{8.205 \times 10^{-5} \times T} \\
\mathrm{H}=\text { Henry's coefficient, } \frac{\text { air }, m g / L}{H_{2} O, m g / L}
\end{array}
$$

A, B = Constants

$\mathrm{T}=$ Temperature $\left({ }^{\circ} \mathrm{K}\right)$

Calculated Henry's coefficient values at $50^{\circ} \mathrm{C}$ for the BTX test compounds were calculated and are summarized in Table 5.

Table 5 Calculated Henry's Law Coefficients for selected compounds

\begin{tabular}{|l|c|c|c|}
\hline Compounds & $\mathbf{A}$ & $\mathbf{B}$ & Henry's Law Coefficient at 50 \\
\hline Benzene & 5.53 & 3190 & 0.45 \\
\hline Toluene & 5.13 & 3020 & 0.56 \\
\hline P-xylene & 6.93 & 3520 & 0.71 \\
\hline O-xylene & 5.54 & 3320 & 0.45 \\
\hline
\end{tabular}

$\mathrm{K}_{\mathrm{L}} \mathrm{a}$ value for oxygen and terpinenes were determined for the laboratory SSGR at different gas flow rates and temperature. Figure 9 shows an example of the oxygen concentration data for the aeration test to determine the oxygen $\mathrm{K}_{\mathrm{L}} \mathrm{a}$ value. The oxygen $\mathrm{K}_{\mathrm{L}}$ a values for the SSGR tests are summarized in Table 6. The oxygen $\mathrm{K}_{\mathrm{L}}$ a of $21.1 \mathrm{hr}^{-1}$ at $50^{\circ} \mathrm{C}$ for the $150 \mathrm{~mL} / \mathrm{min}$ air flow rate at the $1.8 \mathrm{~L}$ volume is representative of the SSGR operating conditions. The other data show that $\mathrm{K}_{\mathrm{L}}$ a is not effected by depth $(2.4 \mathrm{~L}$ versus $1.8 \mathrm{~L}$ was a result of increasing depth), and that $\mathrm{K}_{\mathrm{L}}$ a increases with temperature and air flow rate, as expected (U.S. EPA, 1985). 

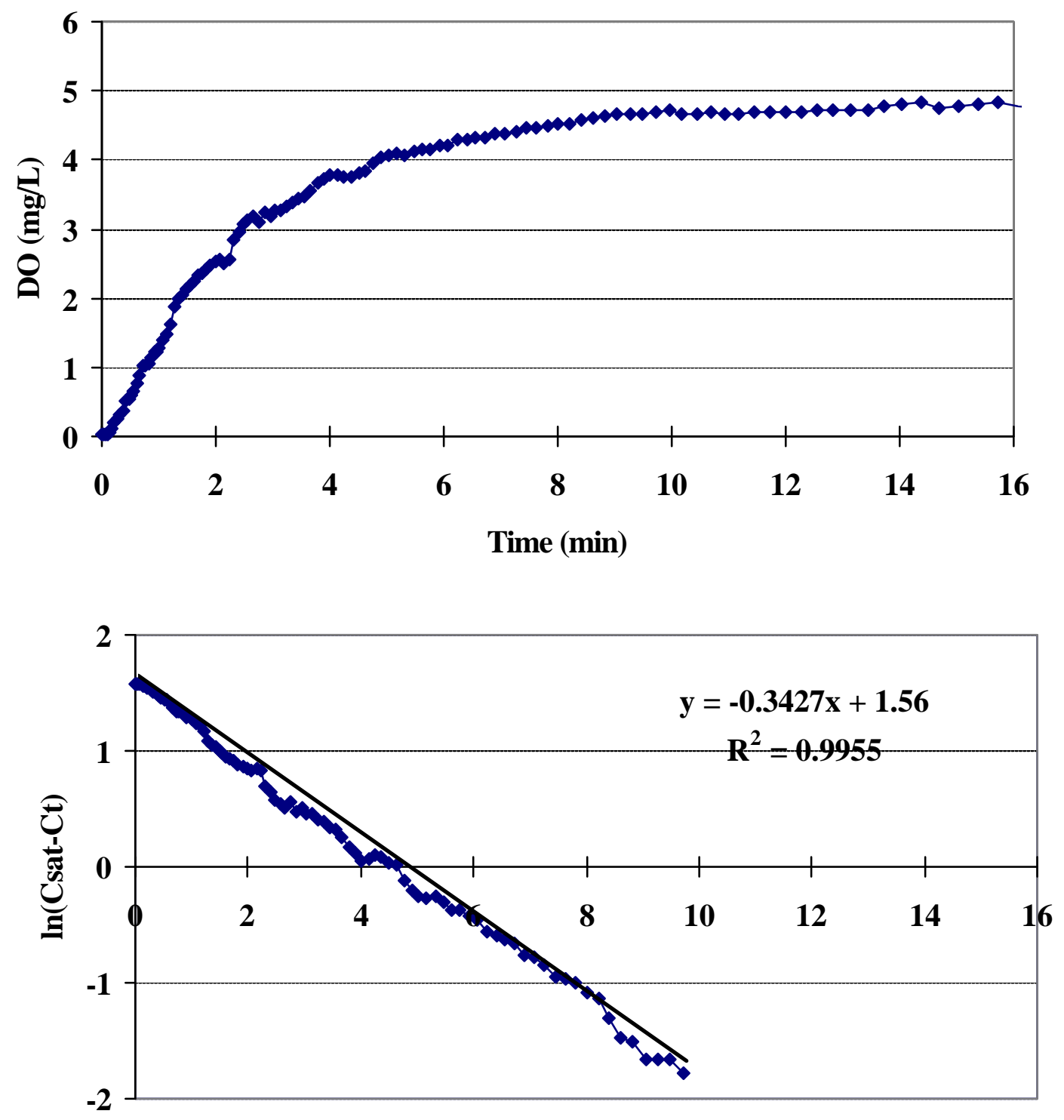

Time (min)

Figure 9 An example of $K_{L}$ a test result for oxygen at $50^{\circ} \mathrm{C}$, liquid volume $2.4 \mathrm{~L}$ and flowrate of $150 \mathrm{~mL} / \mathrm{min}$ 
The $\mathrm{K}_{\mathrm{L}} \mathrm{a}$ values of the terpene compounds was determined by air stripping tests with dissolved terpene concentration measured with time. Figure 10 shows an example of a terpene compound gas/liquid mass transfer test and linear regression fit to obtain $\mathrm{K}_{\mathrm{L}} \mathrm{a}$. As the temperature was increased from $35^{\circ} \mathrm{C}$ to $50^{\circ} \mathrm{C}$, the $\mathrm{K}_{\mathrm{L}}$ a increased by a factor of about 3.5, as shown in Table 6.

Table $6 K_{L} a$ for oxygen, toluene, $\alpha$-terpinene and $\gamma$-terpinene

\begin{tabular}{|l|c|c|c|c|c|}
\hline & Temp & Vl (ml) & $\begin{array}{c}\text { Flow rate } \\
(\mathbf{m l} / \mathbf{m i n})\end{array}$ & $\mathbf{K}_{\mathbf{L}} \mathbf{a}(\mathbf{h r}-\mathbf{1})$ & st dev \\
\hline Oxygen & 50 & 2.4 & 150 & 20.2 & 0.8 \\
\hline & 50 & 1.8 & 150 & 21.1 & 0.6 \\
\hline & 50 & 1.8 & 100 & 9.1 & 0.4 \\
\hline & 50 & 1.8 & 48 & 7.4 & 0.5 \\
\hline & 20 & 2.4 & 89.3 & 10.1 & \\
\hline Alpha-terpinene & 35 & 1.8 & 150 & 5.4 & 0.6 \\
\hline & 50 & 1.8 & 150 & 19.2 & \\
\hline Gamma-terpinene & 35 & 1.8 & 150 & 7.8 & 1.2 \\
\hline & 50 & 1.8 & 150 & 29.4 & \\
\hline
\end{tabular}

Alternatively, when the $\mathrm{K}_{\mathrm{L}}$ a for oxygen is known, the $\mathrm{K}_{\mathrm{L}} \mathrm{a}$ of another compound can be estimated using the ratio of the liquid diffusion coefficient of the compound to that for oxygen (Bielefeldt and Stensel 1998):

$$
K_{L} a_{V O C}=K_{L} a_{O_{2}} \frac{D_{c m p d}}{D_{O_{2}}}
$$

Where:

$\mathrm{D}_{\mathrm{cmpd}}=$ Compound diffusion coefficient, $\mathrm{cm}^{2} / \mathrm{sec}$

$\mathrm{D}_{\mathrm{O} 2}=$ Oxygen diffusion coefficient, $\mathrm{cm}^{2} / \mathrm{sec}$

$\mathrm{K}_{\mathrm{L}} \mathrm{a}_{\mathrm{cmpd}}=$ Compound mass transfer coefficient, $\mathrm{hr}^{-1}$

$\mathrm{K}_{\mathrm{L}} \mathrm{a}_{\mathrm{O} 2}=$ Oxygen mass transfer coefficient, $\mathrm{hr}^{-1}$ 

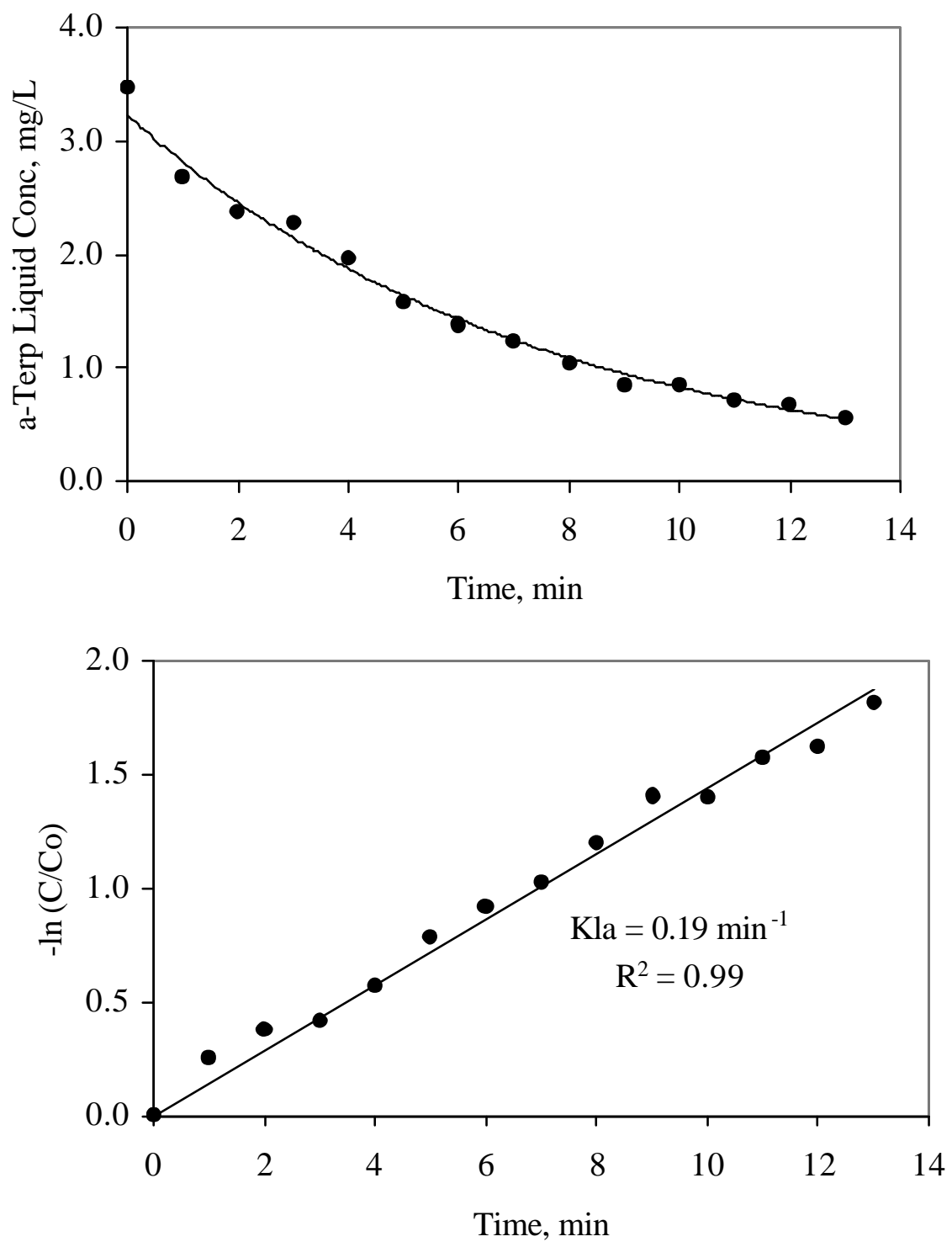

Figure 10 Alpha-terpinene liquid concentration versus time for a $K_{L}$ a test and $K_{L} a$ data fit at $50^{\circ} \mathrm{C}$ and gas flow rate of $150 \mathrm{~mL} / \mathrm{min}$

Estimated $\mathrm{K}_{\mathrm{L}}$ a values are summarized in Table 7 for methanol and BTX compounds based on the SSGR oxygen $\mathrm{K}_{\mathrm{L}}$ a of 21.1/ hr. Of these volatile compounds, methanol has the higher $\mathrm{K}_{\mathrm{L}}$ a value. In view of the intensive analytical effort that would be required to test the $\mathrm{K}_{\mathrm{L}} \mathrm{a}$ of each HAP studied, the use of equation 14 should provide a reasonable estimate of the $\mathrm{K}_{\mathrm{L}}$ a for SSGR treatment application. 
Table 7 Calculated $K_{L}$ a for methanol and other more volatile compounds tested in SSGR at $50^{\circ} \mathrm{C}$. Based on oxygen $\mathrm{K}_{\mathrm{L}}$ a of $21.0 / \mathrm{hr}$

\begin{tabular}{|l|c|c|}
\hline Compounds & $\begin{array}{c}\text { Diffusion coefficient } \\
\left(\mathrm{cm}^{2} / \mathrm{sec}\right) \times 10^{-5}\end{array}$ & $\begin{array}{c}\text { Calculated } \mathrm{K}_{\mathrm{L}} \mathrm{a} \\
\left(\mathrm{hr}^{-1}\right)\end{array}$ \\
\hline Oxygen & 2.50 & 21.0 \\
Methanol & 1.60 & 13.5 \\
Benzene & 1.30 & 10.9 \\
Toluene & 1.24 & 10.9 \\
Para-xylene & 1.15 & 9.7 \\
Ortho-xylene & 1.15 & 9.7 \\
\hline
\end{tabular}

${ }^{\mathrm{a}}$ Chem.engr handbook (Perry, 1973)

The oxygen $\mathrm{K}_{\mathrm{L}}$ a was also measured by an in-situ, non-steady state test performed during the reactor treatment operation. In this test the oxygen concentration was perturbed by sparging with pure oxygen temporarily. The oxygen concentration was me asured with a DO probe with time as it decreased to its steady state value under the normal aeration. A semi- $\log$ plot of DO concentration versus time yields the $\mathrm{K}_{\mathrm{L}}$ a value (Bielefeldt, 1996). The $\mathrm{K}_{\mathrm{L}} \mathrm{a}_{\mathrm{O} 2}$ at the reactor operating condition was $21 / \mathrm{hr}$, which is similar to the aeration test $\mathrm{K}_{\mathrm{L}}$ a values at that operating condition.

The effect of temperature on the $\mathrm{K}_{\mathrm{L}}$ a of oxygen at $20^{\circ} \mathrm{C}$ and $50^{\circ} \mathrm{C}$ in the SSGR is compared to the $\mathrm{K}_{\mathrm{L}}$ a temperature relationship provided in the ASCE clean water standard (1984): (ASCE 1984)

$$
K_{L} a_{T}=K_{L} a_{20} \cdot 1.024^{T-20}
$$

Where:

$$
\begin{aligned}
& \mathrm{K}_{\mathrm{L}} \mathrm{a}_{\mathrm{T}}=\mathrm{K}_{\mathrm{L}} \mathrm{a} \text { at temperature } \mathrm{T}, \mathrm{hr}^{-1} \\
& \mathrm{~K}_{\mathrm{L}} \mathrm{a}_{20}=\mathrm{K}_{\mathrm{L}} \text { a at } 20^{\circ} \mathrm{C}, \mathrm{hr}^{-1} \\
& \mathrm{~T}=\text { temperature, }{ }^{\circ} \mathrm{C}
\end{aligned}
$$

Based on equation 15 , the oxygen $\mathrm{K}_{\mathrm{L}}$ a at $50^{\circ} \mathrm{C}$ should be 2.04 times the oxygen $\mathrm{K}_{\mathrm{L}}$ a at $20^{\circ} \mathrm{C}$. This compares well to the ratio of the $\mathrm{K}_{\mathrm{L}}$ a in table 6 of 20.2/10.1 or 2.0. 


\subsubsection{Biokinetic Coefficients}

Since methanol is a surrogate parameter for the cluster rules, it was selected as the compound to be used in the SSGR model.

The Michealis-Menten biokinetics coefficients for methanol were obtained from a series of experiments using the indirect test procedure described in the methods section. Kinetic tests were done using biomass taken directly from the SSGR system during testing for treatment of organic compounds.

Figure 11 shows an example of the oxygen consumption versus time during a methanol indirect kinetic test at $50^{\circ} \mathrm{C}$. The oxygen concentration was elevated due to pre-aeration with pure oxygen. The initial oxygen consumption prior to substrate (methanol) addition was due to endogenous respiration of the bacteria. Following the substrate addition, the oxygen consumption rate increased due to substrate degradation. The degradation rate was constant for about 120 minutes, when the rate began to decline due to the effect of substrate concentration on the substrate removal rate. When the substrate was completely consumed, the oxygen consumption rate returned to near the initial endogenous oxygen consumption rate.

The oxygen consumption due to substrate degradation is calculated by removing the rate due to the endogenous respiration rate, which is shown in Figure 12. The oxygen consumption rate is then converted to a substrate consumption rate using the following equation (Ellis et al. 1994):

$$
S_{t}=S_{o}-\left[\frac{D O_{\text {int }}-D O_{t}}{D O_{\text {int }}-D O_{\text {fin }}}\right] S_{o}
$$

Where:

$$
\begin{aligned}
& \mathrm{S}_{\mathrm{t}}=\text { substrate concentration at time } \mathrm{t}, \mathrm{mg} / \mathrm{L} \\
& \mathrm{S}_{\mathrm{o}}=\text { initial substrate concentration, } \mathrm{mg} / \mathrm{L}
\end{aligned}
$$


$\mathrm{DO}_{\mathrm{t}}=\mathrm{DO}$ at time $\mathrm{t}$ corrected for endogenous respiration, $\mathrm{mg} / \mathrm{L}$

$\mathrm{DO}_{\text {int }}=$ initial corrected $\mathrm{DO}$ concentration, $\mathrm{mg} / \mathrm{L}$

$\mathrm{DO}_{\text {fin }}=$ final corrected $\mathrm{DO}$ concentration, $\mathrm{mg} / \mathrm{L}$

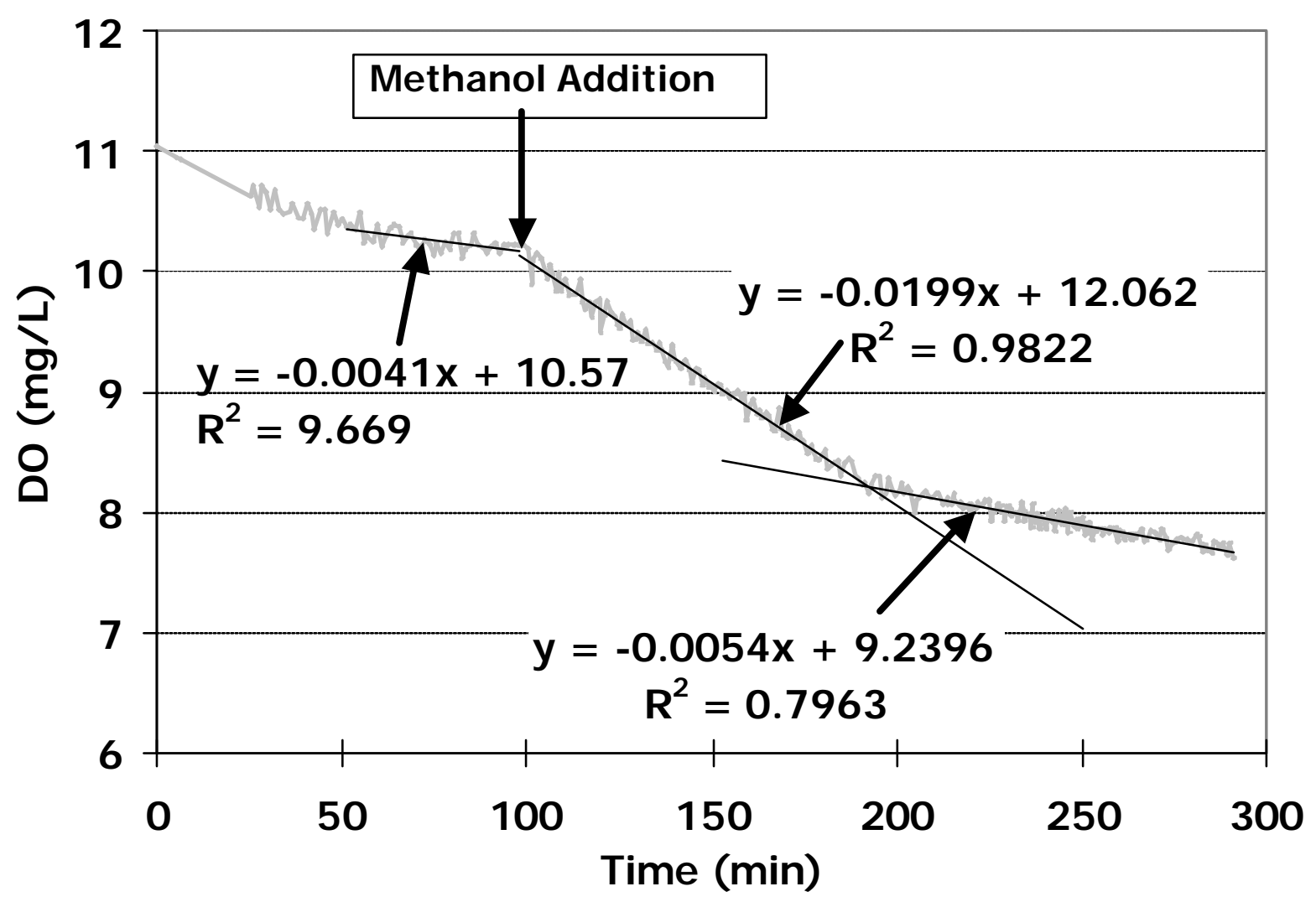

Figure 11 Example plot of DO consumption versus time for indirect test to determine methanol biokinetics $\left(5^{\circ} \mathrm{C}\right)$

Figure 13 shows the calculated substrate concentration versus time using equation 16, the initial substrate concentration added, and data in Figure 12. The results show a fairly constant methanol consumption rate until methanol level falls below $0.2 \mathrm{mg} / \mathrm{L}$, after which time, the methanol concentration affected the methanol degradation rate. 


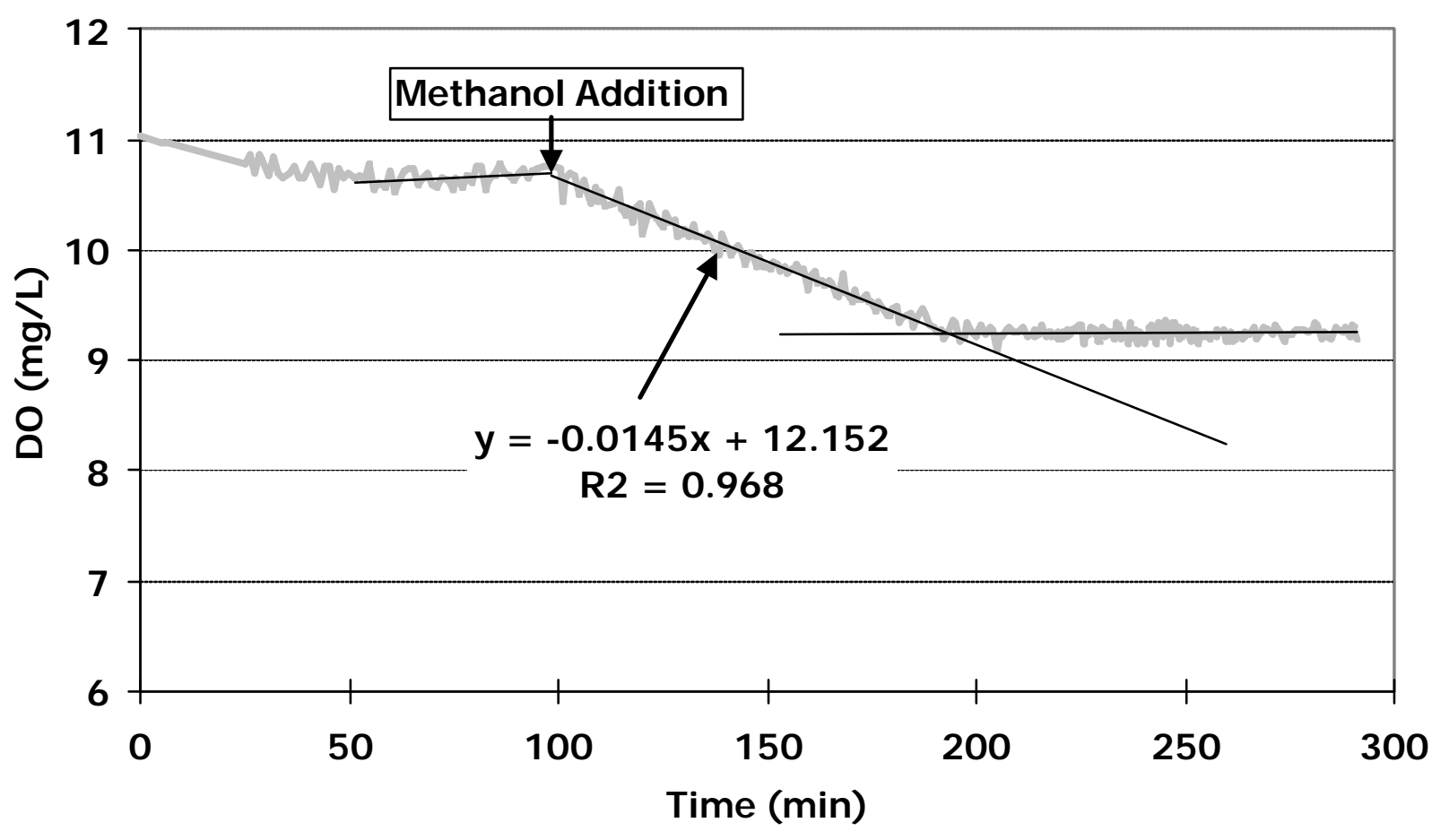

Figure 12 DO consumption curve from Figure 11 after removing endogenous DO consumption rate

The maximum specific substrate utilization rate $(\mathrm{k})$ is determined by the slope of the linear portion of the curve in Figure 13 divided by the biomass concentration (VSS) estimated to be methanol degraders. The biomass in the test contained bacteria that were grown on compounds other than methanol, since the SSGR reactor was fed other compounds as well. The portion of VSS estimated to be methanol degrader is estimated from the ratio of methanol COD to the total COD fed to the reactor per day, which is $27 \%$.

The $\mathrm{K}_{\mathrm{S}}$ value is defined as the substrate concentration where the degradation rate (or slope) is half of $\mathrm{k}$. To determine the experimental $\mathrm{K}_{\mathrm{S}}$ value, the slope of methanol concentration versus time was calculated over small time intervals in a Microsoft ${ }^{\circledR}$ Excel spreadsheet. The $\mathrm{K}_{\mathrm{S}}$ was assigned the value of the substrate concentration where the slope was half the maximum slope value. 


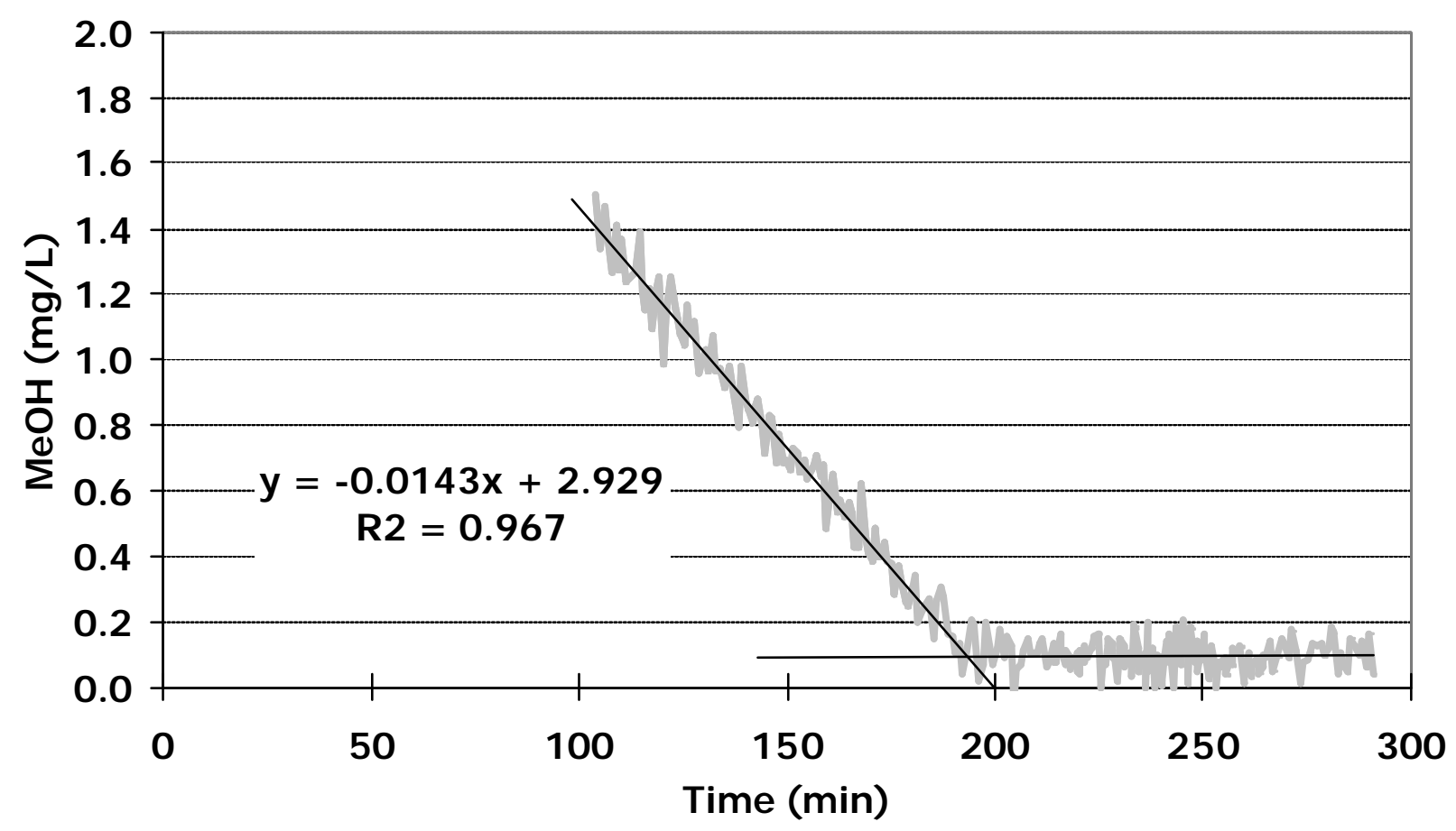

Figure 13 Methanol consumption rate based on DO consumption rate in Figure 12

The endogenous decay value, $b$, was estimated by dividing the slope of the final linear oxygen consumption rate in Figure 5 , by $1.42 \mathrm{~g} \mathrm{O}_{2} / \mathrm{gVSS}$, and dividing by VSS to get $\mathrm{b}$ as gVSS lost/g VSS present-day.

The results from four indirect kinetic tests for methanol done in the same week during the phase III steady state period are summarized in Table 8 along with the estimated methanoldegrading biomass concentration. The maximum specific methanol utilization rate $(\mathrm{k})$ was higher when higher initial methanol concentration were used. This type of response is an indication of a possible substrate induction effect where higher initial substrate concentrations induce greater enzyme activity. The $\mathrm{K}_{\mathrm{S}}$ values range from 0.1 to $0.3 \mathrm{mg} / \mathrm{L}$ and are comparable to the magnitude of $\mathrm{K}_{\mathrm{S}}$ values observed for single substrates in the degradation of BTX compound by Bielefeldt (1996). 
Table 8 Biodegradation kinetic parameters of methanol obtaining from indirect method test at $50^{\circ} \mathrm{C}$

\begin{tabular}{|c|c|c|c|c|c|}
\hline $\begin{array}{c}\text { Initial MeOH } \\
\text { conc. } \\
(\mathrm{mg} / \mathrm{L})\end{array}$ & $\begin{array}{c}\mathrm{VSS}^{*} \\
(\mathrm{mg} / \mathrm{L})\end{array}$ & $\begin{array}{c}\text { Observed } \\
\text { maximum methanol } \\
\text { utilization rate } \\
(\mathrm{mg} / \mathrm{L}-\mathrm{d})\end{array}$ & $\begin{array}{c}\mathrm{k} \\
(\mathrm{mgMeOH} / \mathrm{mgVSS}-\mathrm{d})\end{array}$ & $\begin{array}{c}\mathrm{K}_{\mathrm{S}} \\
(\mathrm{mg} / \mathrm{L})\end{array}$ & $\begin{array}{c}\mathrm{b} \\
(\mathrm{g} / \mathrm{g}-\mathrm{d})\end{array}$ \\
\hline 3.08 & 13.9 & 0.0226 & 2.33 & 0.30 & 0.18 \\
3.08 & 13.1 & 0.0167 & 1.81 & 0.10 & 0.16 \\
1.54 & 13.3 & 0.0145 & 1.54 & 0.15 & 0.16 \\
1.54 & 13.4 & 0.0113 & 1.22 & 0.17 & 0.13 \\
\hline
\end{tabular}

"estimated methanol-degrading biomass

\subsubsection{Application of model to describe SSGR performance with laboratory results}

The model described previously was used to evaluate methanol removal in the SSGR.

Table 9 summarizes the conditions used to calibrate the model to the laboratory results.

The operating conditions that resulted in an average effluent methanol concentration of $10 \mathrm{ppm}$ during phase III are shown; the gas application rate was $1.8 \mathrm{~m}^{3} / \mathrm{m}^{2}-\mathrm{hr}$, the influent methanol concentration was 1050 ppm, the SRT was 10 days, and the reactor liquid depth was $0.36 \mathrm{~m}$. The mass transfer and biokinetic parameters were based on the results of the independent tests already described. The average $\mathrm{K}_{\mathrm{S}}$ value and the higher $\mathrm{k}$ value from the kinetic tests was used, since those values would better represent the maximum rate possible at substrate saturation.

The only parameter not available for application in the kinetic model equations is the synthesis yield coefficient (Y), g VSS/g methanol used. Thus, the model was calibrated to determine a value for $\mathrm{Y}$, where the model predicted an effluent gas methanol concentration of $10 \mathrm{ppm}$. For this fit, a Y value of $0.12 \mathrm{~g} \mathrm{VSS} / \mathrm{g}$ methanol was obtained. This is a reasonable yield value for aerobic degradation of methanol at thermophilic temperatures. 
Table 9 Operating conditions and model parameters used to calibrate gas treatment model for methanol removal in the SSGR

\begin{tabular}{|c|c|}
\hline Model Parameters for Methanol & Value \\
\hline Qg/A & $1.8 \mathrm{~m}^{3} / \mathrm{m}^{2}-\mathrm{hr}$ \\
Cgo & $1050 \mathrm{ppm}(1.37 \mathrm{mg} / \mathrm{L})$ \\
SRT & $10 \mathrm{day}$ \\
Depth & $0.36 \mathrm{~m}$ \\
Temperature & $50^{\circ} \mathrm{C}$ \\
\hline Cge & $10 \mathrm{ppm}$ \\
\hline $\mathrm{H}$ & 0.011 \\
$\mathrm{~K}_{\mathrm{L}} \mathrm{a}$ & $13.5 \mathrm{hr}^{-1}$ \\
$\mathrm{k}$ & $2.33 / \mathrm{d}$ \\
$\mathrm{K}_{\mathrm{S}}$ & $0.14 \mathrm{mg} / \mathrm{L}$ \\
$\mathrm{b}$ & $0.15 \mathrm{~d}^{-1}$ \\
\hline
\end{tabular}

The effect of reactor liquid depth and operating SRT was evaluated with the calibrated model (Figure 14), using the same gas application rate and influent methanol concentration as shown in Table 9. The depth was varied from 0.05 to $0.4 \mathrm{~m}$ and the SRT was varied from $8-30$ days. The figure shows that the performance under these conditions is not mass transfer limited, but biodegradation limited. If it were mass transfer limited, increasing depth would improve the treatment performance. At longer SRTs the effluent gas concentration is lower, since at longer SRTs, a higher biomass concentration is present in the reactor. Thus, a lower liquid methanol concentration is possible, which results in a lower effluent gas concentration (see equations 7 and 8).

Long SRTs are feasible in the SSGR system, since there are no solids separation limitations. An upper limit on SRT would result when the biomass concentration is sufficiently high to cause reactor oxygen utilization rate, that is high enough to prevent a dissolved oxygen concentration sufficient to support efficient biodegradation and low substrate liquid concentration. 


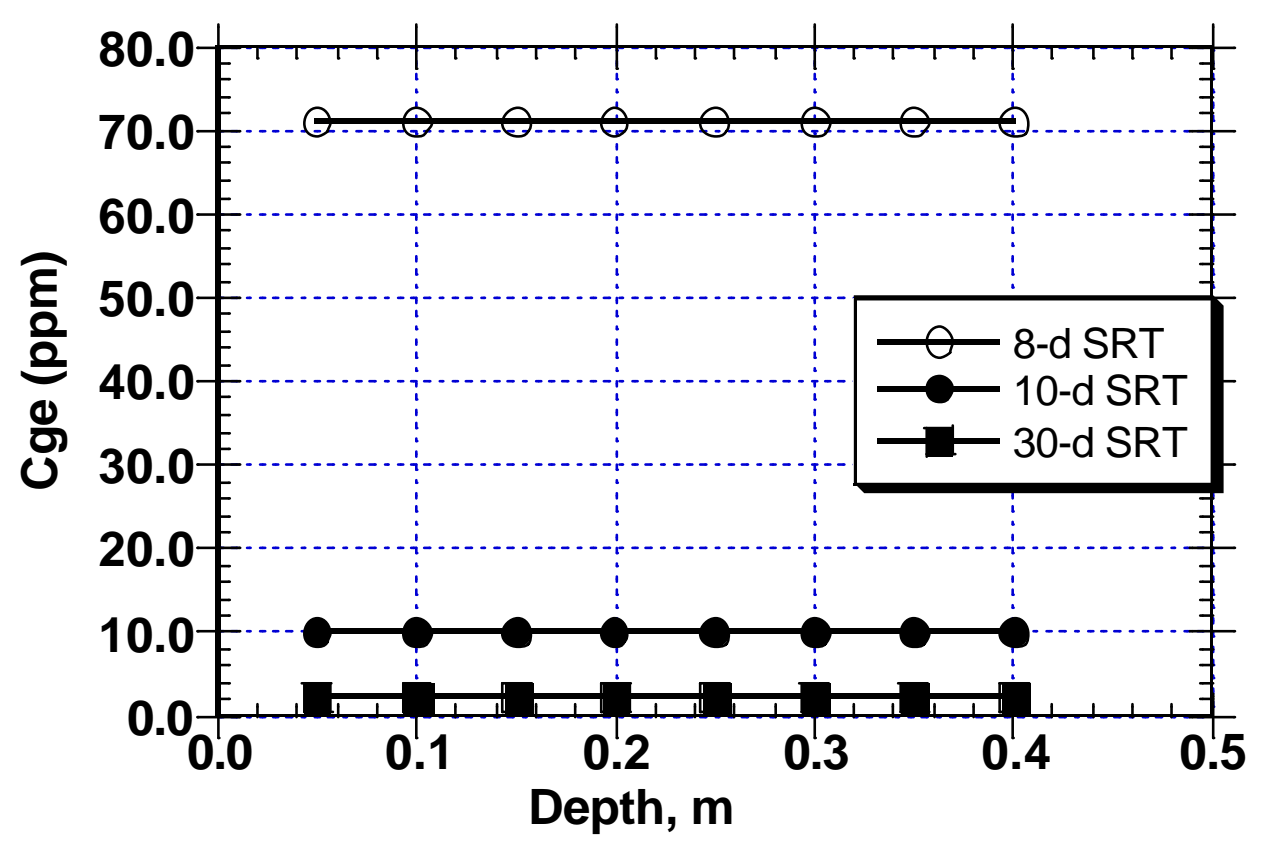

\section{Figure 14 Laboratory SSGR model evaluation; effect of depth and SRT on Effluent gas methanol concentration at $50^{\circ} \mathrm{C}$}

The model example shows only an evaluation of depth and SRT for the laboratory SSGR operation. For the pilot plant operation, a much higher gas application rate was used versus the laboratory system, which would affect the mass transfer characteristics of the SSGR and treatment performance. However, at the higher gas application rate, a higher $\mathrm{K}_{\mathrm{L}} \mathrm{a}$ would occurs. This aspect of the model application and evaluation of the SSGR system for methanol removal in full scale designs will be presented after the pilot plant results.

The model was used to evaluate methanol removal at higher gas application rates, ranging from a practical design range of $0.5 \mathrm{~m}^{3} / \mathrm{m}^{2}-\mathrm{hr}$ to $2.5 \mathrm{~m}^{3} / \mathrm{m}^{2}-\mathrm{hr}$, based on possible diffuser densities. In Figure 15, the model prediction of effluent gas methanol concentration is shown as a function of gas application rate for a reactor liquid as shallow as the lab reactor $(0.4 \mathrm{~m})$ and assuming the same $\mathrm{K}_{\mathrm{L}}$ a of the lab reactor $(13.5 / \mathrm{hr})$. The $\mathrm{K}_{\mathrm{L}} \mathrm{a}$ would increase at higher gas flow rates, so the results in Figure 15 are only illustrative of the possible treatment level for methanol with an unrealistically low $\mathrm{K}_{\mathrm{L}} \mathrm{a}$ value. The results show that even in this case, with such a shallow liquid depth, the 
effluent methanol gas concentration of $20 \mathrm{ppm}$ can be met with a 30-d SRT operation at gas application rates of $2.0 \mathrm{~m}^{3} / \mathrm{m}^{2}$-hr or less.

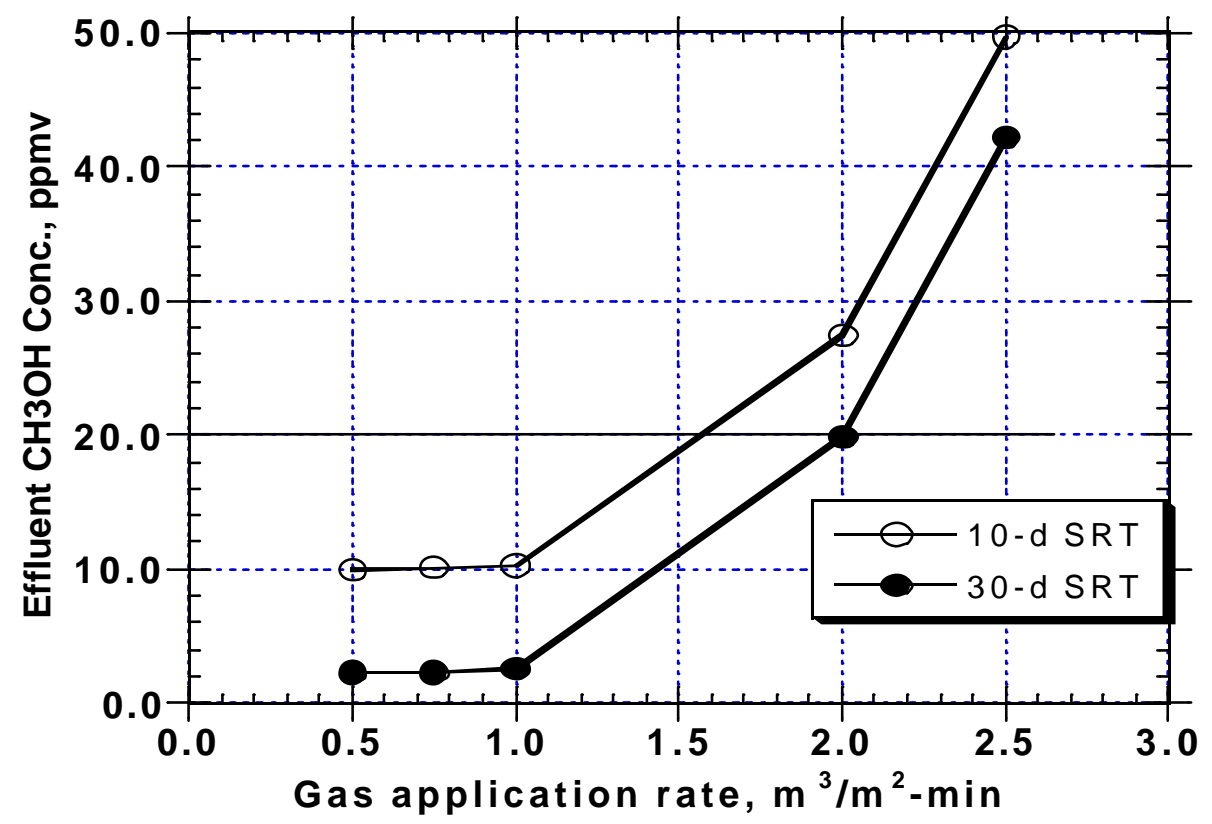

Figure 15 Model simulation on the effect of gas application rate on effluent gas methanol concentration (ppm) for 10-day and 20-day SRT operation at $50^{0} \mathrm{C}$. $\mathrm{K}_{\mathrm{L}}$ a of only 13.5/hr assumed. Reactor liquid depth equal 0.40 meter.

Figure 16 shows results of a similar simulation using a $\mathrm{K}_{\mathrm{L}}$ a value of $50 / \mathrm{hr}$, which is a more of realistic mass transfer condition for a full-scale facility. (The pilot plant results (section 4.4) show that a $\mathrm{K}_{\mathrm{L}}$ a of $50 / \mathrm{hr}$ is possible.) At this $\mathrm{K}_{\mathrm{L}}$ a, Figure 16 shows that methanol removal, even at the high end of practical gas application rates, is not mass transfer limited. The effluent gas concentration is equal to that calculated for the lab reactor at a lower gas application rate but at about the same liquid depth. These results and simulation illustrated that methanol can be easily removed to low effluent gas concentrations using very shallow reactor depth for the SSGR. 


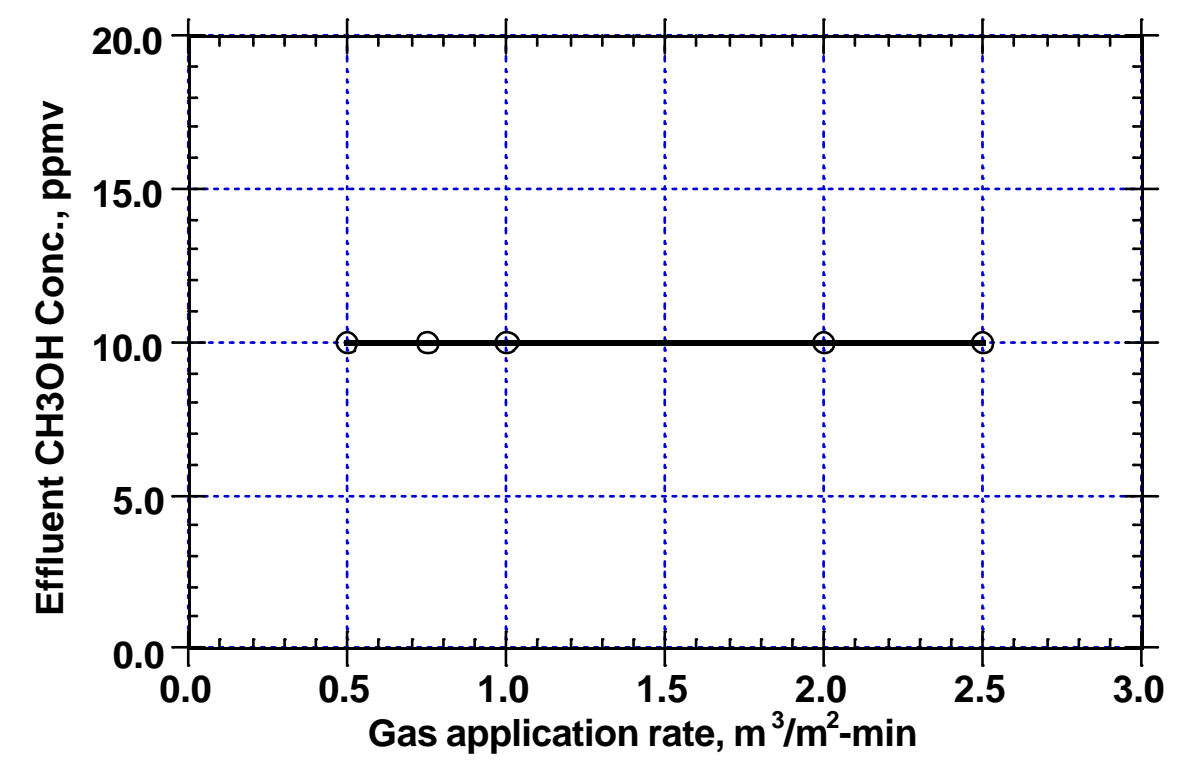

Figure 16 Model simulation of the effect of gas application rate on effluent gas methanol concentration for 10-day SRT and $\mathrm{K}_{\mathrm{L}}$ a of $50 / \mathrm{hr}$ at $50^{\circ} \mathrm{C}$ operation. Reactor liquid depth equal 0.40 meter.

\subsubsection{Model Evaluation of BTX removal in SSGR}

Since the BTX compounds are much more volatile than methanol, their removal potential in the SSGR is of interest. BTX removal was modeled by considering mass transfer limitation only, since they are very biodegradable. Equation (11), (12) and (13) were used for modeling the effect of depth versus \% removal and the results are shown in Figure 17. The removal efficiency increases with the increase of depth and $98 \%$ removal is possible for all the compounds except p-xylene at a liquid depth of only $0.4 \mathrm{~m}$. The model showed that in order to achieve $98 \%$ removal of $\mathrm{p}$-xylene, the reactor depth must be more than $0.6 \mathrm{~m}$, still a relatively shallow liquid depth. 


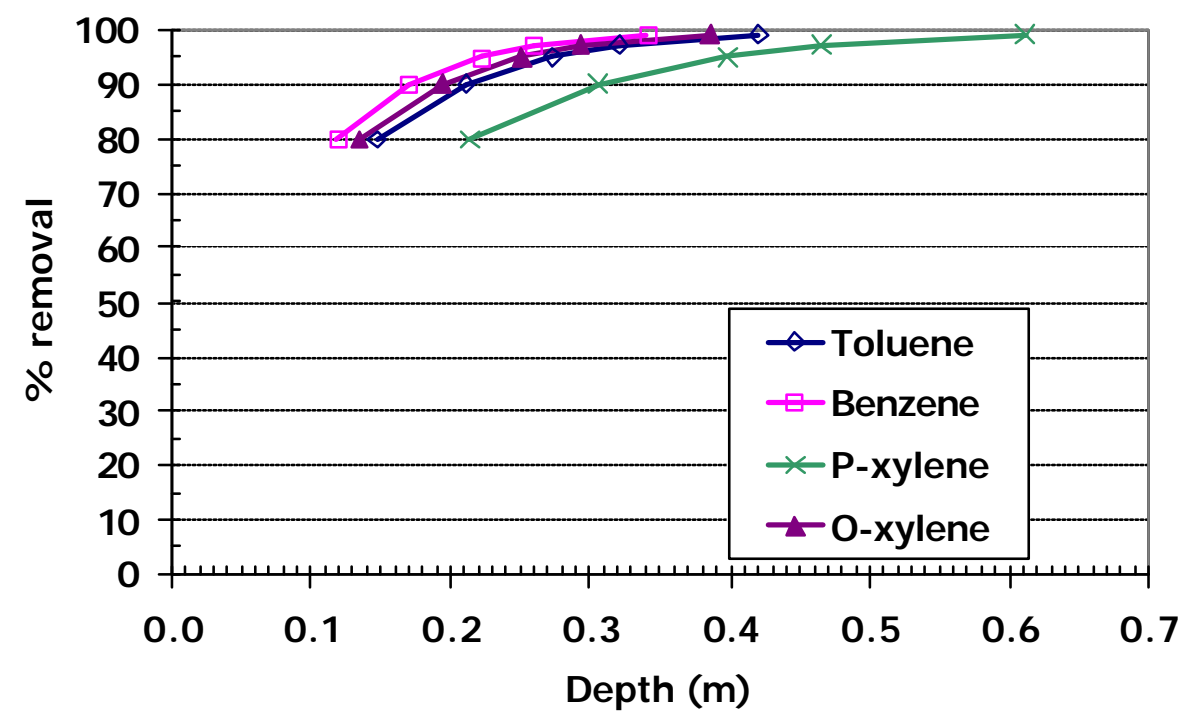

Figure 17 Model simulation of the effect of depth on percent removal of benzene, toluene, and $p$ - and o-xylenes, based on mass transfer limitation only

\section{$\underline{4.3}$ TRS Compounds}

\subsubsection{Acclimation Test}

The first step in studying the treatment of TRS compounds in the SSGR was to develop a microbial population capable of degrading all the TRS compounds. Batch acclimation tests were performed as described in the method section with inocula from a municipal aerobic thermophilic sludge digester, activated sludge from the Simpson Mill, Simpson Mill pulp waster water, high temperature lake sediment, and cultures from a hot spring located on the Olympic peninsula, WA.

Each batch reactor was fed a single compound and incubation continued for up to 120 days.

A summary of the acclimation test results is shown in Table 10. HS and MT degrading populations were easily developed in every seed source. The degradation was fast and no lag time was observed for both compounds. DMDS degradation populations were slower to develop in $50^{\circ} \mathrm{C}$ reactors. A lag time of $4-10$ days was observed for all $50^{\circ} \mathrm{C}$ 
incubations except for the high temperature lake sediment and Olympic hot spring culture, which degradation started without a lag time. In the $35^{\circ} \mathrm{C}$ incubation, no lag time was observed for DMDS degradation, except for the reactor seeded with high temperature lake sediment, which had a lag time of 8 days. In the beginning, DMDS degradation rate was slower than HS and MT. Figure 21 shows DMDS degradation at $50^{\circ} \mathrm{C}$ after 160 days of incubation. It took 4-5 days to completely degrade approximately $450 \mathrm{ppm}$ of DMDS, where as a HS degrading culture degraded $3700 \mathrm{ppm}$ of $\mathrm{HS}$ overnight, as shown in Figure 18.

Table 10 Summary of batch acclimation tests for degradation of reduced sulfur compounds

\begin{tabular}{|c|c|c|c|c|c|c|c|c|}
\hline \multirow[t]{2}{*}{ Seed Source } & \multicolumn{2}{|c|}{ HS } & \multicolumn{2}{|c|}{ MT } & \multicolumn{2}{|c|}{$\overline{\mathrm{DMS}}$} & \multicolumn{2}{|c|}{ DMDS } \\
\hline & $50^{\circ} \mathrm{C}$ & $35^{\circ} \mathrm{C}$ & $50^{\circ} \mathrm{C}$ & $35^{\circ} \mathrm{C}$ & $\overline{50^{\circ} \mathrm{C}}$ & $\overline{35^{\circ} \mathrm{C}}$ & $50^{\circ} \mathrm{C}$ & $\sqrt{35^{\circ} \mathrm{C}}$ \\
\hline $\begin{array}{l}\text { Municipal Aerobic Thermophilic sludge } \\
\text { digester }\end{array}$ & + & + & + & + & - & - & + & + \\
\hline Activated sludge from Simpson Mill & + & + & + & + & - & + & + & + \\
\hline Simpson Mill pulp washer water & + & + & + & + & - & - & + & + \\
\hline High temperature lake sediment & + & + & + & + & - & - & + & + \\
\hline Olympic Hot Spring $\left(40-50^{\circ} \mathrm{C}\right)$ cultures & + & N/A & + & N/A & - & N/A & + & N/A \\
\hline Maximum concentration degraded (ppm) & 6500 & 900 & 400 & 1100 & - & 800 & 475 & 100 \\
\hline
\end{tabular}

+ degraded, - not degraded, N/A no test was performed

DMS was difficult to degrade. No DMS degradation occurred in any of the $50^{\circ} \mathrm{C}$ incubations. The only reactor that showed DMS degradation was a $35^{\circ} \mathrm{C}$ reactor seeded with activated sludge from Simpson Mill. After 120 days, the culture degraded a maximum DMS concentration of 800 ppm overnight. An attempt was made to slowly increase the temperature of this culture. However, the degradation activity decreased when the temperature exceeded $45^{\circ} \mathrm{C}$. After repeated feedings at $45^{\circ} \mathrm{C}$, the activity stopped altogether. 


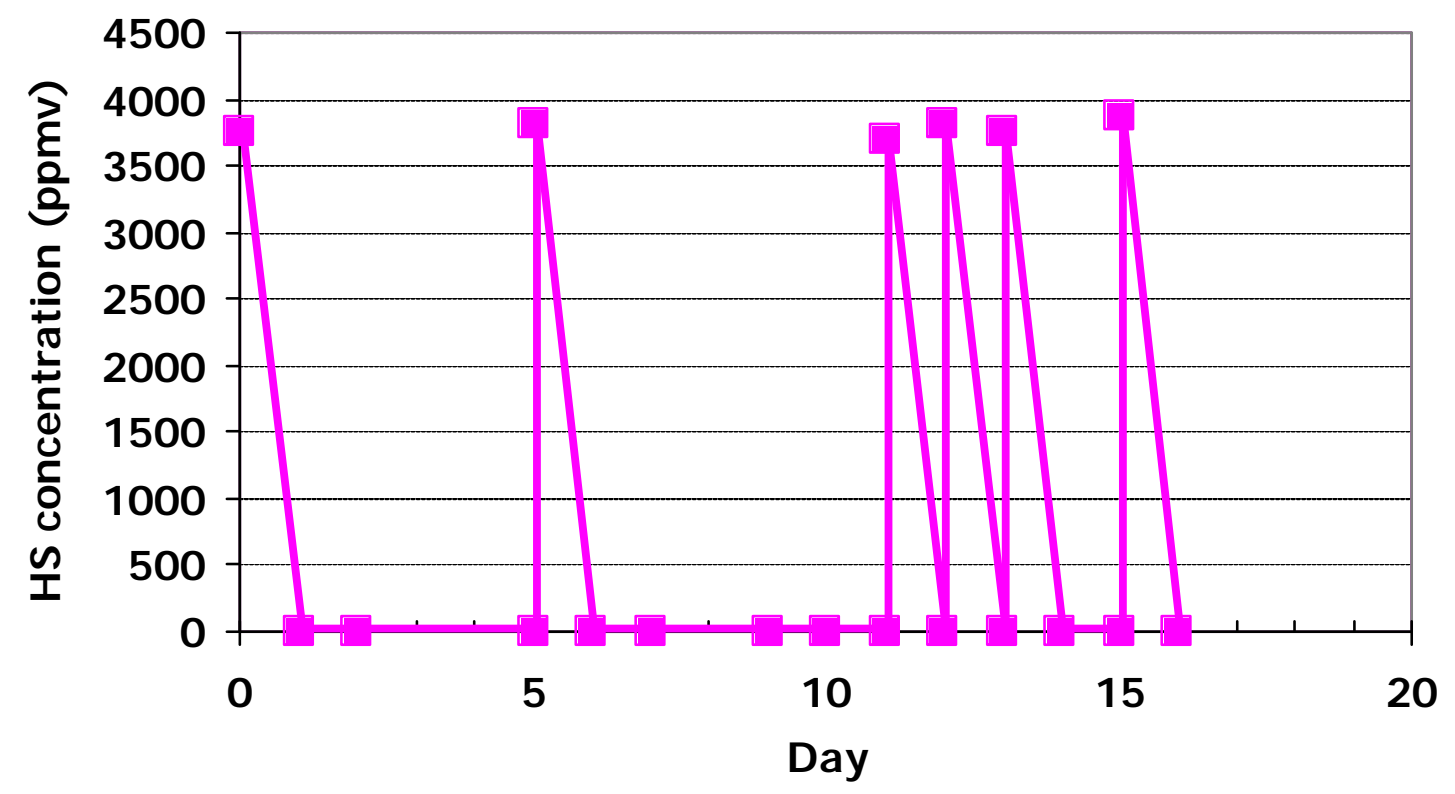

Figure 18 HS degradation in a batch-fed reactor at $50^{\circ} \mathrm{C}$ after 160 days of incubation and repeated feeding of HS

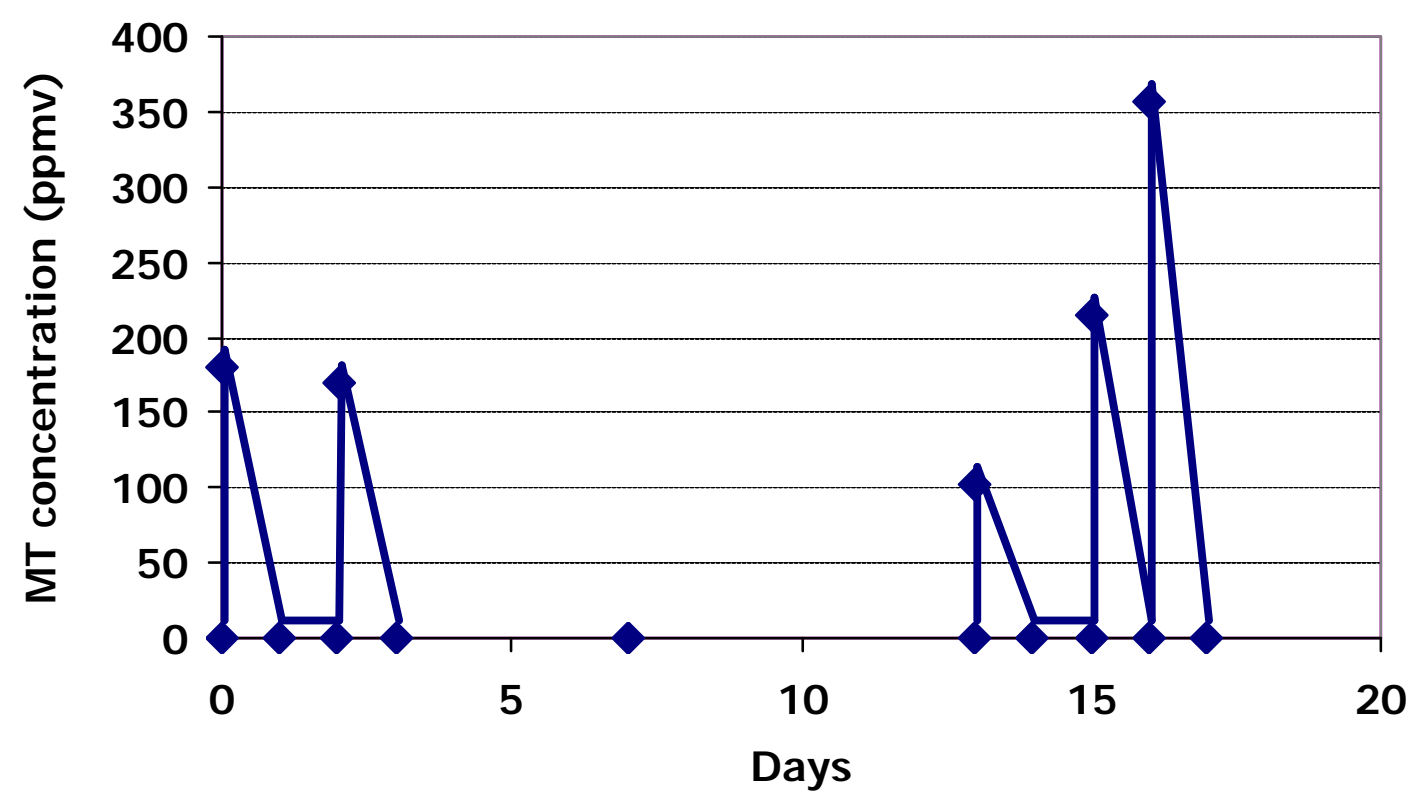

Figure 19 MT degradation in a batch-fed reactor at $50^{\circ}$ after 160 days of incubation and repeated feeding of MT 


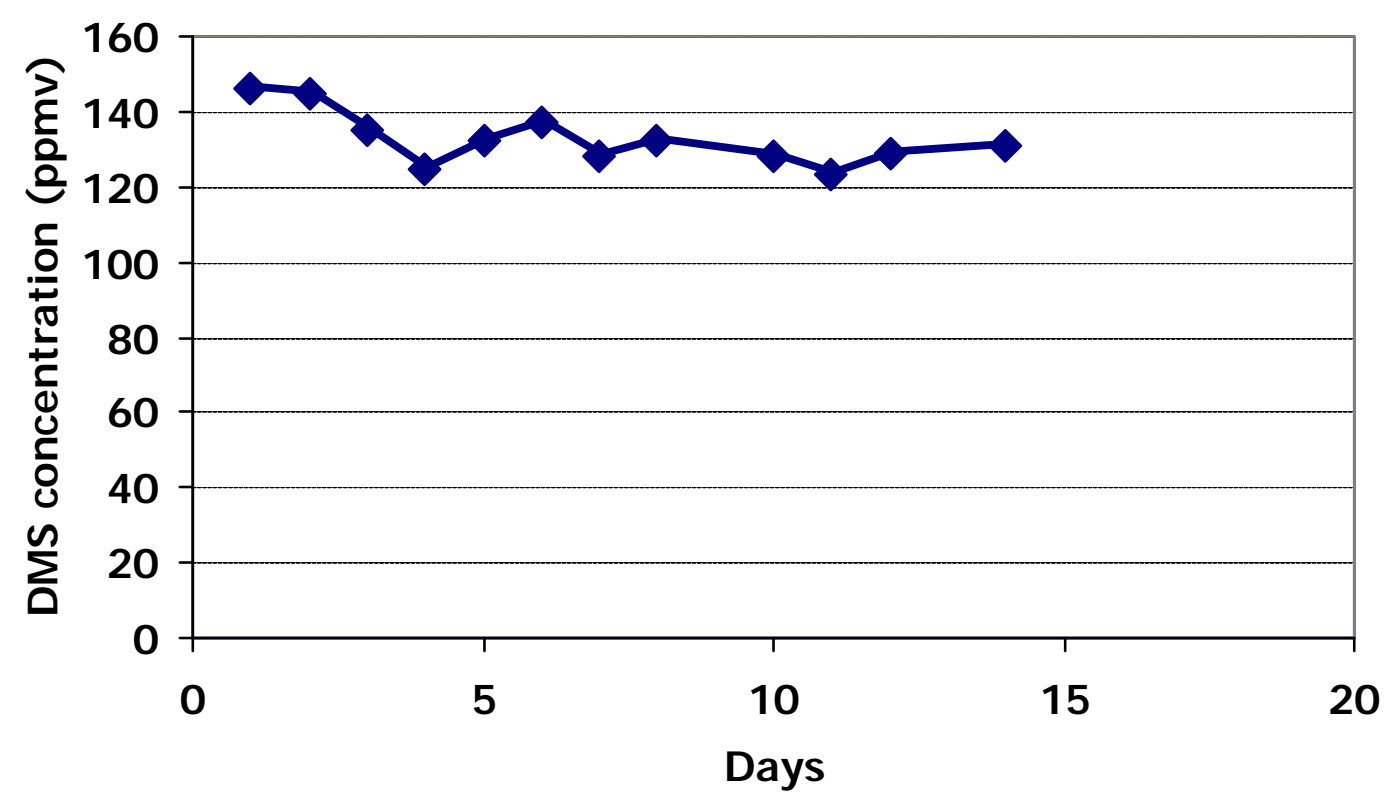

Figure 20 Lack of DMS degradation in a batch reactor at $50^{\circ} \mathrm{C}$ after 75 days of incubation

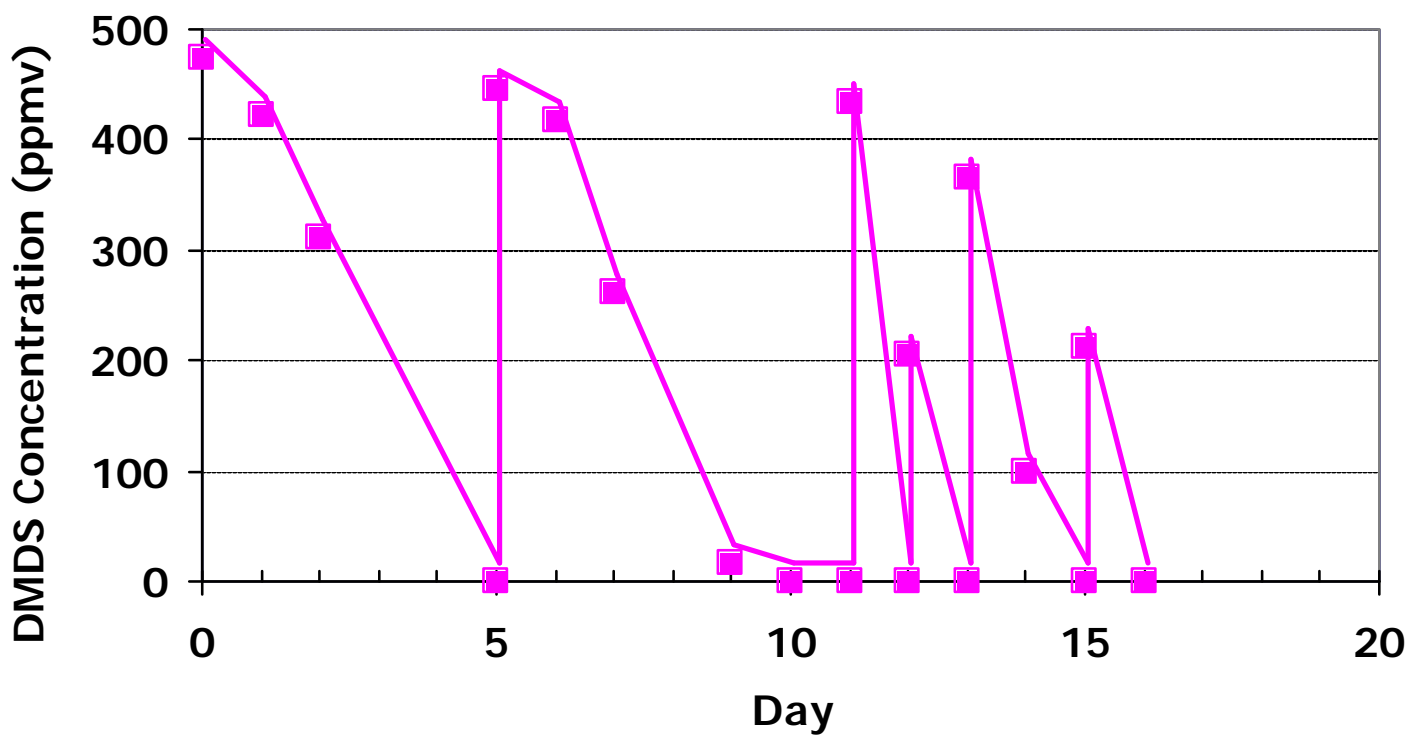

Figure 21 DMDS degradation in a batch-fed reactor at $50^{\circ} \mathrm{C}$ after 160 days of incubation and repeated feeding of DMDS 
Once the populations were acclimated to HS, MT, DMDS and in the case of the $35^{\circ} \mathrm{C}$ reactor, DMS, the initial TRS concentrations were increased. The highest concentrations fed and completely degraded for HS, MT and DMDS in the $50^{\circ} \mathrm{C}$ reactors were 6500,400 and $475 \mathrm{ppm}$, respectively. The highest concentrations fed in the $35^{\circ} \mathrm{C}$ reactors for $\mathrm{HS}$, MT, DMS and DMDS were 900, 1100, 800 and 100 ppm, respectively.

Since HS can also ionize to $\mathrm{H}^{+}$and $\mathrm{S}^{-}$abiotically, the abiotic transformation of HS was tested. Biomass and nutrient from the HS batch reactor was added to two $125-\mathrm{mL}$ serum bottles. In one bottle, formaldehyde was added to kill the biomass. The same amount of HS was added to both bottles. The rate of HS disappearance in the bottle with active biomass was about 5 times higher than that with the killed control, indicating that HS transformation in the batch reactor was mainly biological (data not shown).

Occasionally, DMDS was observed in the reactor fed MT, indicating that MT can be transformed to DMDS. To investigate if this reaction was biotic or not, a study was set up to compare the reaction in the presence of active and inactive biomass. MT was added to two $125-\mathrm{mL}$ serum bottles containing biomass and nutrient solution. Formaldehyde was added to one bottle as a killed control. Without the active biomass, DMDS accumulated in the system. In the active bottle, the MT disappeared while DMDS appeared and then decreased. The test confirmed that MT can be transformed to DMDS abiotically. However, it was unclear whether the microbes consume MT directly or wait for MT to transform to DMDS first or both.

\subsubsection{SSGR treatment performance with TRS compounds}

The SSGR for treating TRS compounds was seeded with return activated sludge from the Simpson wastewater treatment facility. Methanol and formaldehyde were fed along with TRS compounds in order to simulate composition of a pulp mill HVLC gas stream. The gas feed rate was $2.4 \mathrm{~m}^{3} / \mathrm{m}^{2}$-hr and the system was started with a 30-day SRT at $50^{\circ} \mathrm{C}$. The SRT and temperature were varied during 4 periods of operation as shown in Table 11. The temperature was decreased from $50^{\circ} \mathrm{C}$ in periods I and II, to $30^{\circ} \mathrm{C}$ in period III, 
and to $20^{\circ} \mathrm{C}$ in period IV, in an attempt to increase DMS removal efficiency. The feed composition was similar in all 4 periods.

Table 11 SSGR operating conditions and feed concentrations of TRS compounds, formaldehyde and methanol

\begin{tabular}{|l|c|c|c|c|}
\hline Period & I & II & III & IV \\
\hline \# days & 170 & 50 & 50 & 13 \\
SRT, days & 30 & 10 & 30 & 30 \\
Temp, C & 50 & 50 & 30 & 20 \\
VSS, mg/L & $343+/-7$ & $134+/-6$ & $482+/-10$ & $487+/-17$ \\
TSS, mg/L & $445+/-14$ & $198+/-12$ & $721+/-15$ & $731+/-21$ \\
COD, mg/L & $102+/-10$ & $42+/-4$ & $82+/-11$ & $65+/-10$ \\
pH & 7 & 7 & 7 & 7 \\
Gas application rate, & 2.4 & 2.4 & 2.4 & 2.4 \\
m $^{3} / \mathbf{m}^{2}$-min & & & & \\
& & & & \\
\hline Compounds fed & & $67+/-3$ & $79+/-8$ & $79+/-5$ \\
\hline HS & $60+/-20$ & $67+/-6$ & $77+/-6$ & $81+/-5$ \\
MT & $58+/-20$ & $51+/-8$ & $62+/-12$ & $53+/-3$ \\
DMS & $41+/-14$ & $38+/-18$ & $55+/-12$ & $52+/-2$ \\
DMDS & $43+/-20$ & $64+/-7$ & $\mathrm{n} / \mathrm{a}$ & $\mathrm{n} / \mathrm{a}$ \\
Formaldehyde & $60+/-10$ & $90+/-20$ & $87+/-6$ & $91+/-7$ \\
Methanol & $90+/-18$ & \multicolumn{3}{|l}{} \\
\hline
\end{tabular}

Nearly complete removal of HS and MT was observed in all 4 periods. The effluent concentrations for both compounds were below detection limits most of the time.

DMS and DMDS were more difficult to treat. Figure 22 -Figure 25 show the removal efficiencies of DMS and DMDS in the 4 operation periods. DMDS removal improved as the temperature declined. In period I, only $46 \%$ was removed. In period II, even though the SRT was decreased to 10 days, the removal efficiency of DMDS increased to $60 \%$. In period III and IV, the SRT was increased to 30 days, while the temperature was decreased from 50 to $30^{\circ} \mathrm{C}$ and $20^{\circ} \mathrm{C}$, respectively, which resulted in improved DMDS 
removal efficiencies (82 and 91\%, respectively). DMDS was degraded much better at mesophilic temperatures than at thermophilic temperatures.

DMS was the most difficult to degrade. Only $25 \%$ of the DMS was degraded in period I. In period II, the SRT was decreased from 30 to 10 days, and the removal efficiency of DMS dropped to $16 \%$. When the SRT was brought back to 30 days and the temperature was dropped to $30^{\circ} \mathrm{C}$, the removal efficiency increased to $47 \%$. The removal efficiency increased further to $63 \%$ when the temperature was dropped to $20^{\circ} \mathrm{C}$. The trend in temperature effect on DMS degradation was similar to DMDS. Significantly improved degradation of DMS was observed at mesophilic temperatures than at thermophilic temperatures.

Methanol was removed effectively in all 4 periods with over $99 \%$ efficiency observed. Formaldehyde was also efficiently removed. No formaldehyde could be detected in the effluent gas in period I and II, which were the only periods in which its degradation was studied. 
Table 12 The influent, effluent concentrations and removal efficiency of TRS compounds, formaldehyde, and methanol for different operating periods

\begin{tabular}{|c|c|c|c|c|c|c|}
\hline \multicolumn{7}{|c|}{ Period I, SRT $=30$ D, Temp $=50^{\circ} \mathrm{C}$} \\
\hline \multirow[t]{2}{*}{\begin{tabular}{|l|} 
Compounds \\
\end{tabular}} & \multicolumn{2}{|c|}{ Inf. (ppm) } & \multicolumn{2}{|c|}{ Eff (ppm) } & \multicolumn{2}{|c|}{ \% removal } \\
\hline & Aver & SD & Aver & SD & Aver & SD \\
\hline $\mathrm{HS}$ & 60 & 20 & 0 & 0 & 100 & 0 \\
\hline MT & 58 & 21 & 0.85 & 4 & 97 & 14 \\
\hline DMS & 41 & 15 & 31 & 13 & 25 & 17 \\
\hline DMDS & 44 & 21 & 22 & 10 & 46 & 19 \\
\hline Formaldehyde & 61 & 11 & 0 & 0 & 100 & 0 \\
\hline Methanol & 91 & 19 & 0 & 0 & 99 & 1 \\
\hline \multicolumn{7}{|c|}{ Period II, SRT $=10 \mathrm{~d}$, Temp $=50^{\circ} \mathrm{C}$} \\
\hline \multirow[t]{2}{*}{\begin{tabular}{|l|} 
Compounds \\
\end{tabular}} & \multicolumn{2}{|c|}{ Inf (ppm) } & \multicolumn{2}{|c|}{ Eff (ppm) } & \multicolumn{2}{|c|}{ \% removal } \\
\hline & Aver & SD & Aver & SD & Aver & SD \\
\hline $\mathrm{HS}$ & 68 & 4 & 0 & 0 & 100 & 0 \\
\hline MT & 68 & 6 & 0 & 0 & 100 & 0 \\
\hline DMS & 51 & 9 & 43 & 8 & 16 & 8 \\
\hline DMDS & 39 & 18 & 18 & 18 & 60 & 29 \\
\hline Formaldehyde & 64 & 7 & 0 & 0 & 100 & 0 \\
\hline Methanol & 90 & 20 & 1 & 3 & 99 & 3 \\
\hline \multicolumn{7}{|c|}{ Period III, SRT $=30 \mathrm{~d}$, Temp $=30^{\circ} \mathrm{C}$} \\
\hline \multirow[t]{2}{*}{ Compounds } & \multicolumn{2}{|c|}{ Inf (ppm) } & \multicolumn{2}{|c|}{ Eff (ppm) } & \multicolumn{2}{|c|}{ \% removal } \\
\hline & Aver & SD & Aver & SD & Aver & SD \\
\hline $\mathrm{HS}$ & 79 & 8 & 0 & 0 & 100 & 0 \\
\hline MT & 77 & 5 & 0 & 0 & 100 & 0 \\
\hline DMS & 62 & 42 & 30 & 10 & 47 & 15 \\
\hline DMDS & 56 & 33 & 9 & 4 & 82 & 11 \\
\hline Formaldehyde & $\mathrm{n} / \mathrm{a}$ & $\mathrm{n} / \mathrm{a}$ & $\mathrm{n} / \mathrm{a}$ & $\mathrm{n} / \mathrm{a}$ & $\mathrm{n} / \mathrm{a}$ & $\mathrm{n} / \mathrm{a}$ \\
\hline Methanol & 77 & 6 & 1 & 1 & 99 & 2 \\
\hline \multicolumn{7}{|c|}{ Period IV, SRT $=30 \mathrm{~d}$, Temp $=20^{\circ} \mathrm{C}$} \\
\hline \multirow[t]{2}{*}{ Compounds } & \multicolumn{2}{|c|}{$\overline{\text { Inf (ppm) }}$} & \multicolumn{2}{|c|}{ Eff (ppm) } & \multicolumn{2}{|c|}{ \% removal } \\
\hline & Aver & SD & Aver & SD & Aver & SD \\
\hline $\mathrm{HS}$ & 79 & 5 & 0 & 0 & 100 & 0 \\
\hline MT & 81 & 4 & 0 & 0 & 100 & 0 \\
\hline DMS & 53 & 3 & 19 & 6 & 63 & 11 \\
\hline DMDS & 52 & 2 & 4 & 1 & 91 & 2 \\
\hline \begin{tabular}{|l|} 
Formaldehyde \\
\end{tabular} & $\mathrm{n} / \mathrm{a}$ & N/a & $\mathrm{n} / \mathrm{a}$ & $\mathrm{n} / \mathrm{a}$ & $\mathrm{n} / \mathrm{a}$ & $\mathrm{n} / \mathrm{a}$ \\
\hline Methanol & 91 & 7 & 1 & 1 & 99 & 2 \\
\hline
\end{tabular}




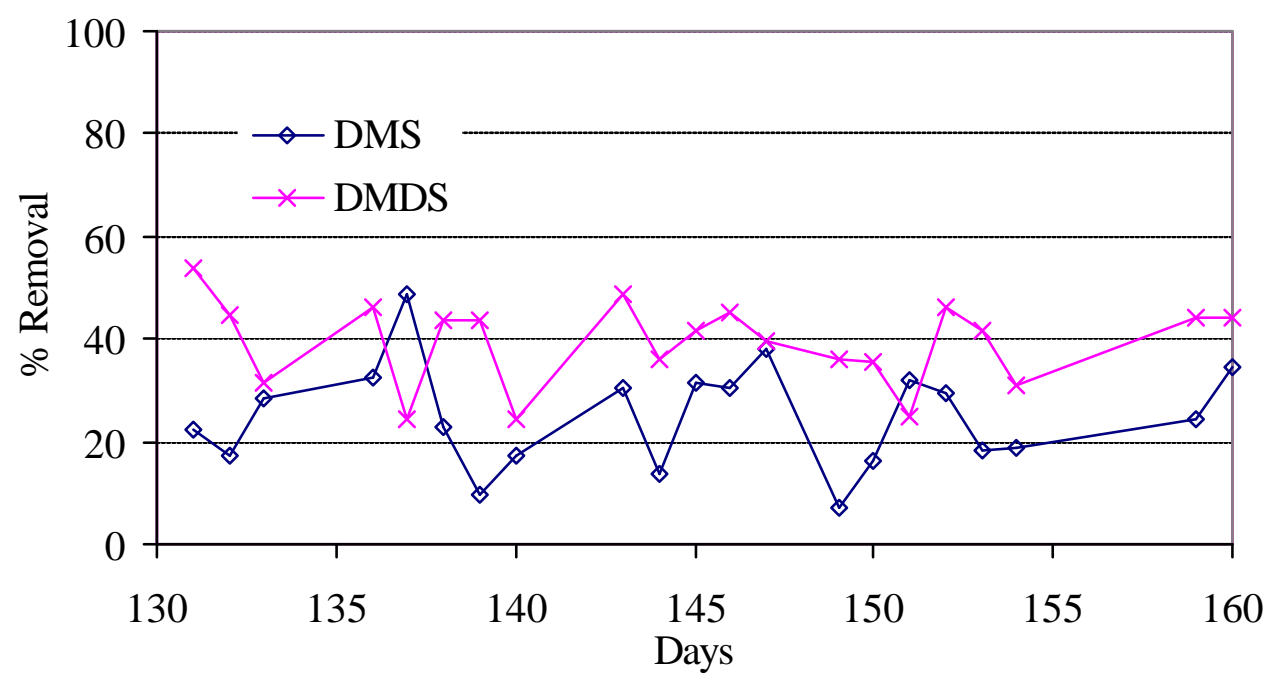

Figure 22 Percent removal of DMS and DMDS in the SSGR in period I, SRT = 30 day, Temperature $=50^{\circ} \mathrm{C}$

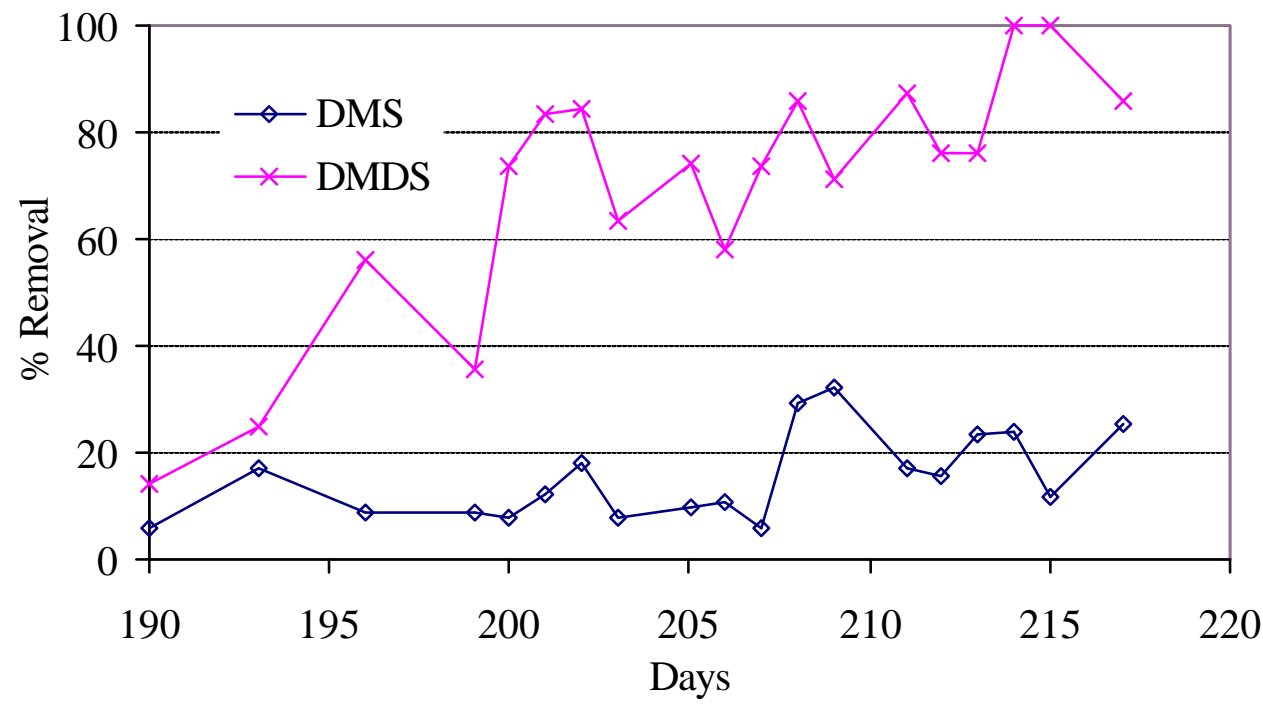

Figure 23 Percent removal of DMS and DMDS in the SSGR in period 1I, SRT = 10 day, Temperature $=50^{\circ} \mathrm{C}$ 


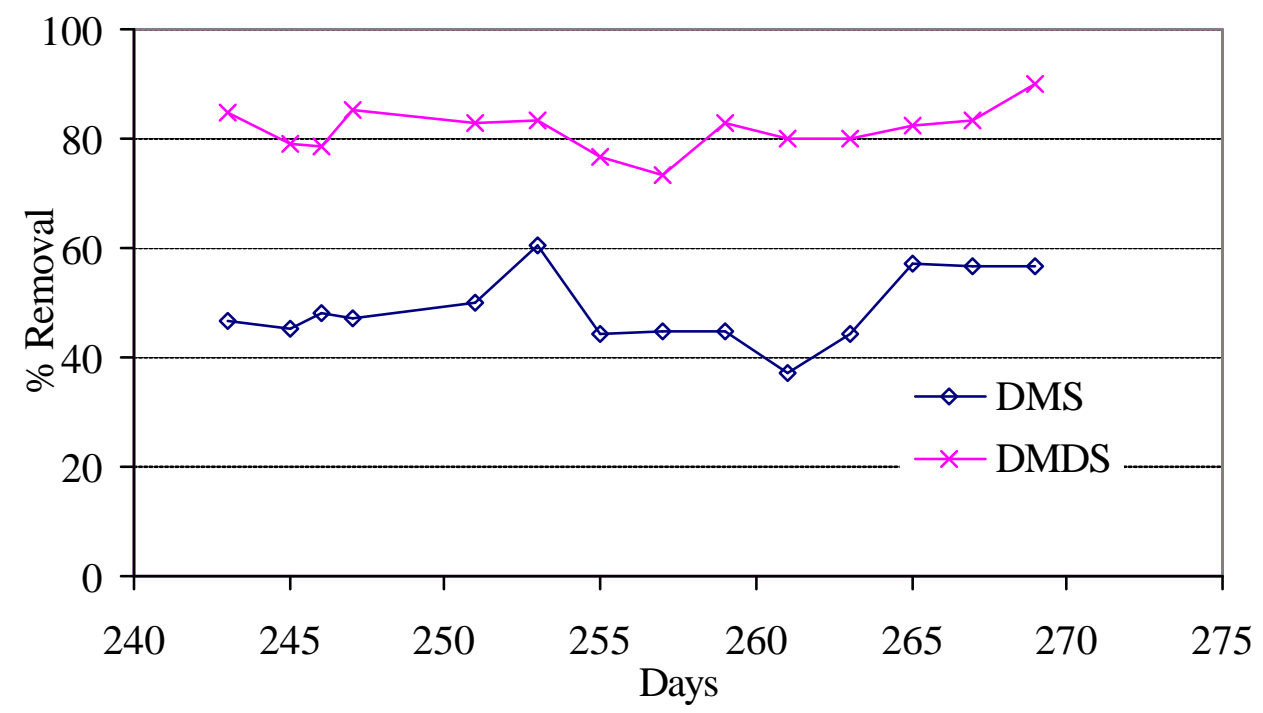

Figure 24 Percent removal of DMS and DMDS in the SSGR in period III, SRT = 30 day, Temperature $=30^{\circ} \mathrm{C}$

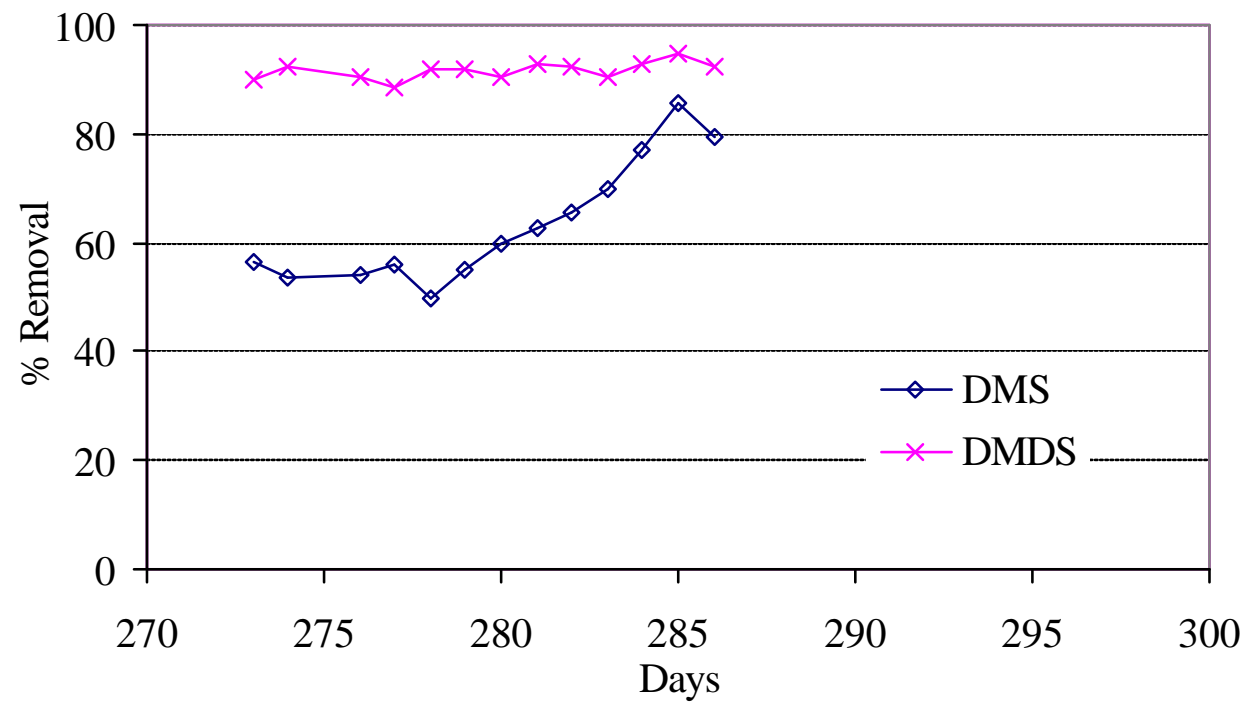

Figure 25 Percent removal of DMS and DMDS in the SSGR in period IV, SRT = 30 day, Temperature $=20^{\circ} \mathrm{C}$ 


\subsection{Pilot Plant Results}

Before starting contaminated gas treatment at the Simpson mill, the mass transfer effectiveness of the SSGR pilot plant was tested. The $\mathrm{K}_{\mathrm{L}}$ a test were done at $1.2 \mathrm{~m}(4 \mathrm{ft})$ water depth, blower feed air temperature of $52^{\circ} \mathrm{C}$, a reactor water temperature of $45^{\circ} \mathrm{C}$ and ambient temperature of $27^{\circ} \mathrm{C}$. Table 13 shows the test conditions and results. Figure 26 shows an example $\mathrm{K}_{\mathrm{L}}$ a test result at an air flow rate of $157.15 \mathrm{ft}^{3} / \mathrm{min}$. The $\mathrm{K}_{\mathrm{L}}$ a of the pilot plant was in the range of 17.4 to $93 \mathrm{hr}^{-1}$ and increased linearly with the air flow rate. The high $\mathrm{K}_{\mathrm{L}}$ a values were the result of high diffuser density design developed for the pilot system. Based on the model evaluation, such a high $\mathrm{K}_{\mathrm{L}}$ a value would assure efficient treatment at shallow depth.

Table 13 Summary of pilot plant $K_{L}$ a test conditions and results

\section{Pilot Plant $K_{L}$ a test}

Water depth

Fed air temperature

Water temperature

Ambient temperature
$1.2 \mathrm{~m}(4 \mathrm{ft})$

$52{ }^{\circ} \mathrm{C}$

$45^{\circ} \mathrm{C}$

$27^{\circ} \mathrm{C}$

\begin{tabular}{|c|c|c|c|}
\hline Test \# & $\begin{array}{c}\text { Gas Application rate } \\
\left(\mathbf{m}^{\mathbf{3}} / \mathbf{m}^{\mathbf{2}} \mathbf{- m i n}\right)\end{array}$ & $\begin{array}{c}\text { Air Flow Rate } \\
\left(\mathbf{f t}^{\mathbf{3}} \mathbf{/ m i n}\right)\end{array}$ & $\begin{array}{c}\mathbf{K}_{\mathbf{L}} \mathbf{a} \\
(\mathbf{1} / \mathbf{h r})\end{array}$ \\
\hline 1 & 0.36 & 60 & 17.4 \\
2 & 0.5 & 83 & 55.8 \\
3 & 0.55 & 90 & 39 \\
4 & 0.55 & 90 & 42 \\
5 & 0.90 & 150 & 80.4 \\
6 & 0.90 & 150 & 81.6 \\
7 & 0.97 & 160 & 88.2 \\
8 & 0.97 & 160 & 93 \\
\hline
\end{tabular}




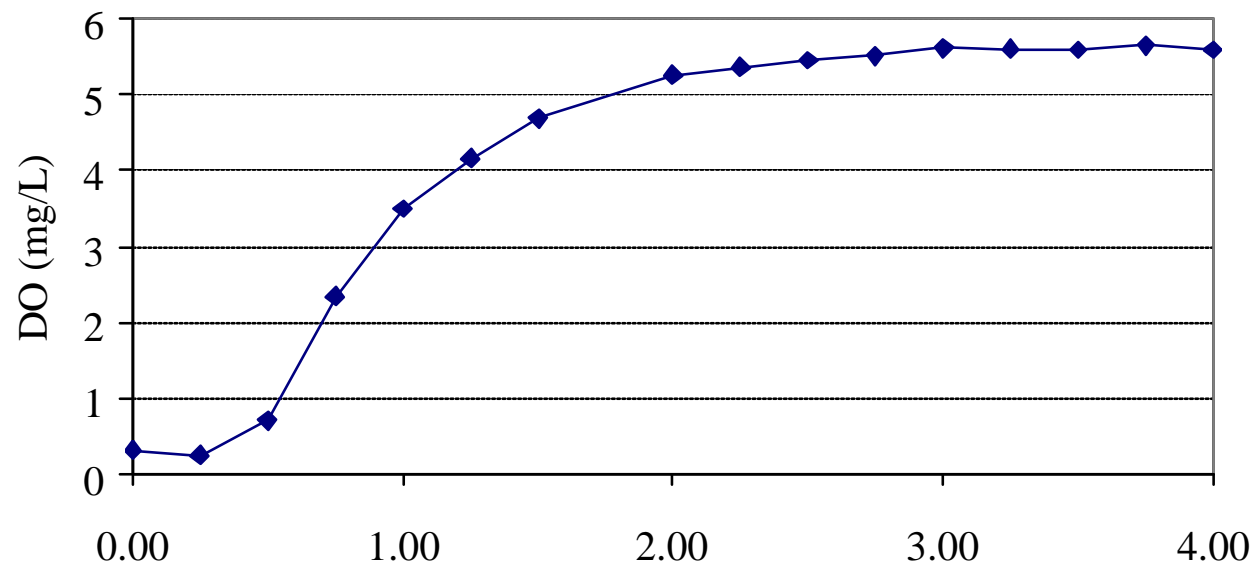

Time (min)

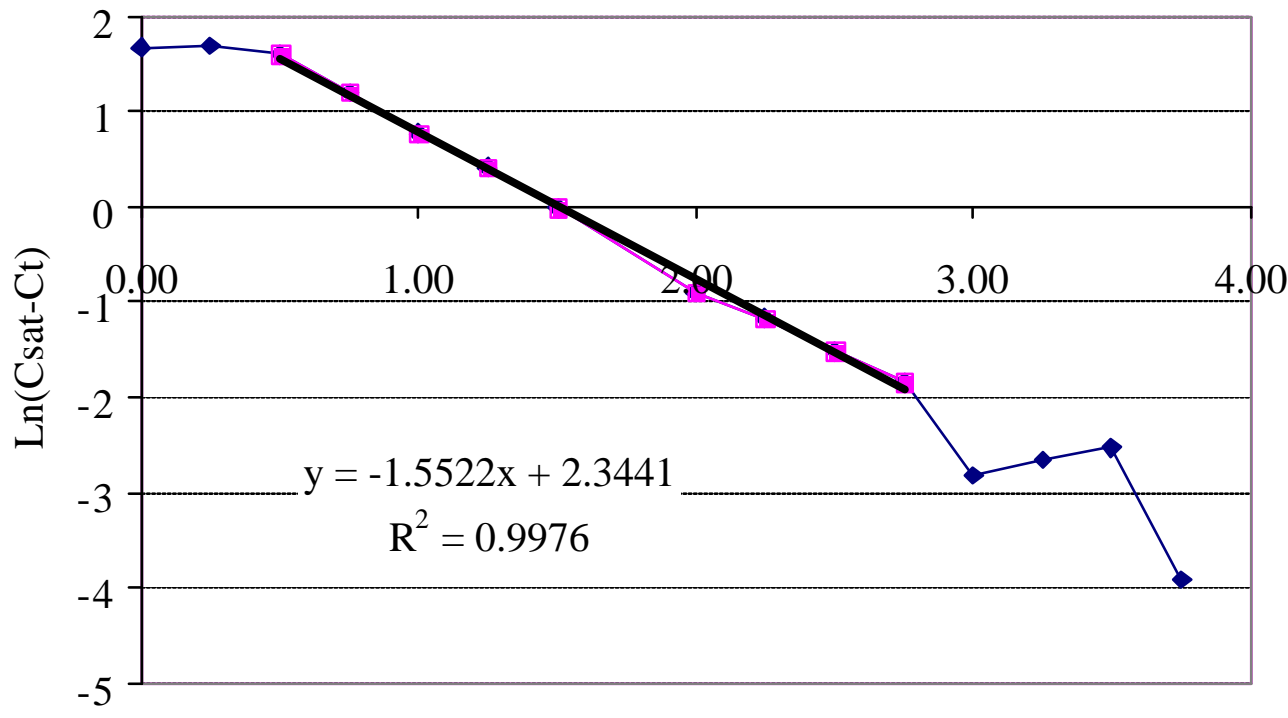

Time (min)

Figure 26 Example of time course of $D O$ for an oxygen $K_{L}$ a test and oxygen $K_{L} a$ data fit of the pilot plant at flow rate of $157.5 \mathrm{ft}^{3} / \mathrm{m}$ 
Return activated sludge from the Simpson wastewater treatment plant was used for seeding the pilot plant. The initial VSS was $474 \mathrm{mg} / \mathrm{L}$ and the $\mathrm{pH}$ was 7.2. Sodium bicarbonate was added to ensure a minimum alkalinity of $1000 \mathrm{mg} / \mathrm{L}$. The temperature of the gas stream coming into the pilot plant was $60-70^{\circ} \mathrm{C}$. A cooling system was used to lower the temperature to $30^{\circ} \mathrm{C}$ to provide a better condition for DMS removal. The gas application rate was approximately $0.95 \mathrm{~m}^{3} / \mathrm{m}^{2}$-min.

The pilot plant gas feed source was from a pipe located above the pulp washers. This location was chosen out of convenience with some awareness that foam from the pulp washer off gas flow could be carried into the pipe. A significant amount of foaming and water did pass through the limited demister design, (indicated by water in the gas flow measurement port). This issue raised an important point about the need to consider the gas source and the potential for contaminants that could give rise to foaming and formation of particulates, affecting the diffusers and operation of the SSGR. Each site will have specific issues about the gas source and quality, and will require appropriate engineering to provide a gas stream that is compatible with the biological treatment process.

The pilot plant was operated for a brief time period from 8/31/00 to $9 / 5 / 00$ after seeding with a small amount of Simpson mill activated sludge. A thermostat failure and a leak in the cooling system forced the premature shutdown of the pilot plant. Influent and effluent samples were taken during the operation. The average influent and effluent concentration and the percent removals are presented in Table 14.

With the exception of acetaldehyde, DMDS and the terpene compounds, the treatment performance conformed to the SSGR laboratory results, with high removal of methanol, HS, MT and the BTX compounds and low removal for DMS. The poor acetaldehyde removal was most likely due to the lack of sufficient time for acclimation. DMDS and terpinene removal was better than expected. 
Table 14 The influent, effluent and removal efficiency of TRS and organic compounds of the pilot plant

\begin{tabular}{|l|c|c|c|}
\hline \multicolumn{1}{|c|}{ Compounds } & $\begin{array}{c}\text { Influent } \\
\text { (ppm) }\end{array}$ & $\begin{array}{c}\text { Effluent } \\
\text { (ppm) }\end{array}$ & \% Removal \\
\hline HS & 0 & 0 & $\mathrm{n} / \mathrm{a}$ \\
MT & 0 & 0 & $\mathrm{n} / \mathrm{a}$ \\
DMS & 956 & 605 & 37 \\
DMDS & 41 & 0 & 100 \\
Acetaldehyde & 1379 & 450 & 67 \\
Methanol & 59 & 2 & 97 \\
Toluene & 2 & 0 & 100 \\
P-xylene & 4 & 0 & 100 \\
M-xylene1 & 82 & 0 & 100 \\
M-xylene2 & 44 & 0 & 100 \\
Alpha-terpinene & 31 & 0 & 100 \\
O-xylene1 & 107 & 0 & 100 \\
O-xylene2 & 109 & 0 & 100 \\
Gamma-terpinene & 29 & 0 & 100 \\
\hline
\end{tabular}

\subsection{Evaluation of Terpenes Removal}

Alpha- and gamma-terpinene compounds were selected as representative chemicals from the group of terpene compounds of evaluation for biotreatment in an SSGR system. To evaluate removal efficiency in an SSGR the mass transfer characteristics (H coefficient and $\mathrm{K}_{\mathrm{L}} \mathrm{a}$ ) and biokinetic parameters must be determined or estimated. The EPICS method was used to determine the $\mathrm{H}$ coefficients of the alpha- and gamma-terpinenes. Reactor stripping tests in clean water were carried out at the same air sparge rate as the laboratory SSGR operation to obtain $\mathrm{K}_{\mathrm{L}}$ a values. Terpinene degrading enrichments were maintained and used to measure biodegradation kinetics. With this information, the removal of these terpinene compounds in an SSGR operation was assessed.

Table 15 summarizes the $\mathrm{H}$ coefficient values determined for the terpinene compounds at $20^{\circ} \mathrm{C}, 35^{\circ} \mathrm{C}$, and $50^{\circ} \mathrm{C}$. The $\mathrm{H}$ coefficient values are very high, and almost a magnitude 
higher than that for such highly volatile compounds such as HS (0.50) and benzene $(0.45)$ at $50^{\circ} \mathrm{C}$. Such a high $\mathrm{H}$ coefficient suggests that these compounds will not be removed well in a biotreatment application, whether it be the SSGR design or a biofilter.

Table 15 Summary of Henry's Law Coefficient values measured by EPICS method for terpene compounds

\begin{tabular}{|c|c|c|c|}
\hline \multirow{2}{*}{ Compounds } & \multicolumn{3}{|c|}{ Henry's Coefficient (L/L) } \\
\cline { 2 - 4 } & $\mathbf{2 0}^{\mathbf{0}} \mathbf{C}$ & $\mathbf{3 5}^{\mathbf{C}} \mathbf{C}$ & $\mathbf{5 0}^{\mathbf{}} \mathbf{C}$ \\
\hline$\alpha$-terpinene & $1.3(0.2)$ & $2.4(0.3)$ & $3.5(1.0)$ \\
\hline$\gamma$-terpinene & $1(0.2)$ & $1.6(0.1)$ & $3.5(0.9)$ \\
\hline
\end{tabular}

Table 16 summarizes the $\mathrm{K}_{\mathrm{L}}$ a for the terpinene compounds at $35^{\circ} \mathrm{C}$ and $50^{\circ} \mathrm{C}$. The effect of temperature on the $\mathrm{K}_{\mathrm{L}}$ a value is higher than expected in comparing the $50^{\circ} \mathrm{C} \mathrm{K}_{\mathrm{L}}$ a to the $35^{\circ} \mathrm{C} \mathrm{K} \mathrm{L}$, but the magnitude of the change was similar for both compounds.

Table 16 Summary of $K_{L}$ a values for terpene compounds

\begin{tabular}{|l|c|c|c|c|c|}
\hline & Temp & Vl (ml) & $\begin{array}{c}\text { Flow rate } \\
(\mathbf{m l} / \mathbf{m i n})\end{array}$ & $\mathbf{K}_{\mathbf{L}} \mathbf{a}\left(\mathbf{h r}^{-1}\right)$ & st dev \\
\hline Alpha-terpinene & 35 & 1815 & 150 & 5.4 & 0.6 \\
\hline & 50 & 1815 & 150 & 19.2 & \\
\hline Gamma-terpinene & 35 & 1815 & 150 & 7.8 & 1.2 \\
\hline & 50 & 1815 & 150 & 29.4 & \\
\hline
\end{tabular}

In batch bottle biokinetic testing the initial specific terpinene degradation rate was observed for different initial terpinene concentrations. The biodegradation rate increased with concentration and a substrate-saturated, maximum degradation rate (as defined by the maximum specific substrate degradation rate in the Michaelis-Menten model) was not observed before the solubility concentration limit for the compounds was approached. Thus, a first-order model was used to describe the terpinene degradation kinetics. The first-order degradation rate coefficients are summarized in Table 17. The degradation 
rates of the two compounds were similar and no significant improvement in rate was found for this enrichment at $50^{\circ} \mathrm{C}$.

Table 17 Specific substrate utilization rate $(\mathrm{K})$ values at $35^{\circ} \mathrm{C}$ and $50^{\circ} \mathrm{C}$ for the firstorder model

\begin{tabular}{|l|c|c|}
\hline & \multicolumn{2}{|c|}{ K, L/mg-VSS-day } \\
\hline & $\mathbf{3 5}^{\mathbf{C}} \mathbf{C}$ & $\mathbf{5 0}^{\mathbf{}} \mathbf{C}$ \\
\hline Alpha-terpinene & 0.18 & 0.16 \\
\hline Gamma-terpinene & 0.13 & 0.14 \\
\hline
\end{tabular}

The mass transfer and biokinetic data were used with the SSGR performance model to evaluate the removal of the terpinene compounds under the same operating conditions as the laboratory reactor (air application rate of $1.8 \mathrm{~m}^{3} / \mathrm{m}^{2}-\mathrm{d}$ and $30-\mathrm{d}$ SRT). Since firstorder kinetics were used instead of the Michaelis-Menten model, equation 8, which calculates the steady state reactor liquid organic compound concentration, was modified as follows:

$$
C_{L}=\frac{1+b S R T}{Y K S R T}
$$

Where:

$$
\mathrm{K}=\text { first order kinetic coefficient, L/mg-d }
$$

The model evaluation found that no significant terpinene removal was possible with the $0.36 \mathrm{~m}$ reactor depth. Even at depths in the range of meters, little removal is predicted at both $35^{\circ} \mathrm{C}$ and $50^{\circ} \mathrm{C}$. The main reason for this result is the high value of the terpinene Henry's coefficient.

Table 18 Summary of $K_{s}$ value for alpha- and gamma-terpinene

\begin{tabular}{|l|c|c|}
\hline \multirow{2}{*}{ Compounds } & \multicolumn{2}{|c|}{$\mathbf{K}_{\mathbf{S}}, \mathbf{m g} / \mathbf{L}$} \\
\cline { 2 - 3 } & $\mathrm{K}_{\mathrm{S}}$ at $35^{\circ} \mathrm{C}$ & $\mathrm{K}_{\mathrm{S}}$ at $50^{\circ} \mathrm{C}$ \\
\hline Alpha-terpinene & $0.14 \pm 0.06$ & $0.17^{*}$ \\
\hline Gamma-terpinene & $0.15 \pm 0.08$ & $0.15^{*}$ \\
\hline
\end{tabular}

*one observation 


\subsection{Evaluation of Full Scale SSGR Designs}

The results from the laboratory bench scale studies, mechanistic model evaluations, and pilot plant operation are incorporated here in an assessment of full scale SSGR designs, in terms of reactor sizing, operating needs, and pretreatment considerations. An SSGR design example for a $5000 \mathrm{cfm}$ gas flow is presented.

A variety of gas streams from different sources will be candidates for a biological treatment alternative to meet the Cluster Rule regulations. The testing program showed that the HAPs and TRSs expected for pulp and paper gas emissions were removed at high levels with the SSGR, with the exception of DMS and the two terpinenes tested. The high Henry's coefficient value for the particular terpenes evaluated make biological treatment impractical, but there are a range of other terpene compounds for which mass transfer characteristics are not know, and thus may have potential for removal in biological treatment.

Removal of DMS, which was present at significant levels in the feed gas at the Simpson Mill pilot plant, was limited and improved with decreasing reactor temperature. Based on the batch incubation tests, which showed higher degradation rates at lower temperatures, the improved removal of DMS in the SSGR at lower temperature was due to improved biological degradation and not related to a mass transfer limitation. Since DMS was biodegradable, further research may develop cultures or treatment conditions that provide more favorable degradation rates. Biological inocula obtained from hot natural environment with high sulfur activities may offer a rich source of bacteria capable of degrading DMS at higher temperatures. Within the time and resources of this project, the effect of temperature on DMS degradation was observed to be significantly inhibited at temperatures greater than $35^{\circ} \mathrm{C}$.

The inability to achieve acceptable DMS removal efficiency does not mean that the SSGR is not a feasible process for pulp and paper mill gas emissions. High removal 
efficiency was observed for other compounds and the cluster rule level for the surrogate HAP, methanol, can be easily met at thermophilic temperatures. Other methods can be used in conjunction with the SSGR to remove DMS at an overall lower cost. Activated carbon adsorption could be used to treat the SSGR effluent gas stream. Treatment with the SSGR before carbon adsorption would assure long carbon life and reduced costs for carbon regeneration. Another approach would be to add powdered activated carbon (PAC) or other efficient sorbent to the SSGR reactor, removal of a side stream for biodegradation of organic compounds on the PAC, and recycling the PAC to the SSGR. This is illustrated in the following schematic.

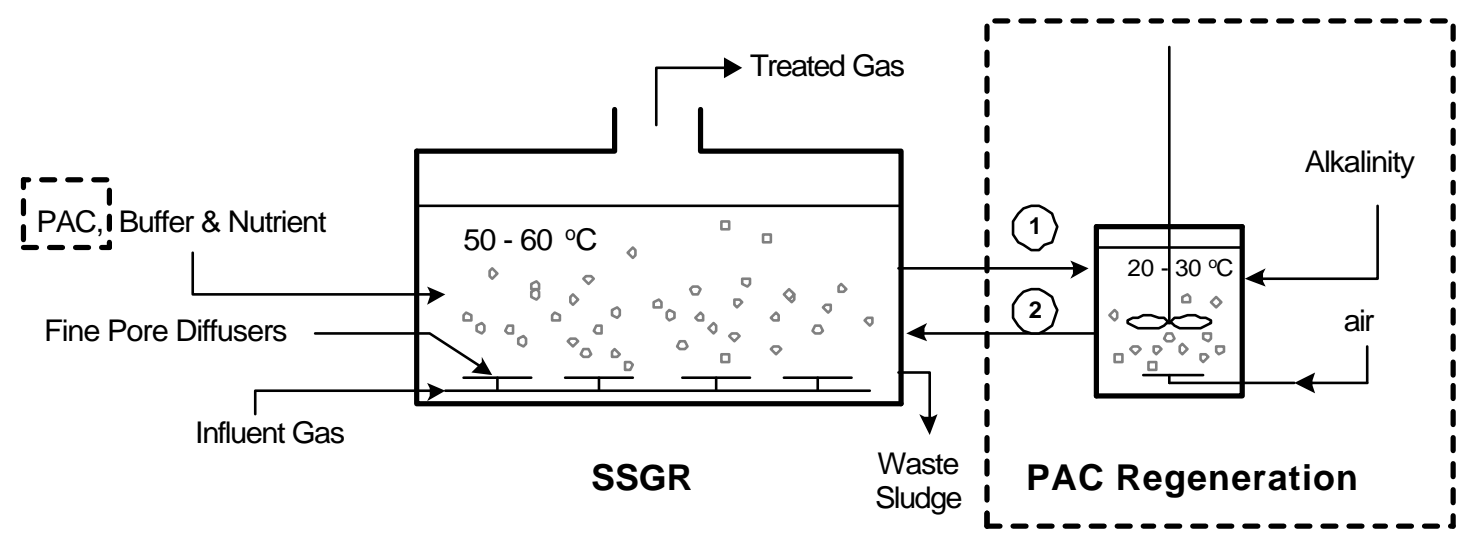

Figure 27 Schematic of Shallow Suspended Growth Reactor (SSGR) for Gas Treatment. (Dashed boxes indicate powdered activated carbon addition to SSGR with biological regeneration of PAC. Mixed liquor with spent and regenerated PAC represented by lines 1 and 2.)

The SSGR alone is not the only solution to pulp mill emission problems, and a proper site evaluation would be needed to produce optimal results. Consideration of pretreatment of the gas and temperature are necessary. Depending on the site conditions, pretreatment of the gas may be needed before the SSGR to prevent fouling of the fine bubble diffusers used to disperse the feed gas. In some cases, a standard filter on the gas feed blower may suffice. In other cases where the gas is highly contaminated with particulates and/or foam, the gas must be pretreated before it is fed to the SSGR. Temperature control may 
also be considered for some locations, depending on the variability of the temperature and operating temperature possible for the SSGR system. For streams without DMS, a higher temperature can be tolerated for biotreatment in the SSGR.

\subsection{SSGR Design}

For this analysis a gas treatment reactor with a treatment capacity of 5,000 cubic $\mathrm{ft} / \mathrm{min}$ (cfm) flow was assumed. This could represent a significant size module for a pulp and paper mill gas treatment system where total HVLC flows may be in the range of 20,000 $\mathrm{cfm}$.

The laboratory results and model evaluation showed that very shallow liquid depths can be used to meet the cluster rules for methanol. A reactor liquid depth of less than $0.4 \mathrm{~m}$ and air application rate of $1.0-2.0 \mathrm{~m}^{3} / \mathrm{m}^{2}$ - min were shown to be feasible by the modeling results. The pilot plant showed that a diffuser density of 37 diffusers (each was $30 \mathrm{~cm}$ or $1.0 \mathrm{ft}$ diameter) in a $4.65-\mathrm{m}^{2}$ area was feasible. This resulted in a diffuser density of $0.58-\mathrm{m}^{2}$ diffuser area $/ \mathrm{m}^{2}$ floor area. Using a reasonable design gas application rate of $0.14 \mathrm{~m} 3 / \mathrm{min}$-diffuser $\left(5 \mathrm{scfm} /\right.$ diffuser), the gas application rate $1.1 \mathrm{~m}^{3} / \mathrm{m}^{2}-\mathrm{min}$. At a gas flow rate of $5,000 \mathrm{cfm}\left(141.7 \mathrm{~m}^{3} / \mathrm{min}\right)$, the SSGR required floor area is $129 \mathrm{~m}^{2}\left(1384 \mathrm{ft}^{2}\right)$. Assuming a $1.2 \mathrm{~m}(4 \mathrm{ft})$ reactor depth, a $4.8-\mathrm{m}(16-\mathrm{ft})$ tall system could contain 4 stacks of SSGR reactors to minimize the floor area needed. This would result in a 6.4- $\mathrm{m}(21-\mathrm{ft})$ diameter unit. Thus, the SSGR for a $5000 \mathrm{cfm}$ gas flow would be $6.4-\mathrm{m}$ diameter by 4.8$\mathrm{m}$ high and contain 1000 diffusers. Assuming a $0.90 \mathrm{~m}$ liquid depth and a blower efficiency of $70 \%$, a $50 \mathrm{Hp}$ compressor would be sufficient to feed the air to the SSGR.

\section{$\underline{4.8 \text { Cost Analysis }}$}

A cost analysis is provided to compare the cost of the SSGR system to that for thermal treatment for the design and gas flow rate described above.

\subsubsection{Capital Cost}

The capital cost of the SSGR are compared to that for thermal treatment based on a report by Govind, 1993. ("Development of novel biofilters for the treatment of volatile organic 
compounds (VOCs).", Presented at the IGT Symposium on Gas, Oil, and Environmental Biotechnology, Colorado Springs, CO.)

Capital Costs, 5,000 cfm units

Biological Reactor (SSGR) \$110,000

Incineration (with scrubber) \$200,000

\subsubsection{Non Variable operating costs}

Based on maintenance costs at $5 \%$ of capital costs and labor for operations at 1 personday $(\$ 40,000 /$ year with overhead) for incineration and $1 / 2$ person-day for biological treatment operations.

Biological Reactor (SSGR)

$\$ 25,500 /$ year

Incineration (with scrubber)

$\$ 50,000 /$ year

\subsubsection{Energy costs}

The following table compares the energy costs for biotreatment versus thermal treatment.

Table 19 Comparison of energy cost to treat $5000 \mathrm{scfm}$

\begin{tabular}{|l|c|c|c|}
\hline Fuel Type & $\begin{array}{c}\text { New Technology } \\
\text { (SSGR) }\end{array}$ & $\begin{array}{l}\text { Thermal } \\
\text { Treatment }\end{array}$ & Comments \\
\hline Electricity (million kWh) & 0.392 & - & $1700^{\circ} \mathrm{F}$ temperature \\
\hline $\begin{array}{l}\text { Natural Gas (million cu. } \\
\text { Ft.) }\end{array}$ & - & 91.4 & $*$ \\
\hline Annual Energy Costs & $\$ 24,000$ & $\$ 338,000$ & $*$ \\
\hline
\end{tabular}

*Assuming electricity at $\$ 0.06 / \mathrm{kWh}$ and gas at $\$ 3.70 / 1000 \mathrm{cu}$. Ft. of gas 


\subsubsection{Total annual costs}

The capital cost was amortized over 10 years at a $7 \%$ interest rate. The annual operating costs for biotreatment compared to incineration is $\$ 64,800$ versus $\$ 415,900$, with the major cost savings related to energy consumption in thermal treatment. 


\subsection{SUMMARY AND CONCLUSIONS}

The overall goal of this project was to develop and evaluate a shallow suspended growth reactor (SSGR) biotreatment system to provide an economical alternative to remove contaminants from high volume, low concentration (HVLC) gas streams at pulp and paper facilities. Of particular interest was the ability to treat a range of organic and reduced sulfur compounds at high temperature. Tests were performed with a bench-scale SSGR for treating a gas stream containing organic contaminants at $50^{\circ} \mathrm{C}$, followed by tests of the treatment of a gas stream with reduced sulfur compounds, formaldehyde, and methanol. The latter laboratory SSGR was operated at temperatures ranging from $30^{\circ} \mathrm{C}-$ $50^{\circ} \mathrm{C}$. A $2.4-\mathrm{m}$ diameter by $1.5-\mathrm{m}$ high pilot plant was designed, fabricated, and installed at the Simpson Mill in Tacoma,WA. The pilot plant was fed exhaust gas from a pulp washer, and was operated for a short period at $30^{\circ} \mathrm{C}$ in September 2000, before a mechanical failure in the gas cooling system prevented further operation.

The following conclusions resulted from this study:

1. The use of a suspended growth shallow reactor to destroy contaminants in pulp and paper gas streams is a feasible process and reactor liquid depths of $1.0 \mathrm{~m}$ or less are practical.

2. A wide range of hazardous air pollutants that are expected to be common for pulp and paper emissions were found to be readily biodegradable at $50^{\circ} \mathrm{C}$ by the cultures developed, except dimethyl sulfide and dimethyl disulfide. Of these two,

the DMS was the most difficult to degrade and DMDS removal rates significantly improved at mesophilic operating temperatures.

3. The Cluster Rule treatment requirements for organic compounds were met in the bench-scale SSGR operation when the $\mathrm{pH}$ was controlled to near 7.0. The removal efficiencies were methanol, $99 \%$, acrolein, $>99 \%$, acetaldehyde, $>99 \%$, 
methyl-ethyl-ketone, $>99 \%$, benzene, $>99 \%$, toluene, >99\%, p-xylene, $97 \%, \mathrm{~m}-$ xylene, 94\%, o-xylene, 97\%, formaldehyde, 99\%, hydrogen sulfide, 99\%, methyl mercaptan, $99 \%$, and dimethyl disulfide, $85 \%$. Of particular importance for these results is that the bench-scale reactor liquid depth was only $0.36 \mathrm{~m}$ (14 inches). A full-scale system. with a 0.6 to $1.2 \mathrm{~m}$ (2-4 ft.) depth, would have improved treatment performance where mass transfer limitations exist. Even at this extreme shallow depth the Cluster Rule requirements for $98 \%$ methanol removal and less than 20-ppm methanol effluent concentration were met.

4. Activated sludge from the Simpson Mill provided a sufficient seed source to degrade all of the reduced sulfur compounds at $35^{\circ} \mathrm{C}$, and all except DMS at $50^{\circ} \mathrm{C}$.

5. Biodegradation rates for DMS and DMDS increased at mesophilic versus thermophilic temperatures. However, the DMS degradation rate was still low enough at $30^{\circ} \mathrm{C}$ to result in poor treatment efficiencies in the SSGR.

6. Biokinetic and mass transfer experimental data was used to calibrate a mechanistic model to predict the removal of methanol in the SSGR. Methanol can be almost completely removed in an SSGR at liquid depths of $0.4 \mathrm{~m}$ or less, and at practical gas application rates of $1.0-2.0 \mathrm{~m}^{3} / \mathrm{m}^{2}-\mathrm{min}$.

7. The SSGR mechanistic model with sufficient mass transfer and biokinetic data can provide a reasonable estimate of the treatment performance of an SSGR system.

8. Alpha- and gamma- terpinene degradation were found to be readily biodegradable at $35^{\circ} \mathrm{C}$ and $50^{\circ} \mathrm{C}$. However, they had extremely high Henry's law coefficients, which suggest little removal of these compounds in a biotreatment reactor.

9. Further research is needed to develop bacteria cultures or environmental conditions that would increase the biodegradation rates of DMS and DMDS. 
10. Future use of the SSGR treatment technology should include pilot plant studies at specific sites with consideration of the particular site characteristics and gas pretreatment needs or temperature control. 


\section{REFERENCES}

Al-Awadhi, N., T. Egli, G. Hamer and E. Wehrli (1989). Thermotolerant and thermophilic solvent-utilizing methylotrophic, aerobic bacteria. System. Appl. Microbiol 11: 207-216.

Anon (2000). Significant cluster rule spending still projected.. Pulp \& Paper Project Report. 20: 2-4.

Arfman, N., K. J. de Vries, H. R. Moezelaar, M. M. Attwood, G. K. Robinson, M. van Geel and L. Diijkhuizen (1992). Environmental regulation of alcohol metabolism in thermotolerant methylotrophic Bacillus strains. Arch Microbiology 1992(157): 272-278.

Arfman, N., L. Dijkhuizen, G. Kirchhof, W. Ludwig, K.H. Schleifer, E. S. Sulygina, K. M. Chumakov, D. White and R. J. Sharp (1992). Bacillus methanolicus sp. nov., a new species of thermotolerant, methanol-utilizing, endospore-forming bacteria. International Journal of Systematic Bacteriology 42(3).

ASCE (1984). A Standard for the measurement of oxygen transfer in clean water". ASCE, New York, NY (1984),

Bielefeldt, A. R. (1996). Ph.D. Thesis. Biotreatment of contaminated gases in a sparged suspended-growth reactor.. Department of Civil and Environmental Engineering, University of Washington, Seattle, WA.

Bielefeldt, A. R. and H. D. Stensel (1998). BTEX-contaminated gas treatment in a shallow, sparged, suspended-growth bioreactor. Bioremediation journal 1(3): 241-254.

Brannan, D. K. and D. Caldwell (1980). Thermothrix thiopara: growth and metabolism of a newly isolated thermophile capable of oxidizing sulfur and sulfur compounds. Applied and Environmental Microbiology 40(2): 211-216.

Brannan, D. K. and D. Caldwell (1983). Growth kinetics and yield coefficients of the extreme thermophile Thermothrix thiopara in continuous culture. Applied and Environmental Microbiology 45: 169-173.

Brannan, D. K. and D. E. Caldwell (1986). Ecology and metabolism of Thermothrix thioparus. Advances in Applied Microbiology 31: 233-270.

Chen, C. I. and R. T. Taylor (1995). Thermophilic biodegradation of BTEX by two Thermus species. Biotechnology and Bioengineering 48: 614-624.

Chen, C. I. and R. T. Taylor (1997). Batch and fed-batch bioreactor cultivations of a Thermus species with thermophilic BTEX-degrading activity. Applied Microbiology and Biotechnology 47: 726-733. 
Cho, K.-S., M. Hirai and M. Shoda (1991). Degradation characteristics of hydrogen sulfide, methanethiol, dimethyl sulfide and dimethyl disulfide by Thiobacillus thioparus DW44 isolated from peat biofilter. Journal of Fermentation and Bioengineering 71(6): 384-389.

Cho, K.S., M. Hirai and M. Shoda (1992). Enhanced removal efficiency of malodorous gases in a pilot-scale peat biofilter inoculated with Thiobacillus thioparus DW44. Journal of Fermentation and Bioengineering 73(1): 46-50.

deBont, J. A. M., J. P. V. Dijken and W.Harder (1981). Dimethyl sulphoxide and dimethyl sulphide as a carbon, sulphur and energy source for growth of Hyphomicrobiums. Journal of Microbiology: 127,315-323.

deZwart, J. M. M. and J. G. Kuenen (1997). Aerobic conversion of dimethyl sulfide and hydrogen sulfide by Methylophaga sulfidovorans: implications for modeling DMS conversion in a microbial mat. FEMS Microbiology Ecology 22: 155-165.

deZwart, J. M. M., P. N. Nelisse and J. G. Kuenen (1996). Isolation and characterization of Methylophaga sulfidovorans sp. nov: an obligately methylotrophic, aerobic, dimethylsulfide oxidizing bacterium from a microbial mat. FEMS Microbiology Ecology 20: 261-270.

Dijkhuizen, L. and N. Artman (1990). Methanol metabolism in thermotolerant methylotrophic Bacillus species. FEMS Microbiology Re views 1990(87): 215-220.

Ellis, T. G., D. F. Barbeau, B. F. Smets and C. P. L. Grady (1994). Determination of toxic organic chemical biodegradation kinetics using novel respirometric technique. Proceedings of the water environment federation 67th annual conference and exposition.

Hirai, M., M. Ohtake and M. Shoda (1990). Removal kinetics of hydrogen sulfide, methanethiol and dimethyl sulfide by peat biofilters. 70: 334-339.

Jarvensivu, M., R. Lammi and J. Kivivasara (1997). Odor abatement systems of the prevailing TRS emission sources." Proceeding, 1997 TAPPI Environmental Conference \& Exhibit: 645-665.

Kanagawa, T. and E. Mikami (1989). Removal of methanethiol, dimethyl sulfide, dimethyl disulfide, and hydrogen sulfide from contaminated air by Thiobacillus thioparus TK-m. Applied and Environmental Microbiology 55(3): 555-558.

LaGrega, M. D., P. L. Buckingham and J. C. Evans (1994). Hazardous Waste Management., McGraw-Hill, Inc

Lund, H. F. (1971). Industrial Pollution Control Handbook., McGraw-Hill, New York. 
Mehta, Y. M. (1995). Unbleached mills won't escape impact of EPA's "Cluster Rules". Pulp and Paper 1995(May): 61-70.

Metcalf \& Eddy, (1991). Wastewater Engineering: treatment, Disposal and Reuse., McGraw-Hill, Inc.

Misra, B. and S. G. Pavlostathis (1997). Biodegradation kinetics of mono terpenes in liquid and soil-slurry systems. Applied Microbiology 47: 572-577.

Misra, G. and S. G. Pavlostathis (1996). Aerobic biodegradation of selected monoterpenes. Microbiology and Biotechnology 45: 831-838.

Mohseni, M. and D. G. Allen (1997). Biofiltration of a-pinene and its application to the treatment of pulp and paper air emissions. Proceeding 1997 TAPPI Environmental Conference \& Exhibit: 587-592.

Mohseni, M. and D. G. Allen (1998). Biofiltration of mixtures of volatile organic compounds emitted from pulp and paper industries. International Environmental Conference \& Exhibit: 183--189.

NIOSH (1994). Formaldehyde by GC. NIOSH Manual of Analytical Methods (NMAM). MEC. Peter M. Eller. Cincinnati, OH, U.S Dept. of Health and Human Services, Public Health Service, Centers for Disease Control and Prevention, National Institute for Occupational Safety and Health, Division of Physical Sciences and Engineering 2.

Odintsova, E. V., H. W.Jannaach, A. Mamone and T. A. Langworthy (1996). Thermothrix azorensis sp. nov., an obligately chemolithoautotrophic, sulfur-oxidizing, thermophilic bacterium. International Journal of Systematic Bacteriology 46(2): 422-428.

Pisotti, D. A. (1997). Biofilter eliminates more than just VOCs from a press exhaust. Proceeding, TAPPI 1997 International Environmental Conference: 271-276.

Reichert, K., A. Lipski, S. Pradella, E. Stackebrandt and K. Altendorf (1998). Pseudonocardia asaccharolytica sp. nov. and pseudonocardia sulfidoxydans sp. nov., two new dimethyl disulfide-degrading actionomycetes and emended description of the genus pseudonocardia. International Journal of Systematic Bacteriology 48: 441-449.

Suylen, G. M. H., P. J. Large, J. P. V. Dijken and J. G. Kuenen (1987). Methyl mercaptan oxidase, a key enzyme in the metabolism of methylated sulphur compounds by Hyphomicrobium EG. Journal of General Microbiology. 133:2989-2997.

U.S. Environmental Protection Agency (1985) Summary report; fine pore aeration systems, EPA-625/8-85-010, Water Engr. Research Lab, Cincinnati, OH

Vice, K. and R. Carroll (1998). The Cluster Rule: A Summary of Phase I. Tappi Journal 81(2): 91-98. 
Yurteri, C., Ryan, D. F., Callow, J. J., and Gurol, M. D.(1987). The effect of chemical composition of water on Henry's law constant. Journal of Water Pollution Control Federation 59(11): 950-956.

Zhang, L., M. Hirai and M. Shoda (1991). Removal characteristics of dimethyl sulfide, methanethiol and hydrogen sulfide by Hiphomicrobium sp. I55 isolated from peat biofilter. Journal of Fermentation and Bioengineering 72(5): 392-396. 